Portland State University

PDXScholar

1979

\title{
The relationship of maternal childrearing practices to prosocial behavior and resistance to temptation in preschool children
}

Jennifer Anne Deck Jennings

Portland State University

Follow this and additional works at: https://pdxscholar.library.pdx.edu/open_access_etds

Part of the Child Psychology Commons, and the Social Psychology Commons Let us know how access to this document benefits you.

\section{Recommended Citation}

Jennings, Jennifer Anne Deck, "The relationship of maternal childrearing practices to prosocial behavior and resistance to temptation in preschool children" (1979). Dissertations and Theses. Paper 2908. https://doi.org/10.15760/etd.2904

This Thesis is brought to you for free and open access. It has been accepted for inclusion in Dissertations and Theses by an authorized administrator of PDXScholar. Please contact us if we can make this document more accessible: pdxscholar@pdx.edu. 
AN ABSTRACT OF THE THESIS OF Jennifer Anne Deck Jennings for the Master of Science in Psychology presented July 5, 1979.

Title: The Relationship of Maternal Childrearing Practices to Prosocial Behavior and Resistance to Temptation in Preschool Children.

APPROVED BY MEMBERS OF THE THESIS COMMITTEE:

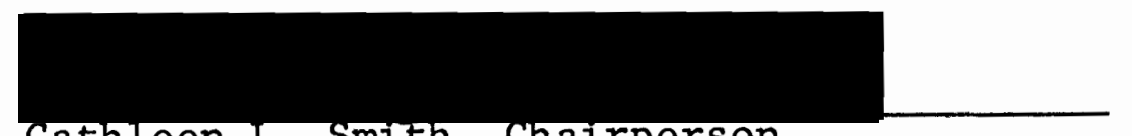

Cathleen L. Smith, Chairperson
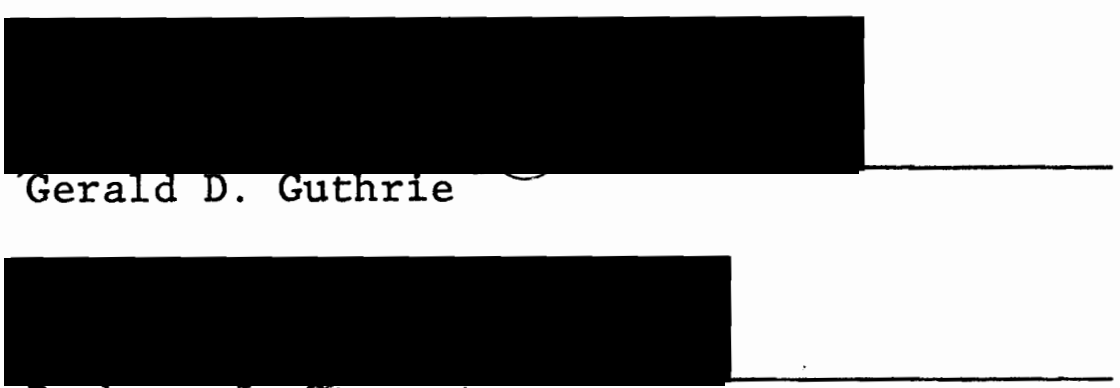

Barbara J. 8tewart

Preschool children's prosocial behavior and resistance to temptation were examined in relation to maternal 1 childrearing practices. Forty-seven children and their mothers participated in the study. At a play session at the child's day care center, each child was given opportunities to behave prosocially, i.e., to help, share, teach, or exhibit sympathy, and to resist temptation, i.e., refrain from playing with an attractive but forbidden toy. Mothers 
of these children were individually interviewed and given a questionnaire developed for this study. During the interview, mothers were presented with typical parent-child situations and ask to imagine them as though their own child were involved. These situations involved both instances of misbehavior of the child (coloring on the wall, getting into another's belongings, breaking a lamp, jumping on the furniture, and getting into items on the shelves of a store) and instances of the child's prosocial behavior (helping to pick up the groceries that have fallen to the floor, sharing a cookie with a friend, teaching a friend to do sommersaults, and finding it difficult to share a toy with another). Mothers were asked to describe exactly what they would do in these situations, and their responses to these open-ended questions were later subjected to a content analysis. Following the description of each situation, mothers were provided with a list of sixteen to eighteen parental practices and asked to rate the frequency of their own use of each practice on a four-point scale (Usually, Sometimes, Rarely, Never).

When the frequency of parenting techniques was investigated, in both punishment and prosocial situations, mothers were most likely to state rules or reminders, whether the mothers' response was obtained from the openended questions or from the list items. When responding to list items in prosocial situations, mothers indicated 
that they often used physical affection and emphasized the needs or feelings of others. In response to the open-ended questions, mothers indicated that praise was the most common reaction to their child's spontaneous prosocial behavior. When individual parent-child punishment incidents were examined, parents' responses to these situations were quite consistent across situations. This was not the case in prosocial situations, where varying responses from mothers, particularly to the open-ended questions, were elicitèd.

When the relationship of mothers' responses to list items and the open-ended questions was examined, consistency across these measures, particularly on prosocial scales, was not pronounced. While the punishment scales were significantly related across the two measurement modalities $(\mathrm{p}<.05)$, the scales for the prosocial situations displayed few significant correlations. The subsequent factor analysis of selected punishment scales brought the composite scales of induction and power assertion into question. The child's overall prosocial score was negatively related to mothers' neutral responses to both misbehavior and prosocial behavior in her child, Children's sharing and sympathetic behavior was positively related to the mothers' use of feeling statements, and sympathy was significantly related to mothers' use of other-oriented rationales in prosocial situations. Resistance to temptation was 
related to a number of parenting behaviors and no consistent pattern emerged. Examination of demographic variables revealed that girls were spanked more often than boys.

When the relationship between prosocial behavior and resistance to temptation was examined, only one significant correlation emerged, between helping and the duration of deviation $(r=.24, p<.051)$. Mothers'perceptions of their child's prosocial behavior were not related to their child's actual behavior. 
THE RELATIONSHIP OF MATERNAL CHILDREARING PRACTICES

TO PROSOCIAL BEHAVIOR AND RESISTANCE TO

TEMPTATION IN PRESCHOOL CHILDREN

$$
\text { by }
$$

JENNIFER ANNE DECK JENNINGS

A thesis submitted in partial fulfillment of the requirements for the degree of

\author{
MASTER OF' SCIENCE \\ in \\ PSYCHOLOGY
}

Portland State University 
TO THE OFFICE OF GRADUATE STUDIES AND RESEARCH:

The members of the Committee approve the thesis of Jennifer Anne Deck Jennings presented July 5, 1979.

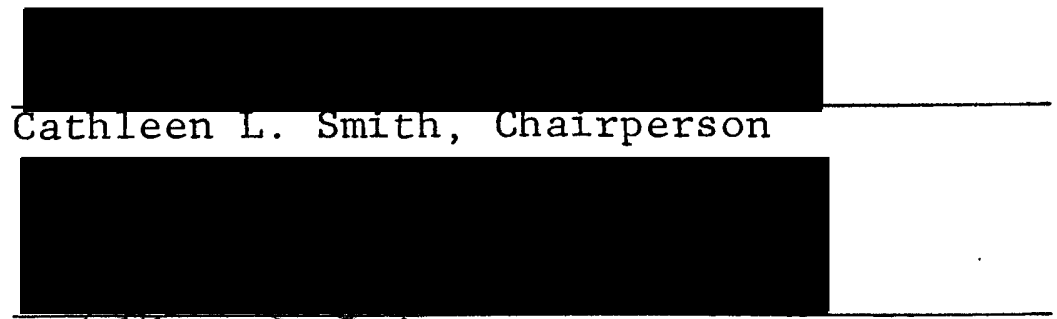

Gexald D. Guthrie

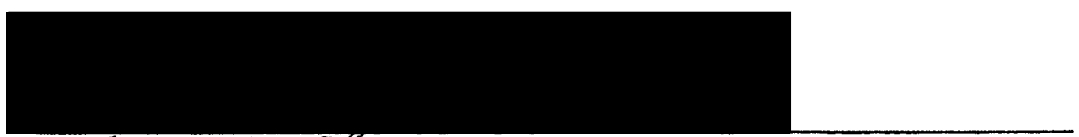

Barbara J. SEewart

APPROVED :

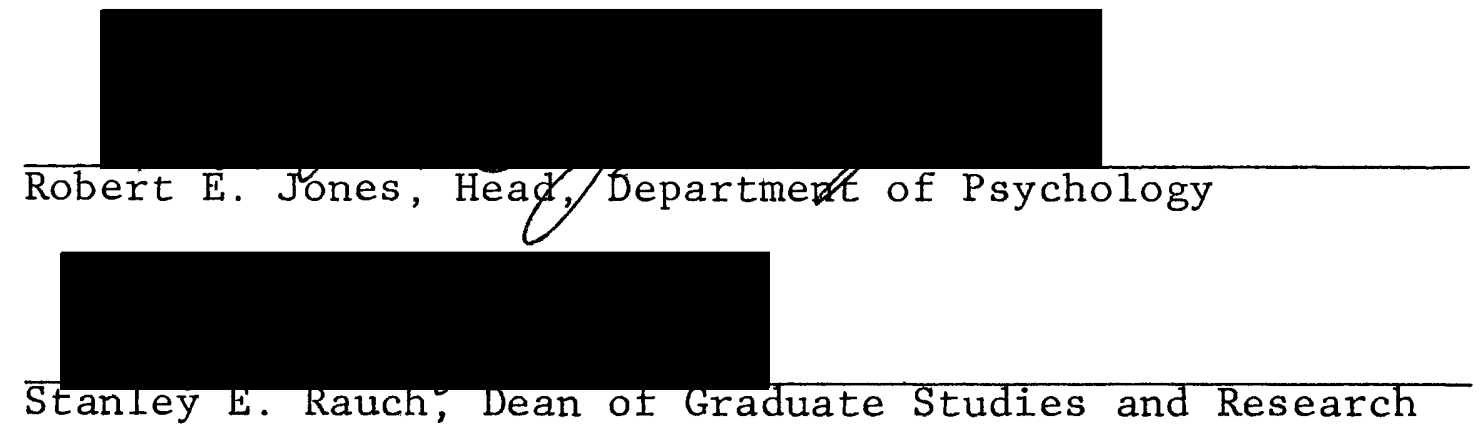




\section{ACKNOWLEDGEMENTS}

First of all, I would like to extend my appreciation to my thesis chairperson, Dr. Cathleen Smith, who not only spent much time and energy in the preparation of this manuscript, but served as an active member of the day-to-day research team. Dr. Smith's intense involvement in and knowledge of this research area was invaluable to the progression of this project, and to its conclusion. I would like to express my appreciation to Dr. Barbara Stewart for the many hours spent in questionnaire development and statistical consultation. Dr. Stewart's enthusiasm and interest in this research and myself was instrumental in the completion of this thesis, and in my appreciation for, and even enjoyment of, computer programming. I would also like to express my appreciation to Dr. Gerald Guthrie, who provided many interesting comments and ideas throughout the course of this project.

I also wish to thank those members of our research team who have been unending in their support of this project, in both time and interest. I would like to thank Carolee Garcia-Bengozia, Susan Elliot, and Jane Uphoff for their support and assistance in both working with the children and interviewing and assessing mothers' responses. I would also like to thank Beverly Ott for her assistance in 
the content analysis. And to my fellow graduate student and friend, Jane Blackwe11, I wish to express many thanks not only for her assistance in this project but for her support and cooperation in coordinating our two endeavors.

I wish to express gratitude to the two day care centers which allowed us to make use of their facilities. The directors of these centers, Don Deena Johnson at Holladayland Day nursery and Carol Leonhardt at Mountain Park Learning Tree Day Care Center, were very helpful in providing our research team with any assistance needed.

I also wish to extend appreciation to the mothers who gave the time to be involved in this study and discuss with us such a sensitive and interesting issue as childrearing. It is only through these mothers' involvement and overwhelming cooperation that this research was possible. And finally, I wish to thank my husband, John, for his unending encouragement of my continued education, and for his support of this project. I thank him for living with me through a trying time, but exceedingly more for his unending belief in my abilities, and more importantly, in me. 
TABLE OF CONTENTS

PAGE

ACKNOWLEDGEMENTS

LIST OF TABLES

CHAPTER

Review of the Literature . . . . . .

Resistance to Temptation

Prosocial Behavior

Sex and Age Differences

The Present Study . . . . . . . . . 23

II METHOD . . . . . . . . . . . . . . 25

Subjects and Experimenters . . . . . 25

Setting . . . . . . . . . . . . . . 25

Procedure . . . . . . . . . . . 26

Measure of Child's Prosocial

Behavior and Reliability

Measure of Resistance to

Temptation and Reliability

Measure of Maternal Childrearing

Practices

Development of Childrearing

Practices Measure

Closed-ended Responses:

Description of Scales for

Punishment Situations

Closed-ended Responses:

Description of Scales for

Prosocial Situations 
Content Analysis of Mothers'

Responses to Open-ended

Questions and Reliability

Data E.nalysis

Overview

Description of Maternal Behaviors . .

Mothers' Responses across All Situations

Mothers' Responses to Specific Situations

Measurement Considerations . . . . .

Relationship of Open-ended and Closed-ended Measures

Interrelationships of Children's Moral

Behaviors, Maternal Responses, and Demographic Variables . . . . .

The Relationship of Prosocial Behavior to Maternal Responses

The Relationship of Resistance to Temptation to Maternal Responses

Factor Analysis of Selected Punishment Scales

The Relationship of Punishment Factors and Moral Behaviors

The Relationship of Demographic Variables to Parental Responses and Children's Moral Behavior

The Relationship of Prosocial Behavior to Resistance to Temptation

The Relationship of Mothers' Perceptions of Prosocial Behavior and the Child's Actual Behavior 
vii

CHAPTER

PAGE

IV DISCUSSION . . . . . . . . . . . . . 88

REFERENCES . . . . . . . . . . . . . . 101

APPENDICES . . . . . . . . . . . . . . . . . 106

A SCORING SYSTEM . . . . . . . . . . . 107

B MATERNAL QUESTIONNAIRE AND RELATED FORMS • 114 


\section{LIST OF TABLES}

TABLE

PAGE

I The Three Scoring Strategies . . . . . . .

II Rankings, Means, and Standard Deviations of

Childrearing Scales. Averaged across A11

Mothers in Each Measurement Modality .

III Ranking and Means of Frequent Childrearing

Practices Averaged across Mothers in

Each Parent-child Situation and

Measurement Modality . . . . . . . .

IV Intercorrelation of Open-ended and Closed-

ended Measures Using Pearson $r$. . . .

V Pearson Correlations of Prosocial Behavior with Mothers' Responses to Punishment and Prosocial Situations . . . . . . . .

VI Pearson Correlations of Resistance to

Temptation with Mothers' Responses to

Punishment and Prosocial Situations...

VII Pearson Correlations of Punishment Factors with Children's Prosocial Behavior and Resistance to Temptation . . . . . . . 
VIII Pearson Correlations of Demographic

Variables with Mothers' Responses

to Punishment and Prosocial

Situations . . . . . . . . . . . . . . 83

IX Pearson Correlations of Demographic

Variables with Prosocial Behavior

and Resistance to Temptation . . . . . 84 
CHAPTER I

\section{INTRODUCTION}

Children's earliest socialization experiences occur in the home in interaction with parents. It seems evident that this intimate relationship of parent and child produces lasting effects on a variety of the child's behaviors, including the development of concern for others. Moral behaviors in the very young child are probably strongly affected by the manner in which parents respond both to their child's transgressions and their child's positive behaviors. In fact; these parent-child interactions may well be the child's initial encounter with the moral expectations or demands of society, and may influence the behavior of the child in future related situations in the absence of the parent. Although considerable literature has investigated the parent-child interaction as it affects the suppression of inappropriate behavior in the child, until recently the effects of parenting on the acquisition of cooperative or prosocial behaviors have received little attention. The present study attempts to assess the effects of parenting on the development of children's moral behavior. Specifically, it examines maternal childrearing practices and their relationship to response suppression 
(e.g., resistance to temptation) and to prosocial behavior (e.g., helping, sharing, teaching) in the child. In addition, this study attempts to further examine those parenting styles or patterns traditionally reported in the child development literature in order to assess their precision in describing the parent-child interaction.

Several authors have speculated about the relationship of parental discipline style to punishment effectiveness and the development of moral behavior. Generally, these explanations have emphasized the influence of cognitive components of punishment (e.g., reasoning with the child) in the development of morality. Early investigations by Sears, Maccoby, and Levịn (1957) suggested that the effectiveness of punishment is derived from its love withdrawing qualities. They further suggested that the use of reasoning in conjunction with punishment enables the child to generalize from the specific and current instance in which the child is being trained to other situations where the punishing agent is absent: Aronfreed (1961) likewise emphasized the cognitive components of the discipline encounter. He suggested that punishment which is power assertive (e.g., relies on parental power or force to gain the child's compliance) communicates less of the information necessary for the child to effectively generalize punishment experiences than do techniques which emphasize cognitive, verbal components. Festiger and Freedman (1964) 
suggested that the cognitive dissonance which punishment creates determines its effectiveness in aiding the development of moral values. Cognitive dissonance theory suggests that

. . when a person holds two cognitions that are psychologically inconsistent with each other, dissonance is produced; that is, the existence of this dissonance is uncomfortable, and the person experiencing it will try to reduce the dissonance and achieve consonance (Festiger and Freedman 1964, pp. 220-221).

When a child refrains from transgressing, it can ascribe its own behavior to compliance with external sanctions or to compliance with an individual internal value system. Effective punishment techniques (i.e., those which inhibit future inappropriate behaviors in the absence of the socializing agent) are those which minimize the child's perception of external constraints. Festinger and Freedman (1964) suggested that punishment which is characterized by weak external pressure to comply will aid in the development of moral attitudes through the reduction of dissonance. Hoffman (1963) proposed that

- . discipline techniques which point up the consequences of the child's behavior without exceeding his level of comprehension or creating undue stress or confusion should foster impulse control directly by sensitizing the child to the consequences of uncontrolled behavior (Hoffman 1963, p. 574).

It seems evident that early explanations of the effectiveness of punishment in the development of moral behaviors strongly support the use of a cognitive component in the discipline interaction. 
In recent studies of the relationship of punishment to moral development in children, two indices of moral behavior have received considerable attention, prosocial behavior (e.g., sharing) and resistance to temptation. Prosocial behavior has been defined as "those actions that are intended to aid or benefit another person or group of people without the actor's anticipation of external rewards" (Mussen and Eisenberg-Berg 1977, p. 4). A prosocial behavior such as sharing has typically been assessed in the laboratory by noting the number of candies or certificates donated by the child to an absent needy peer. Resistance to temptation has been defined as "the inhibition of deviant behavior" (LaVoie 1973, p. 393). It has typically involved providing the child with an opportunity to transgress (e.g.) cheat, play with a prohibited toy) after he or she has been specifically cautioned against such behavior, with the child's subsequent compliance or noncompliance observed. Childrearing practices as examined in relation to these indices have generally been conceptualized using discipline categories elaborated by Hoffman and Saltzstein (1967). These authors suggested three large classifications of parental responses, power assertion, love withdrawal, and induction. Power assertion has typically included the use of physical punishment, deprivation of material objects or privileges, the use of force, or the threat of any of these. The term power assertion was 
chosen to emphasize the fact that "in using this technique the parent seeks to control the child by capitalizing on his physical power or control over material resources" (Hoffman and Saltzstein 1967, p. 48). Love withdrawal has generally been described as the withdrawal of affection by the parent through ignoring the child, not speaking to him or her, or by physically separating the child from the parent. Induction as a parenting technique has emphasized the inclusion of reasons or explanations that focus on the "consequences of the child's behavior for himself and others" (Hoffman and Saltzstein 1970, p. 286). It is thought that induction provides additional information to children concerning the appropriateness of their actions and may enable them to "generalize the suppression of misbehavior in the presence of the punishing agent to misbehavior in the agent's absence" (Walters and Grusec 1977 , p. 201). Hoffman (1970) concluded that induction appeared to be the most effective parenting technique for influencing moral behaviors. And in fact, an examination of the literature does provide some support for the effectiveness of reasoning as a punishment technique, although inconsistent results can be found in the research dealing with both prosocial behavior and resistance to temptation.

Due to difficulties in research design and ethical constraints inherent in the nature of childrearing research, many investigators have chosen to examine parenting 
behavior by means of analogue studies, i.e., laboratory manipulations which attempt to simulate the parent-child interaction. However, the usual unfamiliarity of the child with the experimenter and the uncertain authenticity of treatments (e.g., the use of a buzzer as an analogue of physical punishment) bring the usefulness of these studies in assessing the effectiveness of real-life parental behavior into question. Laboratory analogue studies of moral development are similarly problematic. Again, the child is usually unfamiliar with the experimenter and many times is asked to share unlikely objects (e.g., marbles or gift certificates) with absent needy peers. Other measures of altruism rely on peer or teacher reports of the child's altruistic tendencies, and it is unclear whether these reports accurately represent actual behavior. A more naturalistic assessment of moral behaviors in the child would seem a valuable contribution to this literature.

Problems also exist with formats typically used in assessing parenting style. For example, considerable research has taken the form of interviews or questionnaires, given either to the parent or in some cases to children to assess their perceptions of their parent's discipline style. This information is then generally correlated with behaviors and/or characteristics of the child. The difficulties in gathering data using questionnaires or interviews have been amply documented (e.g., Schaffer 1977, pp. 12-15; 
Hetherington and Parke 1975, pp. 312-314). And importantly, because much of this research is correlational in nature, statements of causality cannot be made in the analysis. Hetherington and Parke (1975) isuggested that the assessment of childrearing practices through interview and questionnaire may be improved by asking parents about their reactions to specific behaviors in their children rather than questioning them on their general attitudes concerning parenting. These authors propose that specific questions and probes will increase the ability of these measures to predict behavior.

REVIEW OF THE LITERATURE

Resistance to Temptation

Investigations of the relationship of parenting practices to resistance to temptation in children have typically involved laboratory analogue studies where the effects of reasoning and physical punishment, in the form of an aversive stimulus (e.g., buzzer) have been examined. In general, this literature has suggested that the inclusion of an inductive or reasoning statement in punishment conditions is likely to reduce deviations. Parke (1969) examined the effects of nurturance, induction or reasoning (what he termed cognitive structure), timing and intensity of punishment on resistance to temptation, in this case refraining from playing with a forbidden toy. Children in the high 
cognitive structure group received a statement by the experimenters of the consequences of the deviant behavior ("You should not play with the toys, I don't have any more like them . . and they might get broken" [Parke 1969, p. 222]), while children in the low cognitive structure group received a less informative statement ("You should not play with the toys, and if you do you will hear a buzzer" [Parke 1969 , p. 222]). Results showed that the addition of high cognitive structure increased the effectiveness of the aversive stimulus. As might be expected, high intensity punishment ( $86 \mathrm{db}$. buzzer) was more effective in reducing deviations than punishment of low intensity (60 db. buzzer). The effects of timing were "of only borderline statistical significance with early punishment subjects deviating less frequently than late punishment subjects" (Parke 1969, p. 229). When cognitive structure or intensity of punishment was high, early punishment (as the child touches the toy) was not more effective in reducing deviations than late punishment ( 5 seconds after the child touches the toy). These results provided evidence for the importance of cognitive structure in punishment effectiveness and suggested that the effects of timing may be mediated by cognitive structure or intensity of punishment.

Similarly Cheyne and Walters (1969), investigating the effects of timing, intensity, and cognitive structure of punishment on resistance to temptation, found that early 
punishment (as the child reaches for the toy) was more effective in reducing deviation than later punishment ( 3 seconds after touching the toy). High intensity punishment was also more likely to inhibit deviant behavior. Subjects deviated significantly less when exposed to high cognitive structure which included a statement of the consequences of the deviant act ("Some of these toys you should not touch . . I don't have any others!. . they might get broken" [Cheyne and Walters 1969, p. 234]). In fact; children in the high cognitive structure group picked up the forbidden toys an average of .7 times while those in the low cognitive structure group ("Some of these toys you should not touch . . you will hear a buzzer" [Cheyne and Walters 1969, p. 234]) picked up the toy an average of 4.15 times. Additionally, heart rate was measured, and a startle pattern in response to punishment was more frequent for those in the low cognitive structure group than in the high structure group. Cheyne and Walters (1969) asserted that this startle pattern is the emotional component of the punishment experience. They further suggested that resistance is effectively fostered either through high intensity punishment, containing an emotional component, or high cognitive structure, containing cognitive cues to appropriate behavior. They concluded that cognitive control may not develop without some anxiety-arousing avoidance training (e.g., through the use of an aversive stimulus) in addition to reasoning. 
In accordance with earlier evidence, Cheyne (1971) found that high intensity punishment ( $98 \mathrm{db}$. buzzer) was more effective in reducing deviations than punishment of low intensity ( $75 \mathrm{db}$. buzzer), and early punishment more likely to reduce deviations than late punishment. High cognitive structure was found to be superior to low cognitive structure in eliciting resistance to temptation, irrespective of the timing or intensity of punishment. In this study, heart rate measures suggested that the timing of a punisher may be more important than its intensity. Cheyne (1971) suggested that in situations where cognitive structure is low, effectiveness of the punishment technique rests on the inmediacy of punishment rather than on its intensity. LaVoie (1973) studied the effects of an aversive stimulus ( $87 \mathrm{db}$. buzzer) and the use of induction or reasoning on the generalization of a prohibition. Although the use of reasoning alone did not decrease deviations, when a rationale which emphasized the consequences of the child's behavior ("I don't want you to play with that toy . . it might get broken.. then I couldn't show it to other boys and girls" [LaVoie 1973, p. 506]) was included in the punishment condition, subjects were more likely to resist deviation. It appears that the additional information provided in the reasoning statement enhanced the child's ability to generalize the punishment experience to additional related situations. 
In a similar investigation, LaVoie (1974) examined the effects of an aversive stimulus ( $87 \mathrm{db}$. buzzer), a rationale ("You're not to play with the toys. . . they belong to another child . . . they might get broken" [p. 183]), withholding of resaurces, and withdrawal of Love. Resistance to playing with a forbidden toy was facilitated by the aversive stimulus, the rationale, and the withdrawal of love, but most strongly by the aversive stimulus. LaVoie (1974) suggested that the apparent effectiveness of the aversive stimulus was due to its innate aversive, anxietyarousing qualities, and further proposed that the subjects, who were first graders, had not achieved sufficient levels of cognitive development to make use of information provided in the rationale. Although these results do not demonstrate the superiority of reasoning over other techniques in the development of resistance to temptation, they lend support to the usefulness of reasoning in providing children with information concerning the appropriateness of their behavior.

A recent study by Verna (1977) measured the effectiveness of timing of punishment (immediately or after four hours) and type of instruction (minimal or specific) in reducing deviations. Minimal instructions consisted of a general statement ("Because of what happened I'11 have to take your toy away" [Verna 1977, p. 622]) while specific instructions included a reminder to the child that the 
punishment was due to his or her specific behavior. Children punished immediately and those receiving specific instructions more effectively resisted temptation. Verna (19.77) suggested that less concern need be placed on catching a child in the act of transgression when the parent includes a cognitive component (i.e., a reminder to the child of what specific behaviors are being punished) in the punishment situation, however long delayed. These results and those discussed earlier provide fairly consistent support for the significance of reasoning. Evidence suggests that reasoning can mediate the effects of punishment timing and intensity, and can provide the child with more information than is available from the application of an aversive stimulus alone.

In accord with laboratory studies, correlational studies of resistance to temptation have suggested the effectiveness of reasoning. Early work by Sears, Maccoby, and Levin (1957) examined parental childrearing practices. Three hundred and seventy-nine mothers were intensively interviewed to assess their childrearing behaviors. Results of these interviews indicated that mothers who used high levels of reasoning were likely to have children with a high level of conscience. (One measure of conscience in this study was the mother's perception of the child's ability to resist temptation.) In addition, sears and his associates (1957) suggested that the effectiveness of 
physical punishment was mediated by the level of nurturance supplied by the mother and that withdrawal of love as a discipline technique tended to increase the emotional dependency of the child on the mother. These interview data were examined by Burton, Maccoby, and Allinsmith (1961) in an early study of resistance to temptation. In this study a positive relationship was found between the level of resistance to cheating on an experimental task and the parent's use of reasoning. Withdrawal of love was positively related to resistance only when that parental technique entailed not talking to the child until he behaved appropriately. When girls' punishment consisted of deprivation of material goods, resistance, was negatively related to punishment. Although his results did not reach significance, Grinder (1962) found pósitive correlations between resistance to temptation and both withdrawal of love and the use of reasoning.

These results support the effectiveness of reasoning in facilitating resistance to temptation; however, there is at least one study which indicates that these effects need to be further investigated in naturalistic settings. Greenglass (1972) directly observed Italian and Canadian mother-child interactions and' presented children with a resistance to cheating paradigm. Greater resistance to cheating was found to be associated with restrictive and authoritarian maternal patterns and negatively related to 
reasoning. These results certainly contradict the data from other studies of resistance to temptation and strongly suggest that the effects of reasoning on this index of moral behavior are not at all clear.

In summary, research relating punishment and resistance to temptation in children suggests the usefulness of reasoning as a punishment technique, although evidence is certainly not conclusive. On the one hand, the results of correlational studies suggest that reasoning, and in some cases love withdrawal, are effective tools in promoting resistance to temptation (Burtion, Maccoby, and Allinsmith 1961; Grinder 1962). However, when Italian and Canadian mothers were directly observed in interaction with their children, clearly opposite results were found (Greenglass 1972). Analogue studies of punishment and resistance to temptation also show similar conflicting results. Research which has found cognitive structure a mediating variable in the effects of timing and intensity of punishment (Parke 1969; Cheyne and Walters 1969; Cheyne 1971; LaVoịe 1973; Verna 1977) must be examined in light of evidence which indicates that an aversive stimulus or buzzer is the most effective technique in reducing deviations (LaVoie 1974).

Prosocial Behavior

Studies of the relationship of childrearing practices to prosocial behavior lend some additional support to the 
effectiveness of reasoning in discipline situations. Analogue studies of prosocial behavior and childrearing techniques have commonly examined the effects of a variety of verbal instructions, including induction, on children's donating behavior. Grusec and Skubiski (1970) measured the effect of modeling and verbalizations (e.g., "I guess they expect us to give to the poor children. . . that's probably what we'd better do" [p. 355]) on donating behavior. Children exposed to an altruistic model donated more than children exposed to the verbalization, with the exception of females in verbalization groups receiving high levels of nurturance. These results conflicted with the authors' hypothesis that verbalization would be as effective as modeling in eliciting donating behavior. However, the verbalizations used by Grusec and Skubiski (1970) do not appear to be inductive in nature; that is, they did not supply the child with a statement describing the consequences of his or her behavior. Rice and Grusec (1975) altered this design so that it appeared that the experimenter would have an opportunity to share. Results of this study indicated a positive relationship between altruism and both modeling and verbalizations, confirming the earlier hypothesis. The verbalizations employed by Rice and Grusec (1975), though they did not include a statement of consequences, may have been effective because they clearly conveyed to the child the expectation of donating ("Weli now, I guess they expect 
us to give some to the poor children. Probably that's what one had better do" [p. 586]). In contrast, Bryan and Walbek (1970) found that preaching statements ("If I win some money today I'm going to give it to the poor children... it would make them happy" [p. 333]) were ineffective in eliciting donating, while observation of a generous adult model increased children's sharing.

Staub (1971) examined the effects of induction and role playing on sharing and helping behavior. Girls who received inductive statements had a slight tendency to help, while boys in the inductive group tended to share slightly more than those in the control group. In fact, when the experimenter "accidentally" dropped some paper clips, those in the induction group were less likely to help pick them up than other groups. These results certainly do not provide support for the hypothesis that induction increases altruism. Staub (1971) suggested that the lack of a positive effect for induction may have been due to "psychological reactance," in that children may have perceived the inductive statement as pressure to comply.

More recently, Depalma (1974), in a study of donating behavior in the laboratory, found that higher intensity punishment (e.g., a larger number of candies taken away for a transgression) elicited greater donating behavior than low intensity punishment. However, children whose moral orientation reflected parents who emphasized induction 
donated more than those children whose moral orientation reflected parents who emphasized power assertion, regardless of the severity of punishment. Although this study does suggest that induction may be important in the development of prosocial behavior, in general the analogue studies of prosocial behavior provide inconsistent findings.

Correlational studies of the relationship of childrearing practices to prosocial behavior provide.some additional evidence concerning the usefulness of reasoning in the development of moral behaviors. Hoffman (1963) described an investigation of the naturally occurring prosocial behavior of 22 nursery school children and its relation to maternal childrearing practices. Due to the infrequency of naturally occurring prosocial behavior, only the child's active concern for the well-being of others and the child's wish to change another's behavior (i.e., showing awareness of another's needs, and taking them into account by offering a substitute) could be included in the final analysis. Maternal childrearing practices were assessed in an interview in which the mother's acceptance of the child and her use of inductive discipline was examined. Results suggested that those mothers who used little power assertion and emphasized the use of inductive discipline tended to have more prosocial children.

Hoffman and Saltzstein (1967) measured a number of dimensions of moral development in seventh graders, 
including peer ratings of the child's consideration of others. All indices were then related to childrearing practices of parents as assessed by questionnaire. Parents were asked to describe the techniques they currently used as well as the methods they used when the child was five years old. Parental practices were assigned to three categories, induction, power assertion, and love withdrawal. When all indices of moral development were combined . . the frequent use of power assertion by the mother was consistently associated with weak moral development. The use of induction, on the other hand, was consistently associated with advanced moral development (Hoffman and Saltzstein 1967, p. 50).

However, the effects of childrearing practices on consideration of others, although positively related to the consistent use of induction in females, was positively related to the mothers' present use of power assertion for males. The authors suggested this may be due to "the measure of consideration of others being a poor one, especially for boys" (Hoffman and Saltzstein 1967, p. 51). It was suggested that since males were less likely to value helping others than females, this would affect the incidence of prosocial behavior reported by the boys' peers.

Hoffman (1975) conducted similar parent interviews assessing childrearing practices and measured altruism by peer reputation. The parental questionnaire included situations in which the child had an opportunity to harm another (e.g., by making fun of another child), and parents received 
scores according to the degree of concern expressed for the victim of each situation (e.g., receiving a higher score for encouraging reparation from their child and a lesser score for eliciting an apology). Children who were perceived as altruistic by their peers had opposite-sexed parents who received a high score on victim-centered discipline. This study suggests that parents who stress concern for others may facilitate the development of the child's altruistic tendencies, at least as measured by peer judgments.

In a study of father absence, Santrock (1975) investigated the effects of induction, power assertion, and love withdrawal on sharing behavior in young boys. No significant relationships between maternal discipline and altruism were found, although teacher ratings of moral behavior were significantly correlated with sharing. Boys with divorced parents received lower moral behavior scores from teachers and were likely to come from families where power assertion was emphasized. These results seem to lend some support to the notion that the use of power assertion as a discipline technique may negatively influence the development of altruism.

Dlugokinski and Firestone (1973) investigated the relationship between children's other-centeredness (i.e., children's concern for others) and their perceptions of maternal discipline. Children in fifth- and eighth-grade 
classes were interviewed about their parents' discipline style, and peer ratings of consideration for others and measures of donating behavior were obtained. The measures of discipline style and consideration for others were those of Hoffman and Saltzstein (1967). Children who perceived their parents' discipline style as emphasizing induction donated more and were rated as more considerate by their peers. Power assertive discipline was not related to measures of other-centeredness, measured either by consideration of others or donating behavior. These results are consistent with the Hoffman and Saltzstein (1967) study and further suggest the influence of the inductive parenting style on altruism.

Olejnik and McKinney (1973) studied parental discipline and its relation to sharing behavior in four-yearolds. The discipline style of parents was assessed in interviews, as was the value orientation (e.g., doing good versus avoiding bad) of both parent and child. Results indicated no relationship between parental discipline and altruism but a positive relationship between the value orientation of the parent and the child's level of altruism. Those parents who emphasized a prescriptive moral orientation (e.g., doing good) had more altruistic children. This study suggests that punishment itself may be less instrumental in the development of altruism than the parents' general moral orientation. 
A more recent study (Zahn-Waxler and Radke-Yarrow 1978) examined the naturally occurring prosocial behavior of 1-1/2- to 2-1/2-year-old children and its relationship to maternal childrearing practices. Prosocial behavior was recorded by mothers at times when the child was the cause of someone's physical or psychological stress, and at times when the child was only a bystander. It was found that when the child was the cause of the distress, the mother was likely to explain to the child the painful consequences of his or her actions for another. When the child was merely a bystander, explanations, were given in a more neutral tone. In relation to the child's prosocial behavior, - . the more altruistic children were those whose mothers used affectively-arousing explanations in handling their child's transgressions. The more neutrally messages were not effective in eliciting porsocial behavior (Zahn-Waxler and Radke-Yarrow 1978, p. 4).

These authors further suggest that

. . the differential effectiveness of emotional and neutral verbal instructions indicates the need for further research to distinguish the several forms of behavior that have been customarily grouped together in research and theory as psychological, verbal inductive statements (Zahn-Waxler and Radke-Yarrow 1978, p. 5).

In addition to providing further support for the influence of strongly stated explanations on prosocial behavior, this study stresses the importance of further differentiation of that group of behaviors commonly designated as induction. In addition, this study suggested that discipline techniques 
which are also "affectively arousing" may be important in the development of altruism.

In summary, the inconsistency that is shown in the resistance to temptation literature appears in the altruism research as well. While positive relationships between reasoning and verbalizations and altruism have been reported (Rice and Grusec 1975; Hoffman 1963; Depalma 1974; Hoffman and Saltzstein 1967), not all studies support this conclusion (Grusec and Skubiski 1970; Staub 1971; 01ejnik and McKinney 1973). With regard to the analogue studies, the lack of broad measures of altruism and the reliance on the paradigms of sharing improbable objects with absent needy children further weaken the conclusions which can be made. It is questionable whether donating marbles (Rice and Grusec 1975; Grusec and Skubiski 1970) or gift certificates (Bryan and Walbek 1970) to needy children or ratings by peers of consideration of others (Hoffman and Saltzstein 1967; Dlugokinski and Firestone 1974; Hoffman 1975) are accurate measures of a child's altruistic tendencies. It appears that naturalistic studies of a broad range of altruistic behaviors may be a more effective means of addressing this issue.

$\underline{\text { Sex and Age Differences }}$

In the previously discussed investigations, effects of sex and age proved inconsistent. When significant sex differences did emerge, females appeared more likely to 
resist deviation (LaVoie 1973) and exhibit greater altruistic tendencies (Hoffman and Saltzstein 1967), although Staub (1971) found boys displayed greater donating behavior. In fact, a considerable portion of these studies have dealt exclusively with boys (Santrock 1975; Cheyne 1971; Parke 1969; Cheyne and Walters 1969). Studies of the effects of age differences on the acquisition of moral behaviors, although inconsistent, provide some support for the notion that these behaviors increase with age. While Grusec and Skubiski (1970) found no sex or age differences, LaVoie (1973) found that the latency of the first deviation in the resistance to temptation situation increased with age.

\section{THE PRESENT STUDY}

The present study examined the relationship of maternal childrearing practices to prosocial behavior and resistance to temptation in preschool children. The measures of prosocial behavior were designed to maximize their similarity to events which children actually encounter in their daily lives; e.g., helping to find lost objects. Since prosocial behavior is infrequent in this age group, the experimental situation was arranged so as to provide opportunities for the child to help, share, teach, and exhibit sympathy. A measure of resistance to temptation, i.e., whether the child played with a forbidden toy, was also included. Maternal childrearing practices were assessed in 
systematic interviews. In contrast to previous research, which examined parental reactions to punishment situations exclusively, the current investigation assessed parental reactions to situations in which the child behaves prosocially as well. This study further described those childrearing styles most often used by parents, their frequency, and their use in particular parent-child situations. Since few investigations have included both measures of resistance to temptation and prosocial behavior, it was of interest in this study to examine the relationship of these indices to each other and to maternal childrearing practices. Unlike previous studies, questions asked in this interview attempted to differentiate among behaviors which in the past have been grouped together as "inductive" or "power assertive." As a result, this information allowed for further discrimination of those components of induction and power assertion which may have differential effects on the deve1opment of prosocial behavior and resistance to temptation. However, limitations of this research must also be noted. This study does not investigate the effects of modeling or observe actual parent-child interaction. 
CHAPTER II

METHOD

\section{SUBJECTS AND EXPERIMENTERS}

Subjects were forty-seven mothers who gave fullyinformed written consent and their individual children. The twenty-four girls and twenty-three boys attended one of two local day care facilities in the middle- to uppermiddle-class Portland metropolitan area. Children ranged in age from 46 to 69 months and the distribution of ages and sex were approximately equal for both schools.

Two women graduate students experienced in working with children acted as experimenters during the play session with the children. Two women graduate students and a post-baccalaureate student with experience in working with children and training in the specific interview techniques used in this study conducted the interviews with the mothers.

\section{SETTING}

Measures of children's prosocial behavior and resis-. tance to temptation were taken in two Portland day care facilities, Holladayland Day Nursery in northeast Portland and Mountain Park Learning Tree Day School in Lake Oswego. The experimental setting at Holladayland was a small area 
partitioned off from a larger room. At Mountain Park, a small play room was used. At each location, a portable observation booth with one-way mirrors (approximately four feet wide, ten feet long, and six feet tall) was installed. In addition, the setting included three small folding chairs, a child's folding table, two trunks, and several colorful posters which decorated the walls and observation booth.

Mothers were interviewed at their convenience in their home at a time when interruptions were minimal, in a quiet room at their child's day care center, or at other prearranged locations.

\section{PROCEDURE}

Measure of Child's Prosocial Behavior and Reliability

The child's level of prosocial responding was measured in a 30- to 40-minute play session in which individual children were provided with real-life situations in which helping, sharing, teaching, and sympathy were appropriate behaviors. Individual children were invited to "be the special person" by one of the experimenters and were then escorted to the playroom. In the first part of the session the experimenters attempted to establish a positive, nurturant rapport with the child by directing the conversation to a poster of a farm scene and by playing a guessing game. This friendly interaction continued into an activity of planting 
seeds in paper cups during which several opportunities for the child to respond prosocially (three opportunities each for helping, sharing, teaching, and one for sympathy) were embedded as naturally as possible into the ongoing situation by taking advantage of the materials and play at hand.

Opportunities to help occurred when an experimenter needed assistance moving supplies to the table, when she accidentally dropped some wooden sticks, and when her special box became lost. Sharing opportunities involved incidents in which the experimenter was in need of objects which only the child possessed (cup in which to plant seeds, flower sticker, animal cracker). Teaching opportunities occurred when an experimenter stated she did not know how to do something ( $\mathrm{plant}$ seeds, water seeds, make a flower stick). Finally the child was provided with an opportunity to show sympathy when an experimenter appeared to have accidentally bumped her knee on the edge of the table.

These prosocial behaviors were introduced by means of a verbalization of need in which the experimenter labeled the situation as one in which a prosocial response would be appropriate. For example, the verbalizations of need for helping indicated an opportunity to come to the aid of the experimenter by presenting a brief statement of the problem plus a possible solution (e.g., "Oh, I spilled the sticks. They need to be picked up"; "My special box is lost. It needs to be found"). The verbalization of need 
signalling a sharing opportunity indicated the experimenter's desire for an object or material in the child's possession (e.g., "I'd like to plant seeds, but I don't have a cup"; "I really like animal crackers, but I don't have any"). A verbalization of need indicated a teaching opportunity when one of the experimenters acknowledged that she did not know how to do something (e.g., "I don't know how to water seeds like that"; "I don't know how to make a flower stick"). Each teaching opportunity pertained to a simple task that the child had just learned from the other experimenter, and therefore the possibility of differential learning backgrounds and skills was eliminated. Furthermore, al1 teaching situations were designed to consist of three components (e.g., to plant seeds, one must use three scoops of dirt in each cup, drop in three seeds, and poke the seeds down), and in order to ensure that all components were incorporated into the child's repertoire, he or she was questioned about the procedure. For example, after demonstrating to the child how to plant seeds, the expermenter asked the child, "Do you remember how we planted seeds?" "What did we do first?" "Then what did we do?" until all three components were stated or demonstrated by the child. And finally, an opportunity for sympathy was indicated when the experimenter injured herself and demonstrated mild distress and appropriate nonverbal cues (e.g., "Oh, I bumped my knee. It really hurts"). 
Each experimenter delivered an equal number of need verbalizations in the session, with their manner of presentation and order held constant for all children. In order that the child was never exposed to an adult who modeled inaction or nonintervention, the verbalizations of need were presented while one experimenter had temporarily left the room. If the child did not begin the prosocial response within a seven-second interval, the experimenter did not comment, play resumed as before, and the other experimenter reentered the room shortly thereafter.

Although the interactions with the child were warm and supportive throughout the session, the experimenters did not directly praise any prosocial behavior. Therefore, the likelihood of increased prosocial behavior due to praise was eliminated.

Four observers were trained to code the child's prosocial behavior, with at least two observers present for each subject. Observers, behind a one-way glass observation booth, recorded the behaviors of the child and nurturant comments of the experimenters during the session.

The observers scored the child's behavior on a scale ranging from 0 to 5 , according to the following general format:

$$
\begin{aligned}
& 0=\text { active refusal } \\
& 1=\text { no response } \\
& 2=\text { concern with no involvement }
\end{aligned}
$$


3 = concern which poses a solution to the need

4 = prosocial response

5 = prosocial response with special involvement

A complete description of the operational definitions of the prosocial behaviors and the scoring code can be found in Appendix A.

An overall prosocial index was then computed by combining individual scores of helping, sharing, teaching, and sympathy. The correlation of these behaviors with the prosocial index ranged from .67 to .78 , all significant at the .001 level.

Inter-observer reliabilities for each of the prosocial behaviors were calculated using percentage agreement. Exact agreement of observers was 81 percent for helping, 91 percent for sharing, 75 percent for teaching, 77 percent for sympathy. When those disagreements which differed by only one point were included, inter-observer reliability reached 99 percent for helping, 99 percent for sharing, 94 percent for teaching, and 94 percent for sympathy. Those observer scores which differed by more than one point were not considered sufficiently similar to warrant agreement.

Measure of Resistance to Temptation and Reliability

As the play session came to a close, one adult offered to take the child's plants back to his or her room. A few moments after the first adult left, the second adult 
finished putting the materials away and in the process opened a trunk in which the Shogun Warrior was kept (the Shogun Warrior is a $60 \mathrm{~cm}$. high, brightly colored toy selected for its popularity with children). As the experimenter pretended to search for some items, she laid the toy on the table, seated the child, and said that she was leaving to check on something. As she exited, she said, "Don't touch the toy while I'm gone." While the child was alone, observers recorded the latency to the first deviation, the number of deviations, and their duration in seconds.

The adults then reentered after approximately four minutes; they thanked the child for playing and expressed how fun it was playing with him or her.

Pearson product-moment correlation coefficients were used as indices of inter-rater reliability for measures of resistance to temptation. Four observers scored children's responses, with at least two observers present for each subject. Pearson $r^{\prime} s$ examined the inter-rater reliability of each of the possible pairs of observers. Correlation coefficients for latency ranged from .95 to .99 , with a mean of .98. Pearson $r$ 's for duration of deviations ranged from .91 to .99 , with a mean of .97 . For number of deviations, correlation coefficients ranged from .76 to .98 , with a mean of .88 . 
Measure of Maternal Childrearing

Practices

Reports of individual mothers' typical childrearing practices were collected through hour-long interviews conducted by trained female interviewers. Assessment of maternal parenting practices was made with the use of a questionnaire consisting of common problem situations and situations in which the child had spontaneously helped, taught, or shared with another peer or parent.

Preceding the presentation of the questionnaire, the interviewer engaged the mother in friendly conversation in a warm and supportive manner. It was explained to each mother that the purpose of the study was to look at ways in which parents respond to their child's positive and negative behaviors. It was emphasized that there are no right or wrong answers in parenting and that the interviewer's interest was in the practices that work best for this particular mother. The interviewer then read the instructions and obtained additional signed consent for participation in the interview. Each mother was then asked to fill out a general information sheet which included such items as the number of children in the home, the number of adults in the home, and the occupations and educational levels of adults in the home. The latter two factors were used to obtain a score of social position using the Hollingshead Two Factor Index of Social Position (Hollingshead 1957). In addition, mothers were asked to rate their own child's helping, 
sharing, teaching, and sympathetic behavior in relation to other children by indicating whether their child was "more likely to behave prosocially than other children, just as likely to behave prosocially as other children, or less likely to behave prosocially than other children."

Each mother was then presented with nine situations which she was asked to imagine as though her particular child were involved. The nine situations were systematically rotated to eliminate any order or fatigue effects that might be present. Situations in which disciplinary reactions were appropriate included finding the child coloring on the wall, getting into personal belongings of another, breaking a lamp, jumping on furniture, and getting into items on the shelves of the store. Situations dealing with the child's prosocial behavior included the child helping to pick up groceries that have fallen to the floor, sharing a cookie with a friend, teaching a friend to do sommersaults, and an item from the Hoffman and Saltzstein (1967) questionnaire dealing with a child's difficulty in sharing a toy with another. Following each situation, the mother was asked to describe exactly what she would do and exactly what she would say in that situation or one similar to it. The mothers' responses to these open-ended questions were later subjected to a content analysis. Each parent was then provided with a list of sixteen to eighteen parental practices and was asked to rate the frequency of her 
own use of the provided items on a four-point scale (Usually, Sometimes, Rarely, Never). The childrearing practices measure and corresponding information sheets can be found in Appendix B.

Three scoring strategies were devised to quantify mothers' responses to the parent-child situations provided. These strategies are presented below in Table I. Mothers' responses to list items were first scored so as to take advantage of the full range of scores possible in a 1-4 scoring system. Mothers' responses to the open-ended portion of the interview were assessed in a content analysis by observing the relative frequency of each parenting behavior in each parent-child situation. In this way, mothers received a score of 0 or 1 for each parenting scale for each parent-child situation. In addition, to maximize the similarity of open-ended and closed-ended measurement modalities, the closed-ended four alternative response format was then dichotomized with "never," "rarely," and "sometimes" keyed 0 and "usually" keyed 1 . In this way, assessment was made of those items mothers checked "usually" on the lists in each situation, similar to the question asked each mother in the open-ended case (e.g., "What do you usually do when something like that happens?"). 
TABLE I

THE THREE SCORING STRATEGIES

\begin{tabular}{|c|c|c|c|}
\hline & Responses & Scoring & Scales \\
\hline I. & $\begin{array}{l}\text { Closed-ended } \\
\text { responses }\end{array}$ & $\begin{array}{l}1=\text { never } \\
2=\text { rarely } \\
3=\text { sometimes } \\
4=\text { usually }\end{array}$ & $\begin{array}{l}\text { A. Punishment scales } \\
\text { (14 scales) } \\
\text { B. Prosocial scales } \\
\text { (12 scales) }\end{array}$ \\
\hline II. & $\begin{array}{l}\text { Closed-ended } \\
\text { responses }\end{array}$ & $\begin{aligned} 0= & \text { never } \\
& \text { rarely } \\
& \text { sometimes } \\
1= & \text { usually }\end{aligned}$ & $\begin{array}{l}\text { A. Punishment scales } \\
\text { (14 scales) } \\
\text { B. Prosocial scales } \\
\text { (12 scales) }\end{array}$ \\
\hline III. & $\begin{array}{l}\text { Open-ended } \\
\text { responses }\end{array}$ & $\begin{array}{l}\text { content analysis; } \\
0=\text { not mentioned } \\
1=\text { mentioned }\end{array}$ & $\begin{array}{l}\text { A. Punishment scales } \\
\text { (19 scales) } \\
\text { B. Prosocial scales } \\
\text { (19 scales) }\end{array}$ \\
\hline
\end{tabular}

Development of Childrearing

Practices Measure

Selection of parent-child situations to be included in this questionnaire was achieved by discussions with parents concerning common disciplinary and prosocial incidents. For purposes of comparison an additional situation was included from the Hoffman and Saltzstein (1967) questionnaire. These situations were then pretested to determine those incidents which a variety of parents perceived as most realistic. Those situations viewed as unlikely by a majority of parents and those incidents which included a number of parent response items correlating at a low level with their respective scales were not included for use in the final questionnaire.

Parental response items included in the lists provided to mothers were developed through interaction with 
parents and adaptation of items from earlier instruments. Numerous discussions with parents resulted in the construction of items which were assigned to scales according to their apparent relationship with particular parenting styles. In addition, items were adapted from the Hoffman and Saltzstein (1967) childrearing practices questionnaire for inclusion in this instrument. In the case of the prosocial situations, some items originally used by Hoffman and Saltzstein (1967) to describe parental responses to disciplinary encounters were transformed to be descriptive of responses to children's prosocial behavior (e.g., "Not let him have something he likes to do" became "Let him have something he likes to do").

Some of the existing scales were developed rationally, i.e., items were included which appeared to embody the characteristics. of the particular parenting style in question (e.g., attribution, rules). Next, some items were adapted from the Hoffman and Saltzstein (1967) instrument and assigned to their original corresponding scales (love withdrawal). Additionally, those items which Hoffman and Saltzstein (1967) originally designated as representative of power assertion or induction were differentiated into component scales (e.g., "power assertion: became "spank" and "withdrawal of privileges").

The possible responses to the items were scaled a priori as 4 for a "Usually" response, 3 for "Sometimes," 
2 for "Rarely," and 1 for an item checked "Never" by mothers. For each subject, items were summed and divided by the numbers of items on a given parenting scale to compute a score for each mother for each individual scale. For example, the guilt scale for discipline situations was comprised of two items, "Ask him why he behaves that way when you do so much for him" and "Tell him when he behaves that way he doesn't care about me" on each of the five punishment situations. Each mother received a score for each of the ten guilt items which were averaged across punishment situations to obtain a score for the guilt scale. Correlations between item scores and total scores for each scale were calculated. The 154 item total correlations ranged from .10 to .91 , with a median correlation of .68 . The three item total correlations below .24 were removed from their respective scales due to their questionable relationship to the total scale scores.

In summary, the instrument used in this study included items suggested by parents and those adapted from the Hoffman and Saltzstein (1967) questionnaire.

Close-ended Responses: Description of Scales for Punishment Situations

Scales developed to measure reactions to disciplinary situations are described below. Descriptions of the scales for prosocial situations follows. Each of the forty-seven 
mothers received a score of 1 to 4 on each of these twentysix scales.

Guilt. Emphasis on instillment of guilt as punishment for misdeeds (e.g., Ask him how he can behave that way after all we do for him).

Consequence-oriented Rationale. Emphasis on stating to the child the consequences of his or her behavior (e.g., Tell him not to color on the wall because it won't come off the wall).

Feelings. Emphasis on the negative feeling of the parent elicited by the behavior of the child (e.g., Tell him not to color on the wall because it makes me angry).

Spank. The use or threat of physical punishment (e.g., Hit or spank him).

Physical Stop. Taking away the object the child is using; grabbing child's arm (e.g., Physically stop him, take away the color crayons).

Rules. Statement of rules regarding behavior (e.g., Tell him not to color on the walls because it is the rule of the house).

Withdrawal of Privileges. Emphasis on removal of privileges as a means of punishment (e.g., Tell him he can't have something he likes or something he likes to do). Love Withdrawal. Withdrawal of affection verbally or by separation from the mother (e.g., Send him to his room). 
Ignoring. Emphasis on not paying attention to the child because of misbehavior (e.g., Show him I don't like what he did by not talking to him for awhile).

Neutra1. No reaction or response to the child's behavior (e.g., Do nothing, don't say a word).

Delegation to Another. Placement of responsibility for discipline on another person (e.g., Tell spouse or another adult and let them handle it).

Internal Attribution. Statement which refers to characteristics of the child that do not allow him to misbehave (e.g., Tell him not to color on the wall because he is the kind of person who takes care of his room).

In addition, composite scales for Induction and Power Assertion were developed for comparison with earlier research. This was an attempt to examine the relationships which may exist within the larger group of behaviors generally described as induction or power assertion. In the assignment of items to composite scales, those originally designated by Hoffman and Saltzstein (1967) as inductive or power assertive were retained, and additional items were included which appeared to embody similar characteristics. These scales consisted of the averages of the following items :

Induction. Consisted of the mean of the scales of consequence-oriented rationale, feelings, and guilt. 
Power Assertion. Consisted of the mean of the scales spank, rules, withdrawal of privileges, and physical stop.

Closed-ended Responses: Description of Scales for Prosocial Situations

Scales developed to measure parental reactions to incidents of prosocial behavior are described below:

Guilt. Emphasis that attributes the child's positive behavior to feelings of guilt on the part of the child (e.g., Now I know you care about me, when you pick up the groceries).

Consequence-oriented Rationale. Emphasis on the consequences of the child's behavior (e.g., Tell him he picked up the groceries because your hands were full).

Feelings. Emphasis on the consequences of the child's behavior for the feelings of others (e.g., Tell him because he picked up the groceries, it makes you happy).

Other-oriented Rationale. Emphasis on the consequences of the child's behavior for others (e.g., Tell him because he picked up all of the groceries you can get them put away sooner).

Rules. Statement that attributes the child's positive behavior to his or her understanding that such behavior is the rule of the house (e.g., Tell him he picked up the groceries because it is the rule of the house to help). 
Reward. Emphasis on receipt of material rewards or privileges (e.g., Tell him he can have something he likes or do something he likes to do).

Use of Affection. Verbal affection or increased attention as a response to positive behavior (e.g., Be especially affectionate, spend more time with him).

Physical Affection. Emphasis on physical affection as a response to behaviors (e.g., Give him a hug).

Neutral. No reaction or response to child's behavior (e.g., Do nothing, not say a word).

Delegation to Another. Placement of responsibility for response on another person (e.g., Tell spouse or another adult and let them handle it).

Internal Attribution. Statement which refers to intrinsic characteristics of the child that cause him or her to behave prosocially (e.g., Tell him he picked up the groceries because he is the kind of person who helps others).

Similarly, a composite scale was formed to measure Induction in prosocial incidents. It was the average of the scales guilt, consequence-oriented rationale, feelings, and other-oriented rationale.

Content Analysis of Mothers' Responses to open-ended Questions and Reliability

Mothers' responses to the open-ended questions in each of the nine parent-child situations were examined in a 
content analysis. The scales described in the preceding section which reflected parental reactions to disciplinary situations and to incidents of prosocial behavior were used similarly in the content analysis of the respective incidents. Additional scales were developed for responses in the open-ended questions which did not appear in the list scales.

Verbal Stop. Attempts to gain the child's compliance by speaking in a forceful manner (e.g., Get off the furniture!).

Remedy. Emphasis on reparation for misdeeds (e.g., Make him clean up the wall).

Alternative. Attempts to end inappropriate behavior by distracting the child (e.g., Find him something else to do).

Caution. Emphasis on physical harm that might come to child or another due to his or her behavior (e.g., Don't do sommersaults, you might hurt your neck).

Praise. Nurturant and supportive comments made in regard to prosocial behavior (e.g., Good boy; that's good).

The parental punishment scales Love Withdrawal and Withdrawal of Privileges were included in the content analysis of one particular prosocial incident. These were strategies commonly suggested by mothers in response to the Hoffmand and Saltzstein (1967) situation in which one child is not sharing with another. 
Each mother received frequency scores for the incidence of her open-ended responses falling into a particular parenting scale. Specifically, for each parent-child situation, mothers received a score of 0 or 1 for each parenting scale. In instances in which the mother employed several techniques in combination, subjects received a score of 1 for each respective scale. Composite scales for Induction and Power Assertion were computed in a similar fashion to the list responses.

This content analysis of mothers' responses to openended questions was coded by two persons. One person coded responses of all subjects, while the other coded all data. for 72 percent of the subjects. Inter-rater reliability, computed by means of a Pearson product-moment correlation coefficient, was .91 .

Data Analysis

Analysis of the data proceeded in three phases. First, an examination was made of parenting responses to the punishment and prosocial situations. Each mother's responses to the close-ended items (lists) comprising each scale were averaged across punishment and prosocial situations, respectively. This produced a score for each mother on each punishment and prosocial scale. These scales were then averaged across mothers, and these means and standard deviations were examined to assess the relative frequency of various parenting techniques in both punishment and 
prosocial situations. Additionally, means and standard deviations of the individual items within each of the nine situations were examined to provide a description of parenting behaviors in each situation. All of the above analyses were also performed on mothers' open-ended responses.

Second, the relationship of open-ended and close-ended scales for punishment and prosocial situations, respective$1 y$, was assessed by Pearson product-moment correlation coefficients. Selected punishment scales were then subjected to a factor analysis to assess the relationship of these scales to each other.

Third, Pearson product-moment correlation coefficients were computed to assess the relationships of the parenting scales to the child's prosocial behavior and resistance to temptation. Factors which emerged in the factor analysis described above were also examined in relation to the child's: moral behaviors. Next, demographic variables including parent's age, socioeconomic. status, number of adults at home, sex and age of the child, birth order and number of children in the home were related to the mother's responses and to the child's moral behaviors. Next, the relationship between the two indices of moral behavior, prosocial behavior and resistance to temptation, was assessed. Finally, mothers' perceptions of their child's prosocial behavior were related to the child's actual behavior in the experimental situation. 
CHAPTER III

RESULTS

OVERVIEW

The three phases of data analysis included:

(1) An examination of the means and standard deviations of parenting scales, averaged across punishment situations and averaged across prosocial situations and within each of the nine particular parent-child incidents.

(2) An examination of the relationship between the measures of parenting style, i.e., between the open-ended responses and responses to list items. A factor analysis of selected punishment scales followed.

(3) An assessment of the relationship of parenting scales to children's moral behaviors. Demographic variables were correlated with the parenting scales and children's moral behavior, and the relationship of the indices of moral behavior to each other was investigated. Finally, mothers' perceptions of their child's prosocial behavior were related to the child's actual behavior in the experimental setting.

Following is a summary of the findings for the above three phases. An elaboration of results follows this summary. 
(1) When the frequency of parenting techniques was investigated, in both punishment and prosocial situations, mothers were most likely to state rules or reminders, whether the mothers' response was obtained from the openended questions or from the list items. When responding to list items in prosocial situations, mothers indicated that they often used physical affection and emphasized the needs or feelings of others. In response to the open-ended questions, mothers indicated that praise was the most common reaction to their child's spontaneous prosocial behavior. When individual parent-child punishment incidents were examined, parents' responses to these situations appeared quite consistent across situations. This was not the case in prosocial situations, where varying responses from mothers, particulary to the open-ended questions, were elicited.

(2) When the relationship of mothers' responses to list items and the open-ended questions were examined, consistency across these measures, particularly on prosocial scales, was not pronounced. While the punishment scales were significantly related across the two measurement modalities $(p<.05)$, the scales for the prosocial situations displayed few significant correlations. The subsequent factor analysis brought the composite scales of Induction and Power assertion into question. 
(3) The child's overall prosocial score was negatively related to mothers' neutral responses to both punishment and prosocial incidents. : Children's, sharing and sympathetic behavior was also positively related to the mothers' use of feeling statements, and in the case of sympathy, significantly related to mothers' use of other-oriented rationales in prosocial situations. Examination of demographic variables revealed that girls were spanked more often than boys. When the relationship between prosocial behavior and resistance to temptation was examined, only one significant correlation emerged, between helping and the duration of deviation $(r=.24, p<.051)$. Mothers' perceptions of their child's prosocial behavior have no significant relationship to their child's actual behavior.

These results will be described in detail in the following sections and will be briefly discussed after each section.

\section{DESCRIPTION OF MATERNAL BEHAVIORS}

The frequency of various parenting behaviors used by mothers was first examined, as reported in the open-ended portion of the interview and in mothers' responses to the list items. With regard to the latter, the full range of maternal responses to list items as well as dichotomized responses were evaluated. Table II presents the parental behaviors in these three measurement modalities. 
TABLE II

RANKING, MEANS, STANDARD DEVIATIONS OF CHILDREARING SCALES AVERAGED ACROSS ALL MOTHERS IN EACH MEASUREMENT MODALITY ( $\mathrm{n}=47$ )

\begin{tabular}{|c|c|c|c|c|c|c|c|c|c|c|c|}
\hline \multicolumn{4}{|c|}{ Open-ended } & \multicolumn{4}{|c|}{ Closed-ended $(1-4)$} & \multicolumn{4}{|c|}{ Closed-ended $(0-1)$} \\
\hline Rank & Scale & $\bar{x}$ & S.D. & Rank & Scale & $\overline{\mathrm{x}}$ & S.D. & Rank & Scale & $\bar{x}$ & S.D. \\
\hline \multicolumn{12}{|c|}{ Punishment Scales } \\
\hline 1 & Rules & .71 & .21 & 1 & Rules & .63 & .42 & 1 & $\begin{array}{l}\text { Physical } \\
\text { stop }\end{array}$ & .43 & .59 \\
\hline 2 & $\begin{array}{l}\text { Conse- } \\
\text { quence- } \\
\text { oriented }\end{array}$ & .30 & .25 & 2 & $\begin{array}{l}\text { Conse- } \\
\text { quence- } \\
\text { oriented }\end{array}$ & .60 & .33 & 2 & Rules & .40 & .36 \\
\hline 3 & $\begin{array}{l}\text { Verbal } \\
\text { stop }\end{array}$ & .22 & .19 & 3 & $\begin{array}{l}\text { Physical } \\
\text { stop }\end{array}$ & .58 & .42 & 3 & $\begin{array}{l}\text { Conse- } \\
\text { quence- } \\
\text { oriented }\end{array}$ & .30 & .24 \\
\hline 4 & $\begin{array}{l}\text { Physical } \\
\text { stop }\end{array}$ & .18 & .23 & 4 & $\begin{array}{l}\text { Internal } \\
\text { attribut. }\end{array}$ & .56 & .39 & 4 & $\begin{array}{l}\text { Internal } \\
\text { attribut. }\end{array}$ & .27 & .31 \\
\hline 5 & Remedy & .16 & .14 & 5 & Feelings & .55 & .38 & 5 & Feelings & .24 & .31 \\
\hline 6 & $\begin{array}{l}\text { Withdraw } \\
\text { Priv. }\end{array}$ & .15 & .21 & 6 & Spank & .36 & .29 & 6 & $\begin{array}{l}\text { Love } \\
\text { withdrawal }\end{array}$ & .17 & .21 \\
\hline 7 & Spank & .14 & .22 & 7 & $\begin{array}{l}\text { Love } \\
\text { withdrawal }\end{array}$ & .35 & .25 & 7 & Spank & .08 & .17 \\
\hline 8 & $\begin{array}{l}\text { Love } \\
\text { withdrawal }\end{array}$ & .14 & .19 & 8 & $\begin{array}{l}\text { Withdrawal } \\
\text { of Priv. }\end{array}$ & .31 & .31 & 8 & $\begin{array}{l}\text { Withdrawal } \\
\text { of Priv. }\end{array}$ & .07 & .17 \\
\hline 9 & $\begin{array}{l}\text { Alterna- } \\
\text { tive }\end{array}$ & .09 & .14 & 9 & Ignore & .08 & .19 & 9 & Guilt & .01 & .03 \\
\hline 10 & Feelings & .09 & .15 & 10 & Neutral & .05 & .15 & 10 & Neutral & .01 & .03 \\
\hline 11 & Caution & .06 & .11 & 11 & $\begin{array}{l}\text { Delegate } \\
\text { to another }\end{array}$ & .05 & .15 & 11 & $\begin{array}{l}\text { Delegate } \\
\text { to another }\end{array}$ & 0 & 0 \\
\hline 12 & Guilt & .05 & .11 & 12 & Guilt & .04 & .17 & 12 & Ignore & 0 & 0 \\
\hline 13 & Other & .02 & .06 & & Induction & .40 & .26 & & Induction & .18 & .16 \\
\hline 14 & $\begin{array}{l}\text { Internal } \\
\text { attribut. }\end{array}$ & .004 & .03 & & $\begin{array}{l}\text { Power } \\
\text { assertion }\end{array}$ & .47 & .18 & & $\begin{array}{l}\text { Power } \\
\text { assertion }\end{array}$ & .24 & .21 \\
\hline 15 & Ignore & .004 & .03 & & & & & & & & \\
\hline 16 & Neutral & 0 & 0 & & & & & & & & \\
\hline 17 & $\begin{array}{l}\text { Delegate } \\
\text { to another }\end{array}$ & 0 & 0 & & & & & & & & \\
\hline & Induction & .15 & .11 & & & & & & . & & \\
\hline & $\begin{array}{l}\text { Power } \\
\text { assertion }\end{array}$ & .29 & .13 & & & & & & & & \\
\hline
\end{tabular}


TABLE II--Continued

\begin{tabular}{|c|c|c|c|c|c|c|c|c|c|c|c|}
\hline \multicolumn{3}{|c|}{ Open-ended } & & \multicolumn{4}{|c|}{ Closed-ended $(1-4)$} & \multicolumn{4}{|c|}{ Closed-ended $(0-1)$} \\
\hline Rank & Scale & $\bar{x}$ & S.D. & Rank & Scale & $\bar{x}$ & S.D. & Rank & Scale & $\overline{\mathrm{x}}$ & S.D. \\
\hline \multicolumn{12}{|c|}{ Prosocial Scales } \\
\hline 11 & Praise & .47 & .16 & 1 & $\begin{array}{l}\text { Physical } \\
\text { affection }\end{array}$ & .71 & .37 & $\begin{aligned} 1 \mathrm{P} \\
\mathrm{a}\end{aligned}$ & $\begin{array}{l}\text { Physical } \\
\text { affection }\end{array}$ & .45 & .29 \\
\hline 2 & Caution & .14 & .11 & 2 & $\begin{array}{l}\text { Other- } \\
\text { oriented }\end{array}$ & .71 & .37 & $\begin{array}{ll}20 \\
0\end{array}$ & $\begin{array}{l}\text { Other- } \\
\text { oriented }\end{array}$ & .40 & .33 \\
\hline 3 & $\begin{array}{l}\text { Conse- } \\
\text { quence- } \\
\text { oriented }\end{array}$ & .12 & .13 & 3 & $\begin{array}{l}\text { Conse- } \\
\text { quence- } \\
\text { oriented }\end{array}$ & .69 & .37 & $3 \mathrm{~F}$ & Feelings & .39 & .27 \\
\hline 41 & Rules & .12 & .10 & 4 & Feelings & .63 & .34 & $\begin{array}{r}40 \\
9 \\
0\end{array}$ & $\begin{array}{l}\text { Conse- } \\
\text { quence- } \\
\text { oriented }\end{array}$ & .38 & .33 \\
\hline 51 & Reward & .12 & .11 & 5 & $\begin{array}{l}\text { Internal } \\
\text { attribut. }\end{array}$ & .55 & .41 & $\begin{aligned} & 5 \text { I } \\
& \text { a }\end{aligned}$ & $\begin{array}{l}\text { Internal } \\
\text { attribut. }\end{array}$ & .24 & .36 \\
\hline 61 & Neutral & .11 & .15 & 6 & Affection & .33 & .28 & $6 \mathrm{R}$ & Reward & .10 & .24 \\
\hline 71 & Feelings & .10 & .16 & 71 & Reward & .30 & .28 & $7 \mathrm{~A}$ & Affection & .09 & .15 \\
\hline 8 & $\begin{array}{l}\text { Withdraw } \\
\text { priv. }\end{array}$ & .40 & .50 & 81 & Rules & .21 & .25 & $8 \mathrm{~N}$ & Neutral & .07 & .14 \\
\hline 9 & $\begin{array}{l}\text { Other- } \\
\text { oriented }\end{array}$ & .07 & .10 & 91 & Neutral & .19 & .26 & $9 \mathrm{R}$ & Rules & .06 & .12 \\
\hline 10 & $\begin{array}{l}\text { Alterna- } \\
\text { tive }\end{array}$ & .06 & .10 & 10 & Guilt & .10 & .18 & $10 \mathrm{G}$ & Guilt & .02 & .05 \\
\hline $11 \mathrm{~F}$ & $\begin{array}{l}\text { Physical } \\
\text { affection }\end{array}$ & .05 & .09 & $11 \mathrm{I}$ & $\begin{array}{l}\text { Delegate } \\
\text { to another }\end{array}$ & .03 & .13 & $\begin{array}{rl}11 & D \\
\mathrm{t}\end{array}$ & $\begin{array}{l}\text { Delegate } \\
\text { to another }\end{array}$ & .005 & .04 \\
\hline 12 & $\begin{array}{l}\text { Internal } \\
\text { attribut. }\end{array}$ & .01 & .05 & & Induction & .54 & .29 & & Induction & .30 & .20 \\
\hline $13 c$ & Other & .01 & .04 & & & & & & & & \\
\hline $14 \mathrm{r}$ & $\begin{array}{l}\text { Verbal } \\
\text { stop }\end{array}$ & .004 & .03 & & & & & & & & \\
\hline $15 \mathrm{~A}$ & Affection & .004 & .03 & & & & & & & & \\
\hline $16 \mathrm{I}$ & $\begin{array}{l}\text { Love } \\
\text { withdrawal }\end{array}$ & .02 & .15 & & & & & & & & \\
\hline $17 \mathrm{I}$ & $\begin{array}{l}\text { Delegate } \\
\text { to another }\end{array}$ & 0 & 0 & & & & & & & & \\
\hline \multirow{2}{*}{18} & Guilt & 0 & 0 & & & & & & & & \\
\hline & Induction & .07 & .07 & & & & & & & & \\
\hline
\end{tabular}


Mothers' Responses across

AII Situations

First, mothers' responses were examined across all punishment and prosocial situations, respectively, to investigate the overall use of various parenting techniques.

Punishment Situations. Frequent behaviors across all punishment situations were examined. The open-ended measure indicated that statements or reminders of rules was the most common parental response in these discipline encounters. Other frequent practices included statements of the consequences of the child's behavior and verbal termination of the behavior (i.e., Put that down:). In addition, mothers often physically stopped their child's transgressions, expected reparation (i.e., made child clean up the mess), withdrew privileges, spanked, or withdrew love, usually in the form of sending the child to his or her room. Consistent with results obtained in the open-ended measure, the most common item checked in the closed-ended measure in punishment situations was a statement of rules (i.e., Tell him not to . . . because it is the rule of the house).

This response was followed in frequency by behaviors characterized by statements of the consequences of behavior, physical termination, statements attributing the child's behavior to himself or herself (internal attribution), and those emphasizing the parents' feelings. When close-ended responses were dichotomized, physical stop became the most common practice, with rules remaining similarly frequent. 
Other dichotomized punishment scales were similar in frequency to the original closed-ended measure, although mean frequencies decreased in general.

Infrequent parenting practices were also examined. Open-ended questions revealed that mothers were least likely to delegate disciplinary decisions to another or respond neutrally to misbehavior in punishment situations. Mothers, in the open-ended measure, also did not indicate that they used attributional statements or techniques which consisted of not paying attention to the child because of his behavior (ignore). Similarly, practices in the closed-ended responses which mothers checked infrequently included delegation of responsibility to another, neutral reactions, and guilt statements (i.e., Tell him not to . . because I do so much for him). Also infrequent were techniques emphasizing not paying attention to the child (ignore). When scores were dichotomized, delegation to another and the scale ignore were never mentioned by mothers. Other infrequent responses consisted of guilt statements and neutral reactions. In summary, across all situations and measurement modalities, mothers' most frequent response in punishment situations was a statement of rules. Discipline techniques which included a statement of the consequences of the child's misbehavior and physically stopping the child also appeared frequently. Feeling and attributional statements which were checked frequently in closed-ended measures were 
rarely mentioned in the open-ended assessment. Responses characterized by verbally stopping the child or requiring reparation were commonly reported in the open-ended portion of the interview. The scales neutral, delegation to another, and ignore were infrequently mentioned by mothers in both open-ended and closed-ended measures. Statements which attempted to induce guilt were also consistently low in frequency. Because the scale ignore was never used in the open-ended measure and was rarely used in the closed-ended measure, it will not be discussed further.

Prosocial Situations. According to the open-ended measure, mothers' most frequent response to prosocial behavior in their children was praise. Additionally, statements cautioning the child to harm that might come to self or others (i.e., Be careful, don't hurt yourself), consequence statements, and verbalizations of rules were common responses. Physical rewards and nonintervention were also common. When mothers wished to enforce sharing, withdrawal of the object was used until the child complied. In contrast to the mothers' responses in the open-ended portion of the interview, closed-ended measures indicated that mothers' most frequent responses to prosocial situations were physical affection and statements emphasizing the feelings or needs of others (other-oriented rationale). Other frequent parent behaviors included statements of the positive consequences of prosocial behavior, statements of 
the parents' feelings, and attributional statements.

Dichotomized closed-ended responses were similar to those obtained from the full range of mothers' closed-ended responses. Additionally, the neutral response was a somewhat common response to prosocial behavior across all measurement modalities .

Infrequent responses to a child's prosocial behavior elicited by the open-ended measure were guilt statements and delegation to another. Attributional statements and practices which emphasized an increase in parental love due to prosocial behavior were also infrequent. Techniques not commonly checked by mothers in the closed-ended measure included guilt statements and delegation to another. The dichotomized scores showed a similar pattern of responses.

In summary, mothers' reports of their responses to prosocial behavior in their children varied widely across measurement modalities. Only statements of the positive consequences of prosocial behavior (consequence-oriented rationale) appeared frequently in both open-ended and closed-ended measurements. Physical affection and otheroriented rationales were frequently checked in the closedended measures, while praise and cautionary statements were common responses in the open-ended response mode. Delegation to another and guilt statements were infrequent responses to prosocial behavior in both the open- and closed-ended cases. 
Mothers' Responses to

Specific Situations

The frequency of parenting practices was also examined within each particular punishment and prosocial incident. Table III presents the means and rankings of behaviors in each of these incidents.

Punishment Situations. In response to the open-ended measure, mothers indicated that they used a statement of rules most frequently in all situations. Expectation of reparation was common when the child damaged something as a direct result of his or her misbehavior (i.e., colored on the wall, broke the lamp). According to the open-ended measure mothers frequently verbally stopped misbehavior when the child disturbed her belongings, jumped on furniture, or misbehaved in the store. Physically stopping the child was also a frequent response except when the child had already broken the lamp.

An examination of closed-ended responses, including the full range of maternal responses as well as the dichotomized scores, indicated that rule statements and statements of consequences of behavior were used across all situations, although rule statements were less frequent when the child misbehaved in the store. Physically stopping the child was also common across all situations although less so when the child was jumping on furniture. Attributional statements and statements describing the use of an angry look were also commonly checked. In addition, mothers' closed-ended 
TABLE III

RANKINGS AND MEANS OF FREQUENT CHILDREARING PRACTICES AVERAGED ACROSS MOTHERS IN EACH PARENT-CHILD SITUATION

AND MEASUREMENT MODALITY $(n=47)$

\begin{tabular}{|c|c|c|c|c|c|c|c|}
\hline \multirow{2}{*}{\multicolumn{3}{|c|}{ Open-ended }} & \multicolumn{5}{|c|}{ Closed-ended } \\
\hline & & & \multicolumn{2}{|l|}{$(1-4)$} & \multicolumn{3}{|c|}{$(0-1)$} \\
\hline \multirow[t]{2}{*}{ Rank } & Scale & $\bar{x}$ & Scale & $\bar{x}$ & Rank & Scale & $\bar{x}$ \\
\hline & & Punishment: & Coloring & on $\mathrm{Wa}$ & $11 \mathrm{~s}$ & & \\
\hline $1 \mathrm{~F}$ & Rules & .60 & 1 Rules & .68 & 1 & Rules & .51 \\
\hline $2 F$ & Remedy & .38 & 2 Angry look & .67 & 2 & $\begin{array}{l}\text { Consequence- } \\
\text { oriented }\end{array}$ & .38 \\
\hline $3 \mathrm{~F}$ & Physical stop & .32 & $\begin{array}{l}3 \text { Consequence- } \\
\text { oriented }\end{array}$ & .66 & 3 & $\begin{array}{l}\text { Consequence- } \\
\text { oriented }\end{array}$ & .38 \\
\hline $4 h$ & With. priv. & .23 & 4 Feelings & .62 & 4 & Physical stop & .32 \\
\hline $5 \mathrm{~s}$ & Spank & .23 & 5 Internal att. & .59 & 5 & Angry look & .30 \\
\hline $6 \mathrm{G}$ & Guilt & .17 & 6 Physical stop & .58 & 6 & Internal att. & .23 \\
\hline \multirow{4}{*}{7} & Consequence- & .13 & 7 Send to room & .50 & 7 & Feelings & .25 \\
\hline & & & 8 Spank & .40 & & Send to room & .15 \\
\hline & & & 9 With. priv. & .38 & 9 & With. priv. & .13 \\
\hline & & & 10 Spank (threat) & .36 & & & \\
\hline
\end{tabular}

Punishment: Get in Other's Belongings

\begin{tabular}{|c|c|c|c|c|c|c|c|c|}
\hline 1 & Rules & .70 & 1 & Rule & .71 & 1 & Rule & .49 \\
\hline 2 & $\begin{array}{l}\text { Consequence- } \\
\text { oriented }\end{array}$ & .36 & 2 & $\begin{array}{l}\text { Consequence- } \\
\text { oriented }\end{array}$ & .66 & 2 & Physical stop & .34 \\
\hline 3 & Verbal stop & .21 & 3 & Feelings & .63 & 3 & $\begin{array}{l}\text { Consequence- } \\
\text { oriented }\end{array}$ & .31 \\
\hline 4 & Love withdrawal & .17 & 4 & Physical stop & .57 & 4 & Feelings & .30 \\
\hline 5 & Feelings & .15 & 5 & Internal att. & .56 & 5 & Angry look & .25 \\
\hline 6 & Physical stop & .10 & 6 & Angry look & .55 & 6 & Internal att. & .25 \\
\hline \multirow[t]{3}{*}{7} & Spank & .10 & 7 & $\begin{array}{l}\text { Consequence- } \\
\text { oriented }\end{array}$ & .41 & 7 & $\begin{array}{l}\text { Consequence- } \\
\text { oriented }\end{array}$ & .17 \\
\hline & & & & Send to room & .40 & 8 & Send to room & .15 \\
\hline & & & 9 & Spank & .34 & & & \\
\hline
\end{tabular}


TABLE III--Continued

\begin{tabular}{|c|c|c|c|c|c|c|c|c|}
\hline \multirow{2}{*}{\multicolumn{3}{|c|}{ Open-ended }} & \multicolumn{6}{|c|}{ Closed-ended } \\
\hline & & & \multicolumn{3}{|c|}{$(1-4)$} & \multicolumn{3}{|c|}{$(0-1)$} \\
\hline Rank & Scale & $\overline{\mathrm{x}}$ & Rank & Scale & $\overline{\mathrm{x}}$ & Rank & Scale & $\bar{x}$ \\
\hline \multicolumn{9}{|c|}{ Punishment: Jump on Furniture } \\
\hline & Rule & .81 & 1 & $\begin{array}{l}\text { Consequence- } \\
\text { oriented }\end{array}$ & .75 & 1 & $\begin{array}{l}\text { Consequence- } \\
\text { oriented }\end{array}$ & .36 \\
\hline 2 & $\begin{array}{l}\text { Consequence- } \\
\text { oriented }\end{array}$ & .36 & 2 & Rule & .60 & 2 & Rule & .32 \\
\hline 3 & Verbal stop & .28 & 3 & Internal att. & .60 & 3 & Angry look. & .30 \\
\hline 4 & Alternative & .19 & 4 & Angry look & .57 & 4 & Internal att. & .30 \\
\hline 5 & Physical stop & .15 & 5 & Feelings & .52 & 5 & Physical stop & .28 \\
\hline \multirow{4}{*}{\multicolumn{2}{|c|}{6 Love withdrawal }} & .15 & & Physical stop & .52 & 6 & Feelings & .28 \\
\hline & & & & Send to room & .40 & 7 & $\begin{array}{l}\text { Consequence- } \\
\text { oriented }\end{array}$ & .11 \\
\hline & & & & $\begin{array}{l}\text { Consequence- } \\
\text { oriented }\end{array}$ & .39 & 8 & Spank (threat) & .11 \\
\hline & & & & Spank (threat) & .37 & & & \\
\hline
\end{tabular}

Punishment: Break Lamp

\begin{tabular}{|c|c|c|c|c|c|c|}
\hline 1 Rule & .64 & 1 & Rule & .65 & 1 Rule & .40 \\
\hline 2 Love withdrawal & .32 & 2 & Angry look & .62 & 2 Physical stop & .34 \\
\hline $\begin{array}{l}3 \text { Consequence- } \\
\text { oriented }\end{array}$ & .30 & 3 & Physical stop & .56 & $\begin{array}{l}3 \text { Consequence- } \\
\text { oriented }\end{array}$ & .30 \\
\hline 4 Remedy & .28 & 4 & Internal att. & .53 & 4 Send to room & .30 \\
\hline 5 Spank & .19 & 5 & $\begin{array}{l}\text { Consequence- } \\
\text { oriented }\end{array}$ & .52 & 5 Angry look & .30 \\
\hline 6 With. priv. & .15 & 6 & Send to room & .52 & $\begin{array}{l}6 \text { Consequence- } \\
\text { oriented }\end{array}$ & .23 \\
\hline \multirow[t]{4}{*}{7 Caution } & .13 & 7 & Feelings & .47 & 7 Internal att. & .23 \\
\hline & & 8 & Spank & .43 & 8 Feelings & .19 \\
\hline & & & Spank (threat) & .42 & & \\
\hline & & 10 & With. priv. & .33 & & \\
\hline
\end{tabular}


TABLE III--Continued

\begin{tabular}{|c|c|c|c|c|c|c|c|c|}
\hline \multirow{2}{*}{\multicolumn{3}{|c|}{ Open-ended }} & \multicolumn{6}{|c|}{ Closed-ended } \\
\hline & & & \multicolumn{3}{|c|}{$(1-4)$} & \multicolumn{3}{|c|}{$(0-1)$} \\
\hline Rank & Scale & $\bar{x}$ & Rank & Scale & $\bar{x}$ & Rank & Scale & $\bar{x}$ \\
\hline \multicolumn{9}{|c|}{ Touch Shelves in Store } \\
\hline & Rule & .72 & 1 & $\begin{array}{l}\text { Consequence- } \\
\text { oriented }\end{array}$ & .77 & 1 & $\begin{array}{l}\text { Consequence- } \\
\text { oriented }\end{array}$ & .45 \\
\hline 2 & Verbal stop & .45 & 2 & $\begin{array}{l}\text { Consequence- } \\
\text { oriented }\end{array}$ & .72 & 2 & $\begin{array}{l}\text { Consequence- } \\
\text { oriented }\end{array}$ & .38 \\
\hline & $\begin{array}{l}\text { Consequence- } \\
\text { orfented }\end{array}$ & .36 & 3 & Physical stop & .63 & 3 & Physical stop & .36 \\
\hline 4 & Physical stop & .30 & 4 & Angry look & .60 & 4 & Rule & .28 \\
\hline \multirow{5}{*}{\multicolumn{2}{|c|}{5 With. priv. }} & .25 & 5 & Internal att. & .55 & 5 & Internal att. & .28 \\
\hline & & & 6 & Rule & .53 & 6 & Angry look & .23 \\
\hline & & & 7 & Feelings & .50 & 7 & Feelings & .17 \\
\hline & & & & Spank & .33 & 8 & With. priv. & .13 \\
\hline & & & & & & 9 & Spank (threat) & .11 \\
\hline
\end{tabular}

Prosocia1: Pick up Groceries

\begin{tabular}{lllllll}
\hline 1 Praise & .91 & 1 Physical aff. & .94 & 1 Physical aff. & .83 \\
2 Feelings & .23 & 2 Feeling & .88 & 2 Feelings & .72 \\
& & 3 Other-oriented & .71 & 3 other-oriented & .34 \\
& 4 Affection & .63 & 4 Internal att. & .28 \\
& 5 Internal att. & .62 & 5 Affection & .21 \\
& $\begin{array}{l}6 \text { Consequence- } \\
\text { oriented }\end{array}$ & .43 & 6 Consequence- & .17 \\
& 7 Reward & .42 & 7 Reward & .13 \\
\hline
\end{tabular}

Prosocial: Share Joy Hoffman and Saltzstein (1967)

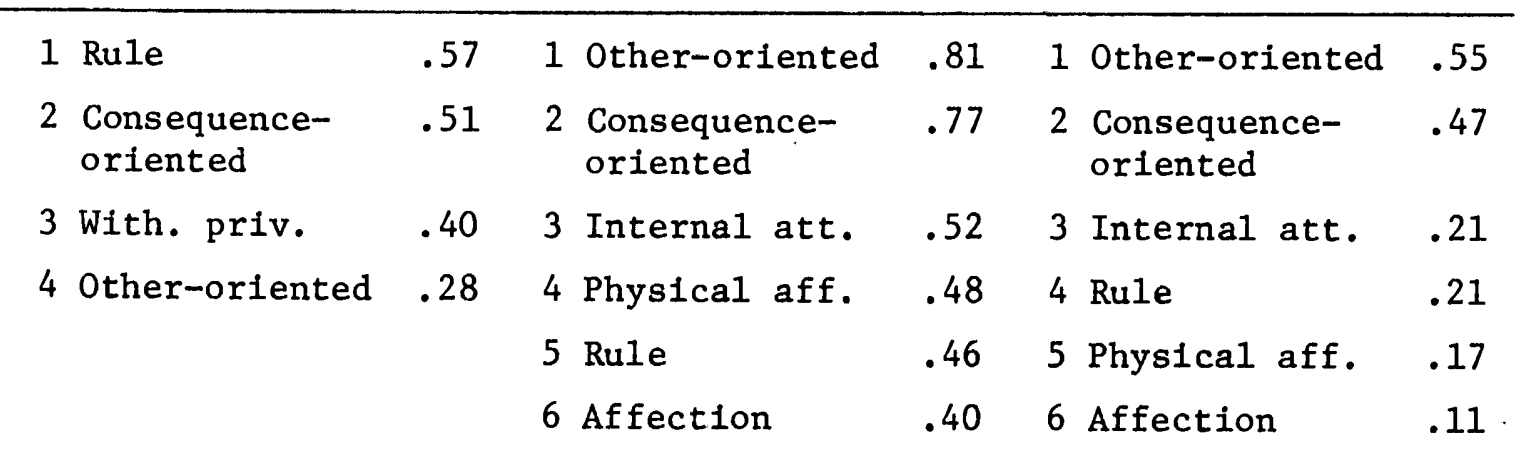


TABLE III--Continued

\begin{tabular}{|c|c|c|c|c|c|c|c|}
\hline \multirow{2}{*}{\multicolumn{3}{|c|}{ Open-ended }} & \multicolumn{5}{|c|}{ Closed-ended } \\
\hline & & & \multicolumn{2}{|l|}{$(1-4)$} & \multicolumn{3}{|c|}{$(0-1)$} \\
\hline Rank & Scale & $\overline{\mathrm{x}}$ & Scale & $\overline{\mathbf{x}}$ & Rank & Scale & $\bar{x}$ \\
\hline \multicolumn{8}{|c|}{ Prosocial: Teach Sommersaults } \\
\hline & Caution & .68 & 1 Physical aff. & .67 & $1 \mathrm{~F}$ & Physical aff. & .34 \\
\hline & Praise & .51 & 2 Feelings & .65 & 2 & $\begin{array}{l}\text { Consequence- } \\
\text { oriented }\end{array}$ & .30 \\
\hline \multirow{4}{*}{\multicolumn{2}{|c|}{3 Neutral }} & .38 & 3 Other-oriented & .64 & 31 & Feelings & .30 \\
\hline & & & $\begin{array}{l}4 \text { Consequence- } \\
\text { oriented }\end{array}$ & .62 & $4 c$ & Other-oriented & .28 \\
\hline & & & 5 Internal att. & .45 & 51 & Neutral & .13 \\
\hline & & & 6 Affection & .38 & 6 & Affection & .11 \\
\hline \multicolumn{8}{|c|}{ Prosocial: Share Cookie } \\
\hline & Praise & .76 & $\begin{array}{l}1 \text { Consequence- } \\
\text { oriented }\end{array}$ & .79 & 10 & $\begin{array}{l}\text { Consequence- } \\
\text { oriented }\end{array}$ & .60 \\
\hline & Reward & .60 & 2 Feelings & .76 & 2 & Feelings & .49 \\
\hline & Neutral & .13 & 3 Physical aff. & .74 & 30 & Other-oriented & .47 \\
\hline \multirow{5}{*}{\multicolumn{2}{|c|}{4 Feelings }} & .13 & 4 Other-oriented & .72 & $4 \mathrm{~F}$ & Physical aff. & .45 \\
\hline & & & 5 Internal att. & .62 & 51 & Internal att. & .28 \\
\hline & & & 6 Affection & .42 & $6 \mathrm{~F}$ & Reward & .15 \\
\hline & & & 7 Reward & .37 & 78 & Affection & .15 \\
\hline & & & & & & Neutral & .12 \\
\hline
\end{tabular}

responses indicated that feeling statements, sending the child to his or her room, spanking, and withdrawing privileges were also used somewhat frequently as disciplinary techniques.

Prosocial Situations. In situations in which the child exhibited spontaneous prosocial behavior, the most frequent parental response according to the open-ended measure was praise. When the child displayed helping 
behavior the parent was likely to praise, express appreciation, and use physical affection to communicate approval. In the teaching sommersaults incident parents frequently expressed concern for safety or did not respond to the child's behavior. In addition to praise, children's sharing a cookie with another child most frequently elicited another cookie from the parent. When attempting to promote prosocial behavior parents emphasized rules to share and the consequences of sharing. Some also removed the privilege of playing with the toy until compliance was achieved or discussed the needs or feelings of others.

Closed-ended responses to prosocial situations were more consistent across incidents. Mothers checked items indicating that they used physical affection, statements of their own feelings or the feelings of others in all situations. Physical affection was more frequent when the child helped, and statements of the positive consequences of behavior were more frequent in incidents of spontaneous sharing. Statements of concern for others and consequences of behavior were also common when the parent wished to promote sharing.

In summary, mothers' responses to closed-ended punishment items were very consistent across situations, while in the open-ended measure, punishment technique was somewhat more varied. Maternal responses to prosocial situations were less consistent overal1, particularly responses to the 
open-ended questions. It may be that the demand characteristics of these prosocial incidents contributed to this situation specificity. The helping incident involved a child aiding his or her mother. In this case, a statement of appreciation or feelings from the mother would seem appropriate. The teaching incident elicited a concern for the danger of sommersaults, whereas danger did not play a part in the other prosocial incidents. Since the sharing incident involved the sharing of a cookie that the mother had given the child, she was likely to give the child and his friend another cookie. This response was scored as a reward in the content analysis of the responses to the openended questions, although mothers themselves did not check the reward items frequently in the lists. It may be that mothers did not perceive these items as representative of their behavior of giving the child an extra cookie. In both the teaching and sharing incidents the child's prosocial behavior was directed toward a peer. The child's involvement with a peer allowed the parent the ability to not intervene, an option which was not present in the helping incident. The Hoffman and Saltzstein (1967) incident required the mother to promote sharing. This often involved the parents' use of love withdrawal or withdrawal of privileges, responses which were not found in the other prosocial incidents. Thus it seems likely that a portion of the 
mothers' inconsistency across prosocial situations may be due to the differences inherent in each of these incidents.

\section{MEASUREMENT CONSIDERATIONS}

The mothers' responses to the list items differed from their reactions to the open-ended questions in the interview. This inconsistency across measurement modalities may have been due to characteristics inherent in each of these approaches. The closed-ended assessment attempted to measure parenting style using scales constructed by averaging items which correlated highly with each other. This measurement technique is valuable in that it:

(1) Allows for objective scoring of parental responses according to the list items relationship to overall scales;

(2) May remind parents of practices they regularly use but do not verbalize in response to the openended questions;

(3) May allow parents an opportunity to more easily admit parenting practices they use but may not feel comfortable with (e.g., spanking); and

(4) Provides assessments of those aspects of parenting that may not be verbalized by the parent in openended situations (e.g., the use of looks or feelings). 
On the other hand, closed-ended measurement techniques are problematic in that:

(1) Parental responses may be easily affected by social desirability, with parents more likely to check items they may perceive as "good answers"; and

(2) The general nature of list items allows for differential interpretation of items by parents.

The evaluation of parenting style using the mothers' responses to the open-ended questions consisted of a content analysis of mothers' exact words. This measurement:

(1) Allows for an estimation of parental style which is less likely to be influenced by social desirability; and

(2) Elicits the parents' exact words and leaves less opportunity for parental interpretation.

However, the content analysis of open-ended responses requires a judgment of parental responses rather than an objective score.

It appears that the characteristics of these measurement modalities contributed to the overall differences between mothers' open-ended responses and their responses to list items. Across punishment and prosocial scales, mean responses to adjusted $(0-1)$ closed-ended scales were larger than mean responses to the open-ended questions. These results would indicate that mothers were more likely to check 
items when responding to the lists than they were likely to verbalize in the open-ended measure. In particular, the effects of social desirability may have increased mothers' responses to list items. For example, scales such as internal attribution were checked frequently in the closed-ended measure. Indeed, mothers were often heard to comment on the value of the attribution statement when it appeared in the lists (e.g., "Oh, that's a good one!"). However, these statements were almost never mentioned spontaneously in response to the open-ended questions. List items may also have reminded mothers of parenting techniques regularly used that they had forgotten to verbalize. The items in the physical affection scale, for example, often reminded mothers to include the physical components of their behavior in their responses.

It will be recalled that in the closed-ended measure, parenting techniques were found to be fairly consistent across both punishment and prosocial situations. Scale means were less consistent overall in the open-ended case, and particularly situation specific in prosocial situations. As the open-ended measure was an assessment of the mothers' exact words, responses were more likely to reflect the specific situation. It is difficult to establish whether the inconsistency across prosocial situations in response to the open-ended questions was due to the nature of the prosocial incidents provided, the measurement modality, or to 
a general inconsistency in parental reactions to prosocial situations.

Relationship of Open-ended and

Closed-ended Measures

The relationships among the three measurement modalities, open-ended, closed-ended, and dichotomized closedended, were examined to assess the relative consistency of mothers' responses across response modes. Table IV presents these correlations.

Punishment Scales. When the relationship of openended responses and original closed-ended responses was examined, twelve correlations were obtained, four of which were significant at $\mathrm{p}<.05$. When the dichotomized closedended responses were related to open-ended responses, an additional twelve correlations were calculated, seven of which were significant at $\mathrm{p}<.05$. Significant correlations between open-ended and closed-ended response modes were also found between response modes on punishment scales characterizing spanking, physically stopping the child, withdrawing privileges, and withdrawing love. Significant correlations were found for the consequence orientation, internal attribution, and composite power assertion scales, although only when the closed-ended data were dichotomized. Significant correlations between modalities were not found for measures of guilt, feelings, and rules. The lack of significant correlations on the guilt scale may be.due to the low 
TABLE IV

INTERCORRELATION OF OPEN-ENDED AND CLOSE-ENDED MEASURES USING PEARSON $r(n=47)$

\begin{tabular}{|c|c|c|}
\hline Scale & $\begin{array}{l}\text { Relationship of } \\
\text { Open-ended to } \\
\text { Closed-ended }(1-4)\end{array}$ & $\begin{array}{l}\text { Relationship of } \\
\text { Open-ended to } \\
\text { Closed-ended }(0-1) \\
\end{array}$ \\
\hline \multicolumn{3}{|c|}{ Punishment Scales } \\
\hline $\begin{array}{l}\text { Guilt } \\
\text { Consequence-oriented } \\
\text { Feelings } \\
\text { Spank } \\
\text { Physical stop } \\
\text { Rule } \\
\text { Withdrawal of priv. } \\
\text { Love withdrawal } \\
\text { Ignore } \\
\text { Neutral } \\
\text { Delegate to another } \\
\text { Internal attribution } \\
\text { Verbal stop } \\
\text { Remedy } \\
\text { Alternative } \\
\text { Caution } \\
\text { Other } \\
\text { Induction } \\
\text { Power assertion }\end{array}$ & $\begin{array}{l}-.04 \\
.16 \\
-.14 \\
.47 * * \\
.40 * \\
.006 \\
.26 * \\
.38 * \\
-.09 \\
\text { NA } \\
\text { NA } \\
.20\end{array}$ & $\begin{array}{l}-.003 \\
.32 * \\
-.09 \\
.58 * * \\
.36 * \\
.17 \\
.51 * * \\
.32 * \\
\text { NA } \\
\text { NA } \\
\text { NA } \\
.25 *\end{array}$ \\
\hline \multicolumn{3}{|c|}{ Prosocial Scales } \\
\hline $\begin{array}{l}\text { Guilt } \\
\text { Consequence-oriented } \\
\text { Feelings } \\
\text { Other-oriented } \\
\text { Rule } \\
\text { Reward } \\
\text { Affection } \\
\text { Physical affection } \\
\text { Neutral } \\
\text { Delegate to another } \\
\text { Internal attribution } \\
\text { Praise } \\
\text { Verbal stop } \\
\text { Alternative } \\
\text { Caution } \\
\text { Other } \\
\text { Withdrawal of priv. } \\
\text { Love withdrawal } \\
\text { Induction }\end{array}$ & $\begin{array}{l}\text { NA } \\
-.21 \\
-.062 \\
.014 \\
-.14 \\
-.04 \\
.08 \\
.14 \\
.51 * * \\
\text { NA } \\
.22\end{array}$ & $\begin{array}{c}\text { NA } \\
-.14 \\
-.118 \\
.098 \\
.113 \\
-.062 \\
.145 \\
.238 * \\
.59 * * \\
\text { NA } \\
.31 *\end{array}$ \\
\hline
\end{tabular}


frequency of guilt items checked and the difficulty in making a clear assessment of guilt in the open-ended measure. Due to the questionable validity of this scale, it will not be discussed further. Statements of feelings, checked frequently in the closed-ended measure of punishment, did not occur frequently in the open-ended case. It may be that al though feelings are incorporated in discipline encounters, parents are less likely to verbalize this practice in response to open-ended questions. Correlations between response modes for statements of rules, a frequent response in both measurement modalities, did not reach significance. It may be that some mothers did not perceive the rule statement in the lists as representative of the rules, or reminders they suggested in the open-ended questions. The remaining punishment scales (ignore, neutral, delegation to another) occurred in only one of the response modalities, and therefore correlation coefficients were not computed.

Prosocial Scales. Corelations between measurement modalities in prosocial situations provided few significant relationships. One of ten correlations (neutral) was significant at $p<.05$ when the full range of mothers' closedended responses was correlated with the open-ended measure. When the closed-ended measure was dichotomized, three of ten correlations were significant at $p<.05$ (involving the scales of physical affection, neutral responses, and internal attribution). (It should be noted in the case of the 
attribution statement, however, that the frequency of this kind of response in the open-ended measure was extremely low. Attributional statements therefore will not be discussed further in relation to either punishment or prosocial situations.) Thus although mothers were consistent across modalities in their reports of physical affection and the likelihood of nonintervention in prosocial incidents, this was not the case for other parental responses. The possible causes of these parental inconsistencies in response to descriptions of prosocial behavior in their children are not clear. The lack of relationships may be due in part to difficulties in the prosocial incidents discussed earlier. It may also be due to a less consistent overall approach by parents to prosocial behavior in their children, which manifests itself not only in the lack of significant correlations but in the situation specificity of responses discussed earlier.

In summary, a comparison of the relationship of responses to open-ended and closed-ended measures indicated that mothers were more consistent across modalities when responding to punishment than prosocial situations. Unlike many of the punishment items used in the present study, items developed to measure parental responses to prosocial behavior had not been extensively tested. It may also be that mothers simply do not have a consistent overall approach to prosocial behavior in their child. 


\section{INTERRELATIONSHIPS OF CHILDREN'S MORAL}

BEHAVIORS, MATERNAL RESPONSES,

AND DEMOGRAPHIC VARIABLES

These results will be presented in six sections: relationships of indices of prosocial behavior to maternal responses, relationships of indices of resistance to temptation to maternal responses, relationships of factors emerging from a factor analysis of punishment scales and children's moral behavior, relationships of demographic variables to maternal responses and children's moral behavior, relationship of indices of children's prosocial behavior to indices of resistance to temptation, and finally the relationship of mothers' perceptions of their children's prosocial behavior to the children's actual behavior.

The Relationship of Prosocial Behavior to Maternal Responses

The relationships of prosocial behavior to parenting scales in punishment and prosocial situations are presented in Table $V$. The $\mathrm{p}<.10$ significance level was employed in addition to traditional levels to examine the consistency of correlations across measurement modalities. When considering the 300 correlations obtained for the five prosocial indices and the parenting scales, 21 were significant at $\mathrm{p}<.05$ (6 were negative) and an additional 10 correlations were significant at $\mathrm{p}<.10$ ( 4 were negative). A description of these relationships follows. 


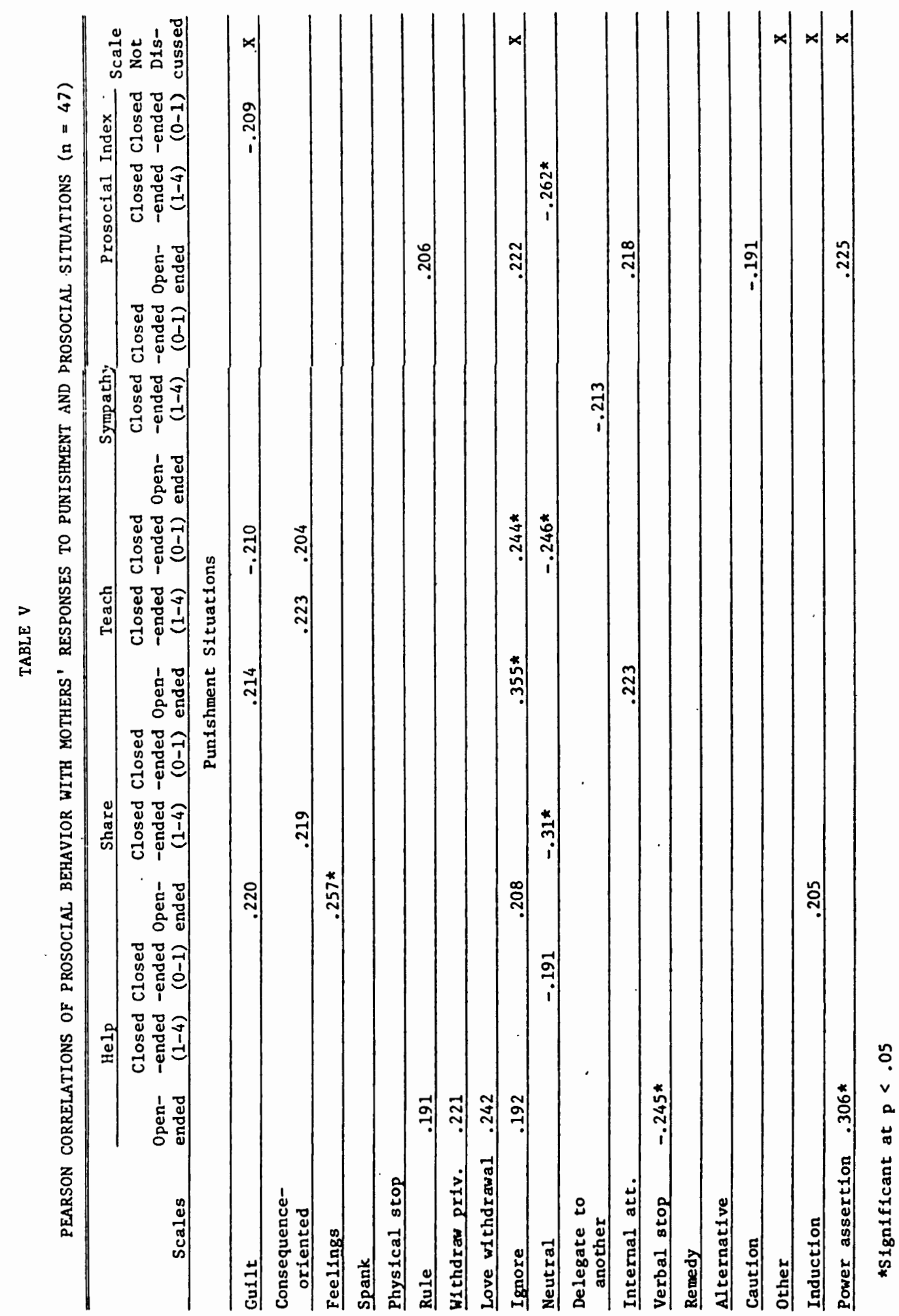




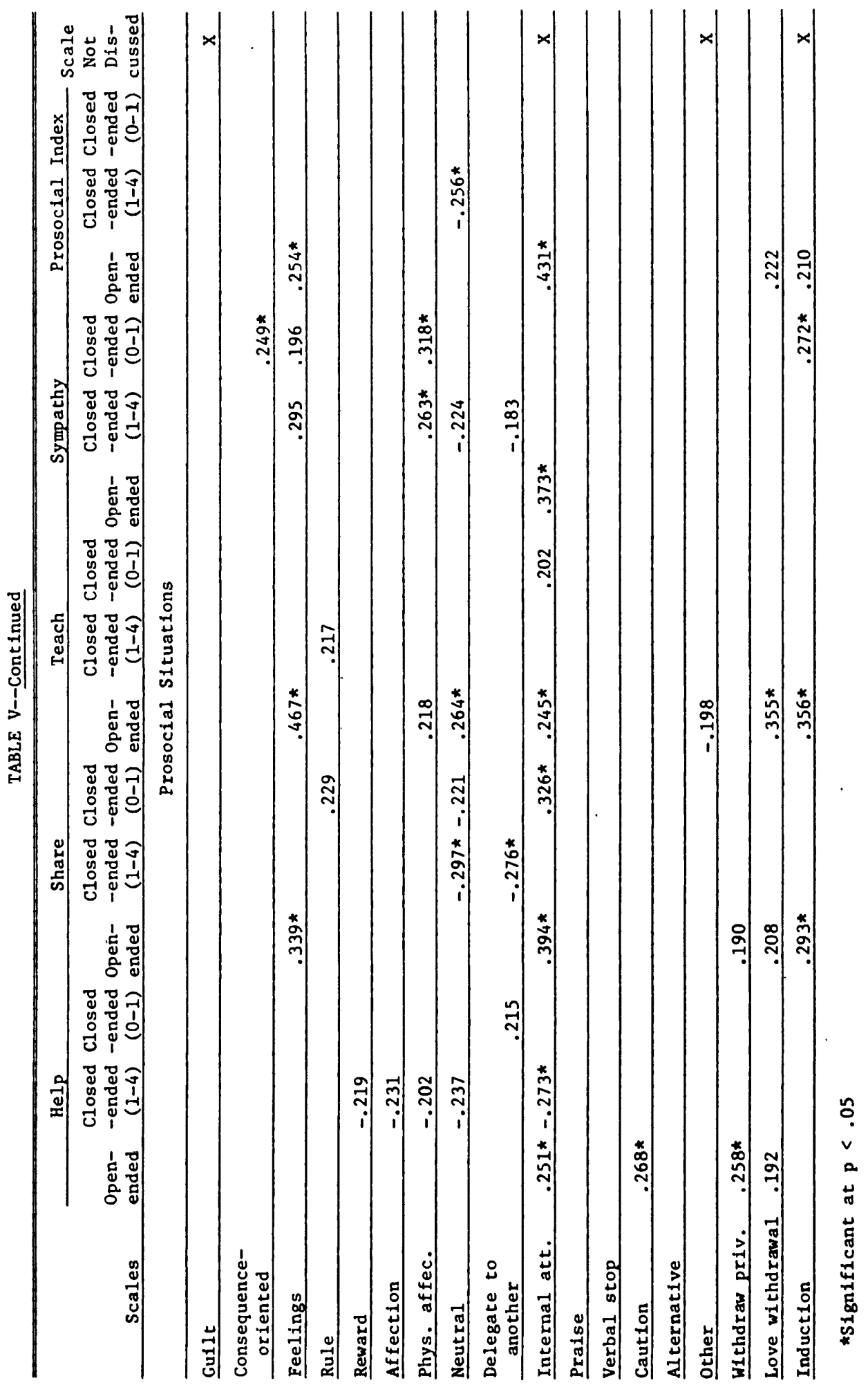


Prosocial Behavior and Its Relation to Maternal Responses to Punishment Situations. These relationships will be examined individually for helping, sharing, teaching, sympathy, and the prosocial index.

Helping was not consistently related across measurement modalities to mothers' responses to misbehavior. When open-ended responses to punishment situations were examined, a significant positive relationship of helping with love withdrawal and a significant negative relationship with verbal stop was obtained. No significant relationships at $p<.05$ were obtained for closed-ended responses, although when closed-ended items were dichotomized, a low level $(\mathrm{p}<.10)$ negative relationship of helping with neutral responses emerged.

Sharing had a significant positive relationship with feelings when maternal responses in the open-ended mode were examined. A significant negative correlation was obtained in the closed-ended measure with sharing and neutral, and a low level positive correlation with consequence-oriented discipline was obtained.

Teaching was negatively related to neutral responses when the dichotomized closed-ended parental responses were examined. In both closed-ended measures, a low level positive relationship of teaching to consequence-oriented discipline was obtained. 
Sympathy was not significantly correlated to mothers' responses in either the open-ended or closed-ended measures.

The overall prosocial index had a low level positive relationship, in the open-ended measure, with the scale rules. A significant negative relationship of the prosocial index with neutral in the closed-ended case was obtained. Prosocial Behavior and Its Relation to Maternal Responses to Prosocial Situations. A description of the relationships of each index of prosocial behavior to parental responses in prosocial situations follows.

Helping was significantly positively correlated with caution and withdrawal of privileges in the open-ended measure. Low level positive relationships were also obtained between helping and rules, withdrawal of privileges, and ignore. No significant correlations with helping were obtained in the closed-ended measure $(p<.05)$, although low level negative relationships were found with affection, rewards, physical affection, and neutral. A low level positive relationship between helping and delegation to another was also obtained.

Sharing had a significant positive relationship with feelings in the open-ended measure. In the closed-ended measure significant negative correlations with sharing were obtained with neutral and spouse. When the closed-ended measure was dichotomized, a low level positive relationship 
was obtained with the scale rules, and a negative relationship with neutral was found.

Teaching was positively significantly related to feelings, neutral, and love withdrawal in the open-ended measure. In the closed-ended case, a low level positive correlation of teaching with the scale rules was obtained. Sympathy was positively correlated $\mathrm{p}<.05$ with mothers' use of praise in the open-ended case. Significant positive correlations in the closed-ended measure were obtained with feelings and physical affection. When the closed-ended measure was dichotomized, significant positive relationships emerged with consequence-oriented and otheroriented discipline.

The prosocial index was positively significantly related to feelings in mothers' open-ended responses. In the closed-ended measure, a significant negative relationship of the prosocial index to neutral was obtained.

The Relationship of Resistance to Temptation to Maternal Responses

Measures of latency to first deviation, duration of deviation, and number of deviations were examined in relation to parenting scales in both punishment and prosocial situations. These correlations are presented in Table VI. of the 180 correlations obtained, 26 were significant at $\mathrm{p}<.05$ ( 7 were negative) and 32 additional correlations were significant at $\mathrm{p}<.10$ (11 were negative). A 
description of the relationships of these indices will be examined for punishment and prosocial situations separately. Resistance to Temptation and Its Relation to Maternal Responses to Punishment Situations. Descriptions of these relationships will be examined for each separate index of resistance to temptation.

Latency to first deviation was not significantly related to any of the parenting scales in the open-ended measure. In the closed-ended case, significant negative correlations with love withdrawal and rules were obtained. When closed-ended responses were dichotomized, significant negative correlations emerged with love withdrawal and withdrawal of privileges.

Duration of deviations was positively significantly related to consequence-oriented discipline, feelings, and remedy in mothers' responses in the open-ended measure. Number of deviations was positively significantly related to love withdrawal in all maternal measures, i.e., children who touched the forbidden toy had mothers who used love withdrawal as a disciplinary technique. In the closedended case, feelings and spank were also positively significantly correlated with number of deviations. When the closed-ended measure was dichotomized, significant positive relationships with feelings and rules were obtained. Resistance to Temptation and Its Relation to Maternal Responses to Prosocial Situations. Latency to first 


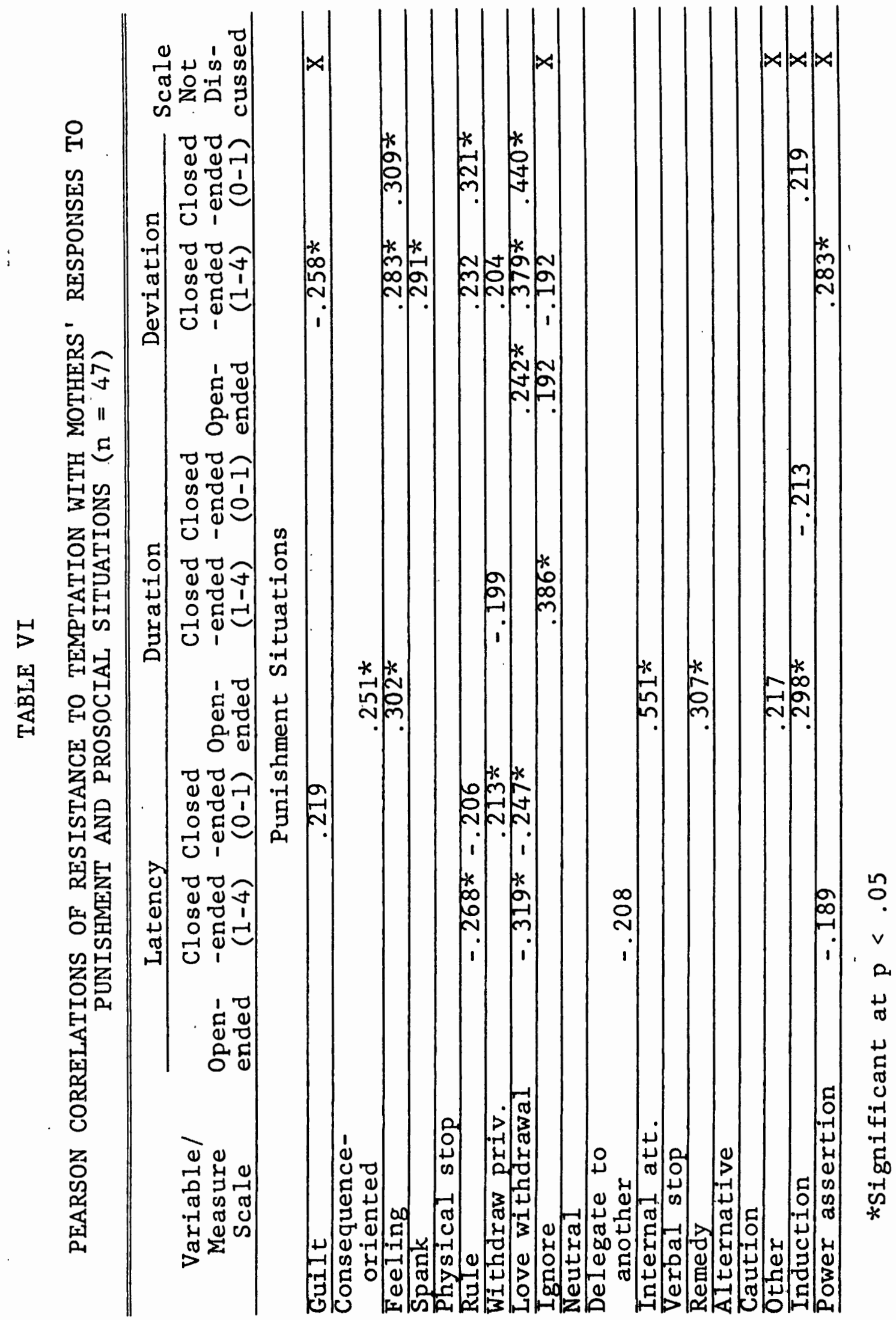




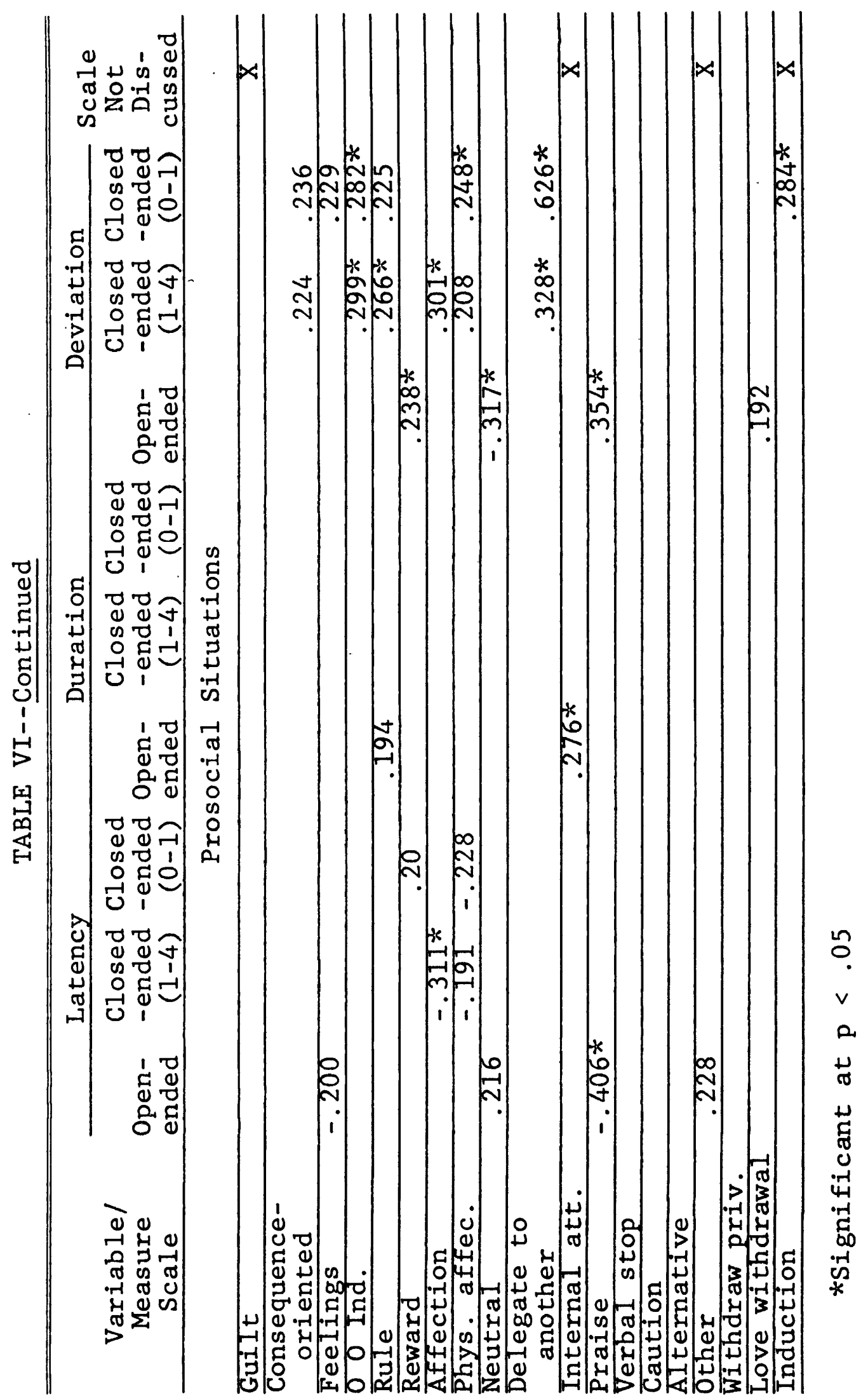


deviation was negatively related $(p<.05)$ to praise in the open-ended measure. In the closed-ended measure, a significant negative relationship of latency with affection was obtained, as well as a low level negative relationship with physical affection.

Duration of deviations was not significantly related to mothers' responses to prosocial behavior on any of the parenting modalities.

Number of deviations was negatively related to neutral and positively related to praise in the open-ended measure. Significant positive correlations were obtained in the closed-ended case with spouse, affection, other-oriented discipline, and rules. When maternal responses were dichotomized, significant positive correlations of number of deviations to other-oriented discipline, physical affection, and spouse (also known as delegation to another) were obtained.

Factor Analysis of Selected Punishment Scales

Punishment scales which were frequent in use, consistent across measurement modalities, and of theoretical importance were included in a factor analysis. This analysis was an attempt to reduce the punishment scales to a smaller number of usable dimensions. In both the open-ended and closed-ended measures, the scales consequence-oriented, feelings, spank, physical stop, rules, withdrawal of privileges, and love withdrawal were used in the factor analysis. 
In the open-ended case, the additional scales of remedy, alternative, and verbal stop were included. Factor analysis using commonality estimates on the main diagonal was the method employed. In general, a factor loading of .40 or greater was required for the inclusion of a scale in interpreting a factor. Because of the small sample size ( $n=47)$, these results must be treated as suggestive.

When the open-ended scales were analyzed, three factors emerged. The first factor included the scales and their corresponding loadings of withdrawal of privileges (.79), love withdrawal (.54), physical stop (.51) and verbal stop $(-.48)$. The second factor included the scales consequence-oriented rationale $(.82)$ and remedy $(.65)$. The third factor included a negative loading for feelings $(-.55)$ and a positive loading for spank (.52). The fourth factor included only the single scale, alternative (.83). The factor analysis of the original (1-4) closed-ended scales resulted in two factors, the first being a combination of love withdrawal (.81), spank (.62), and withdrawal of privileges (.56). The second factor consisted of consequence-oriented rationale $(.80)$ and rules $(.60)$. When the punishment scales were dichotomized, two additional factors resulted. The first factor obtained included the scales feelings (.87), love withdrawal (.69), and spank (.65), while the second included consequence-oriented rationales $(.86)$ and rules $(.54)$. 
It is especially of interest to note that the factor anaiysis results did not produce factors similar to the previous designations of power assertion or induction. Those component scales which had been combined to measure induction and power assertion did not factor together. This suggests that these large component scales may be less effective in describing mothers' responses than their respective component scales. Therefore, the relationship of these combination scales of power assertion and induction to children's behavior will not be discussed.

The Relationship of Punishment Factors to Moral Behaviors

Relationships of punishment factors which emerged in the previously discussed factor analysis to children's prosocial behavior and resistance to temptation are presented in Table VII. Again, the $\mathrm{p}<.10$ significance level was employed for assessment of consistency across measures. When considering the 56 correlations obtained for the eight child behavior variables and seven factors, 5 were significant at $\mathrm{p}<.05$ ( 1 was negative) and 6 were significant at $\mathrm{p}<.10$ (2 were negative).

Measures of Prosocial Behavior. Helping was positively related to the open-ended factor consisting of the scales withdrawal of privileges, love withdrawal, physical stop, and verbal stop (negative value). Sharing was not correlated with any designated factors. Teaching was positively 
TABLE VII

PEARSON CORRELATIONS OF PUNISHMENT FACTORS WITH CHILDREN'S

PROSOCIAL BEHAVIOR AND RESISTANCE TO TEMPTATION

$(\mathrm{n}=47)$

\begin{tabular}{|c|c|c|c|c|c|c|c|c|}
\hline \multirow[b]{3}{*}{ Behavior } & \multirow{3}{*}{ Factor } & \multirow{2}{*}{\multicolumn{3}{|c|}{ Open-ended }} & \multicolumn{4}{|c|}{ Close-ended } \\
\hline & & & & & \multicolumn{2}{|c|}{$(1-4)$} & \multicolumn{2}{|c|}{$(0-1)$} \\
\hline & & $\begin{array}{l}\text { Fac- } \\
\text { tor } 1^{a} \\
\end{array}$ & $\begin{array}{l}\text { Fac- } \\
\text { tor } 2^{b}\end{array}$ & $\begin{array}{l}\text { Fac- } \\
\text { tor } 3^{c} \\
\end{array}$ & $\begin{array}{l}\text { Fac- } \\
\text { tor } 1 \\
\end{array}$ & $\begin{array}{l}\text { Fac- } \\
\text { tor } 2 \\
\end{array}$ & $\begin{array}{l}\text { Fac- } \\
\text { tor }{ }_{1}^{f}\end{array}$ & $\begin{array}{c}\mathrm{Fac}^{-} \\
\text {tor } 28 \\
\end{array}$ \\
\hline Help & & $.302 *$ & & & & & & \\
\hline \multicolumn{9}{|l|}{ Share } \\
\hline Teach & & & & & & .205 & & .210 \\
\hline \multicolumn{9}{|l|}{ Sympathy } \\
\hline \multicolumn{9}{|c|}{ Prosocial index } \\
\hline Latency & & & & & & $-.234 *$ & & \\
\hline Duration & & & $.320 *$ & $-.301 *$ & -.213 & & & \\
\hline Deviation & & & & & $.387 *$ & .205 & $.372 *$ & .209 \\
\hline
\end{tabular}

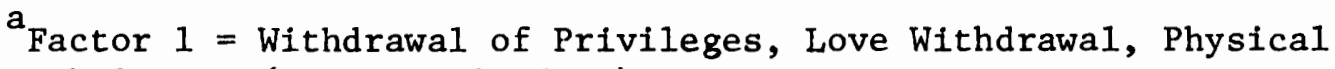
Stop, Verbal Stop (negative loading).

$b_{\text {Factor }} 2$ = Log. Consequences, Remedy.

${ }^{c}$ Factor 3 = Feelings (negative loading), Spank.

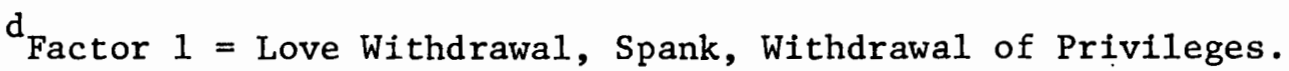

e Factor $2=$ Log. Consequencés, Rule.

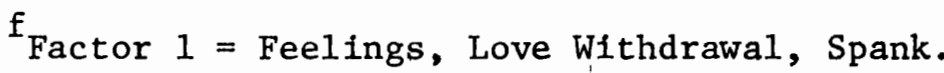

$\mathrm{g}_{\text {Factor } 2}=$ Log. Consequences, Rule

*Significant at $p<.05$

correlated at low levels $(\mathrm{p}<.10)$ with two closed-ended scales both consisting of consequence-oriented discipline and rules (one $1-4$ scale and dichotomized responses scale). Sympathy and the prosocial index were not significantly related to any factor. 
Measures of Resistance to Temptation. Latency to first deviation was positively correlated at a low level with the closed-ended factor consisting of consequenceoriented rationales and rules. Duration of deviations was significantly related to two open-ended factors, one factor consisting of consequence-oriented discipline and remedy, and the other consisting of feelings (negative value) and spank. Number of deviations was significantly related to a factor consisting of love withdrawal, spank, and withdrawal of privileges in the original (1-4) closed-ended measure. When closed-ended scores were dichotomized, a factor consisting of feelings, love withdrawal, and spank was related to the number of deviations.

The Relationship of Demographic Variables to Parental Responses and Children's Moral Behaviors

The relationship of demographic variables of mother's age, social position, number of adults in the home, the sex and age of the child, the birth order of the child, and the number of children in the home to parenting behaviors in both punishment and prosocial situations are presented in Table VIII. When considering the 420 correlations obtained, 61 were significant at $\mathrm{p}<.05$ (24 were negative) and 37 were significant at $\mathrm{p}<.10$ (16 were negative). The relationship of these demographic variables to children's moral behaviors is presented in Table IX. When considering the 56 correlations obtained, 9 were significant at $p<.05$ 
( 7 were negative) and 13 correlations were significant at $p<.10$ (11 were negative). A description of these relationships follows.

Mothers' Age. Mothers' age was positively significantly correlated with feelings, spank, love withdrawal, and withdrawal of privileges, and negatively related to physical stop in punishment situations. In prosocial situations, mothers' age was significantly positively correlated with praise, consequence-oriented discipline, verbal stop, affection, and neutral. None of the indices of children's moral behavior was strongly related to mothers' age.

Social Position. This variable, as assessed by the Hollingshead Two Factor Index of Social Position (1957), was significantly positively related to mothers' use of remedy. A low level positive correlation with consequenceoriented discipline was also obtained. In prosocial situations, social position was significantly related to praise and alternatives. Both sympathy and the prosocial index were significantly related to social position. Low level positive correlations with helping and teaching were also obtained.

Number of Adults in the Home. The number of adults in the home was significantly positively related to spouse, and negatively related to alternatives in punishment situations. In prosocial situations, the number of adults was negatively related to affection, verbal stop, and love 


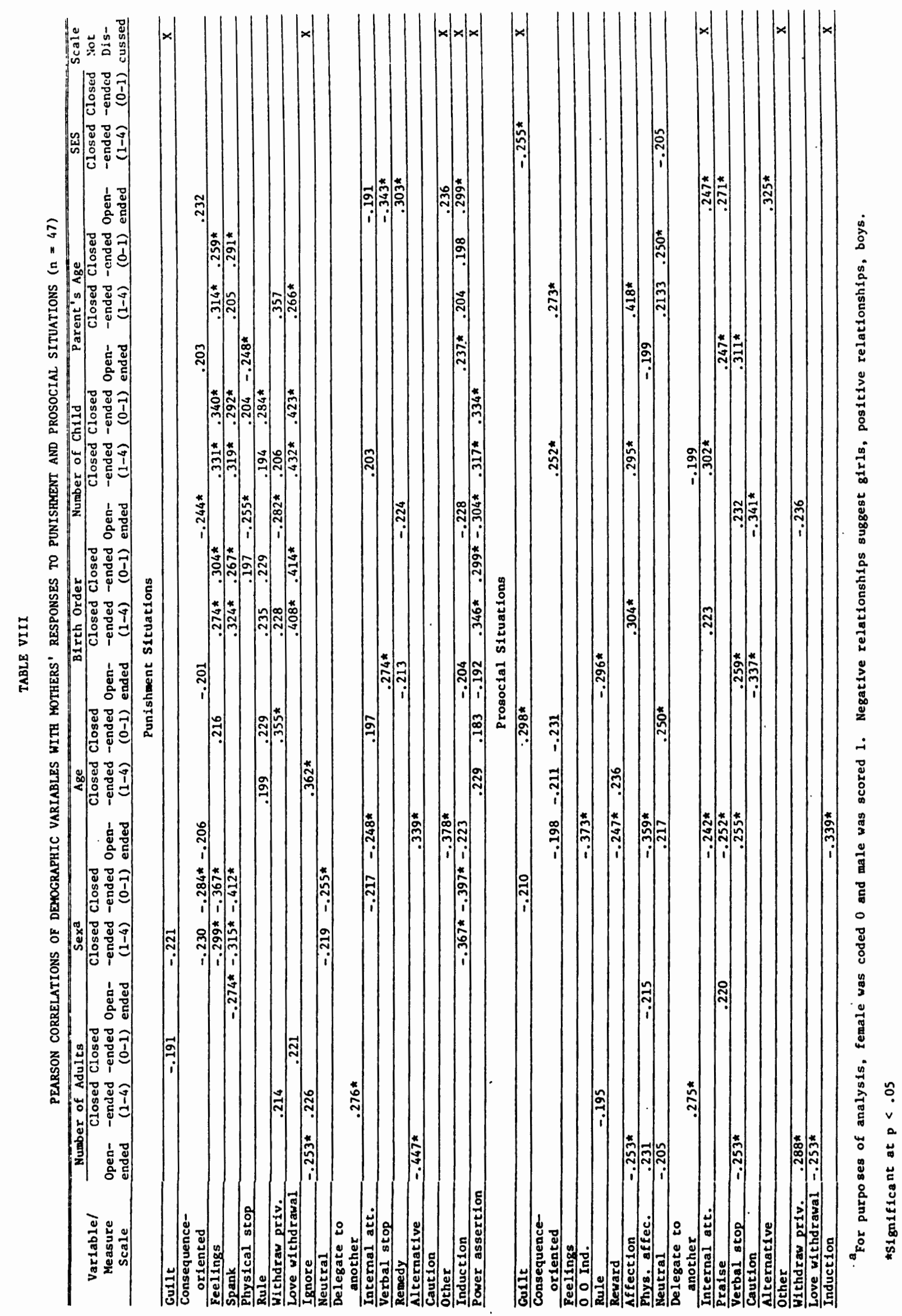


TABLE IX

PEARSON CORRELATIONS OF DEMOGRAPHIC VARIABLES WITH CHILDREN'S PROSOCIAL BEHAVIOR AND RESISTANCE TO TEMPTATION $(\mathrm{n}=47)$

\begin{tabular}{|c|c|c|c|c|c|c|c|c|}
\hline $\begin{array}{c}\text { Demo- } \\
\text { graphic } \\
\text { Variables }\end{array}$ & $\begin{array}{l}\text { Help- } \\
\text { ing }\end{array}$ & $\begin{array}{c}\text { Shar- } \\
\text { ing }\end{array}$ & $\begin{array}{r}\text { Teach- } \\
\text { ing }\end{array}$ & $\begin{array}{c}\text { Sympa- } \\
\text { thy }\end{array}$ & $\begin{array}{c}\text { Proso- } \\
\text { cial } \\
\text { Index } \\
\end{array}$ & $\begin{array}{c}\text { Laten- } \\
\text { cy }\end{array}$ & $\begin{array}{l}\text { Dura- } \\
\text { tion }\end{array}$ & $\begin{array}{c}\text { Devia- } \\
\text { tion }\end{array}$ \\
\hline Parents' age & & & & & -.192 & -.229 & & .21 \\
\hline SES & .223 & & .208 & $.400 *$ & $.351 *$ & & & \\
\hline $\begin{array}{c}\text { Number of } \\
\text { adults }\end{array}$ & & -.205 & & & & & & \\
\hline Sex of $\operatorname{child}^{\mathrm{a}}$ & & & & & & $-.320 *$ & $.283^{*}$ & $.273 *$ \\
\hline Age of child & & -.222 & & & & & & \\
\hline Birth order & $-.415 *$ & -.199 & -.217 & -.234 & $-.364 *$ & -.206 & & .203 \\
\hline $\begin{array}{l}\text { Number of } \\
\text { children }\end{array}$ & $-.392 *$ & -.198 & & & $-.299 *$ & & & \\
\hline
\end{tabular}

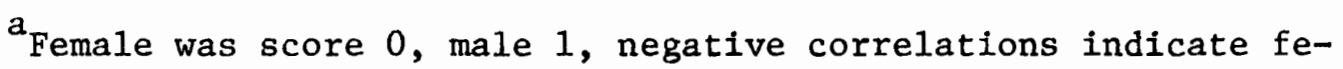
male, positive relationships male.

*Significant at $\mathrm{p}<.05$

withdrawal, and positively related to withdrawal of privileges and spouse. The number of adults in the home was not significantly related to children's moral behaviors.

Sex of Child. Across all modalities, girls were more likely to be spanked in response to misbehavior. Girls also received more punishment characterized by the scales feelings, neutral, and consequence-oriented discipline. Mothers' responses to prosocial situations were unrelated to the sex of their child. Interestingly, there were no sex differences in children's prosocial behavior. In resistance to temptation measures, however, girls were more 
likely to resist temptation for a longer time (latency), while boys deviated more often and for a longer duration. Age of Child. Significant positive correlations were obtained between the child's age and mothers' use of alternatives and withdrawal of privileges. A low level positive correlation of the child's age with rules was also obtained in punishment situations. In prosocial situations, the child's age was significantly related in a negative direction to other-oriented discipline, rewards, physical affection, and praise, and at a lower level to consequenceoriented discipline. Children's moral behaviors were not significantly related to the children's ages.

Birth Order. Latter-born children were significantly more likely to receive discipline responses characterized by mothers' use of verbal stop, feelings, spank, and love withdrawal. These children were also more likely to receive statements of rules $(p<.10)$. In prosocial situations, latter-borns were significantly more likely to receive affection and verbal stop, while first-borns were more likely to receive rules and caution. In relation to measures of children's moral behavior, first-borns were more likely to help and behave prosocially overall, $\mathrm{p}<.05$. The remaining prosocial behaviors (sharing, teaching, and sympathy) were also more frequent in first-borns, $\mathrm{p}<.10$. For resistance to temptation, first-borns touched the toy less often and waited longer before they touched. 
Number of Children in the Home. Number of children was significantly positively related to mothers' use of feelings, spank, love withdrawal, and rules in punishment situations. Children from smaller families were more likely to receive consequence-oriented rationales, physical stop, and withdrawal of privileges in discipline situations. In prosocial situations significant positive correlations were obtained between number of children and consequence-oriented rationales and affection. Among indices of children's moral behavior, children from smaller families helped and behaved more prosocially overall. Children from smaller families also received more statements of caution.

The Relationship of Prosocial Behavior and Resistance to Temptation

When the relationship of indices of prosocial behavior (helping, sharing, teaching, and sympathy) to indices of resistance to temptation (1atency, duration, deviations) was examined, 12 correlations were obtained. Only one of the correlations was significant. Children who helped touched the forbidden toy for a longer period of time $(r=.24, p<.05)$.

The Relationship of Mothers' Perceptions of Prosocial Behavior and the Child's Actual Behavior

Mothers' perceptions of their children's helping, sharing, teaching, and sympathetic behavior were examined in relation to their child's actual helping, sharing, 
teaching, and sympathy scores obtained in the experimental setting. None of the 16 correlations was significant at $p<.10$. 


\section{CHAPTER IV}

\section{DISCUSSION}

This study provided some evidence of the relationship of maternal childrearing practices to children's moral behaviors. Equally important, this study brought to light difficulties in the assessment of childrearing practices, both in regard to the current methods of measurement and to the behavioral categories presently used to delineate punishment techniques.

Investigations of the relationship of parenting technique to moral behavior in children have assumed that parents behave much the same way in all disciplinary encounters (Sears, Maccoby, and Levin 1957). Recently, Grusec and Kuczinski (1978) assessed parenting behavior in punishment situations and found that the variability of responding was greater across situations than across parents, suggesting that parents' responses were more a function of the situation than of a consistent childrearing style. In contrast, this study found mothers to be fairly consistent in their punishment techniques across all the situations provided. Furthermore, mothers were also fairly consistent in their responses across modalities; i.e., they responded in similar ways whether they were asked 
to check items from a list or to generate their own descriptions of their disciplinary behavior. Both of these results provide support for the notion of consistency in mothers' discipline. Perhaps this is not surprising, in that mothers are confronted on a daily basis with discipline situations and so have a number of experiences from which to draw. Through these experiences they may have learned what techniques gain compliance. Discipline technique has also received considerable public attention and concern is often voiced about the consequences of the use of varying punishment techniques. As a result, mothers may be particularly sensitive to the methods they use in disciplinary encounters and may have adopted a consistent response to their child's misbehavior.

This awareness of punishment techniques is in contrast to mothers' reactions to incidents of prosocial behavior in their children. Mothers' responses to their child's prosocial behavior were much less consistent across situations, and particularly situation specific in the openended measure. Mothers not only were likely to say they used differing techniques in each particular situation, but their answers across measurement modalities were inconsistent, i.e., their answers to the open-ended questions did not reflect their responses to list items. Demand characteristics of the prosocial situations may have accounted for some of the inconsistency in mothers' reactions to 
prosocial behavior. For example, mothers' overriding concern for the harm that could come from their child's turning sommersaults was not expected and surely turned attention away from the issue of children's teaching behavior in general. Additionally, the relative lack of previous research assessing parental responses to prosocial behavior in children may have limited the ability of the list items to be representative of mothers' actual responses. This inadequacy of the list items would certainly have influenced the consistency of mothers' responses across measurement modalities.

It is also possible, however, that mothers simply do not have a consistent overall approach to their child's prosocial behavior. Certainly less public attention has been placed on parental responses to positive behavior in children. Furthermore, prosocial behavior in the young child is not a frequent response. Eisenberg-Berg and Neal (1979) observed the naturally occurring prosocial behavior of preschool children. Over a twelve-week period the median number of prosocial incidents per child was between two and three. It seems very likely that mothers of young children have not had sufficient experience with this behavior to incorporate a consistent style or pattern. In fact, even when these infrequent behaviors do occur, mothers have the ability to choose whether or not to intervene, which is usually not the case when the child is misbehaving. This lack 
of experience with their child's prosocial behavior may also account for mothers' inability to predict their behavior. In this study, the child's actual behavior was not related to the mothers' perceptions of his or her prosocial inclinations.

This study made use of a questionnaire-interview format in which mothers were asked to describe their behavior in specific situations rather than their general parenting style, an attempt to improve the ability of the measure to predict behavior (Hetherington and Parke 1979). Additionally, childrearing behaviors were assessed not only by asking mothers open-ended questions but by examining their responses to objective list items as well. Mothers were more consistent across these measurement modalities when questioned about their reactions to misbehavior in their child than when asked about their child's prosocial behavior. It would seem that the items on the punishment lists better approximated actual parental reactions than those on prosocial lists. Mothers' reactions to their child's negative behaviors have been extensively investigated elsewhere, whereas to the author's knowledge, the present study represents the first attempt to question mothers regarding their reactions to prosocial behavior in their young children.

Although punishment situations produced more consistency across response modalities than prosocial situations, 
the mode of response itself was also important. Mothers were found to be more consistent in their disciplinary style when they were asked to check items on a list than when they were asked to generate descriptions of their own behavior. It seems certain that social desirability played a smaller role in mothers' open-ended responses, and that this measure allowed for greater variability in responding. On the other hand, punishment techniques which the parent found difficult to admit spontaneously in response to openended questions may have been more accurately assessed by the closed-ended measure. The fact that not all correlations between the two measures were significant attests to the differing information supplied by these modalities. It seems that naturalistic observation of parenting styles may be the most direct way of obtaining an accurate measure of childrearing practices. As long as parenting remains a sensitive issue and parents are made to worry about their own behavior, it may be unrealistic to attempt to assess parenting behavior in any other fashion than to observe the interaction as it is happening.

Examinations of the relationship of mothers' responses in punishment situations to children's prosocial behavior provided little evidence for the effectiveness of reasoning in promoting prosocial responding. Only one prosocial index was significantly related to the use of inductive techniques. This index, sharing, was related to mothers' use 
of statements of feelings. It may be that by sensitizing the child to the parents' feelings, the child is made aware of the feelings of others. This awareness may promote the child's understanding of appropriate behaviors when a sharing opportunity is presented. While these results provide some support for the value of explanations, the relationship of helping to parenting style is much less clear. Helping was positively related to love withdrawal and in fact, children who helped had parents who used a combination of withdrawal of privileges, love withdrawal, and physically stopping the child. These results bear some similarity to the relationship Hoffman and Saltzstein (1967) found between power assertion and consideration for others in boys. It seems likely that helping and sharing are differentially affected by punishment technique. It may be that helping is fostered by power or love-oriented techniques whose emphasis is obedience rather than explanations. Perhaps helping does not require an awareness of others' feelings but rather compliance with an expected action. Yet sending the child to his or her room, considered a love withdrawal technique, may allow the child to reflect upon the misbehavior.

When the relationship of mothers" disciplinary responses to children's prosocial behavior was examined, the most consistent finding was that prosocial behavior decreased as mothers' nonintervention in punishment situations 
increased. It may be that a mother's nonintervention in punishment situations provides a model of nonintervention for her child and decreases the child's inclination to respond in other situations.

When mothers' reactions to prosocial situations were examined, results provided more support for the effectiveness of reasoning in the development of prosocial behavior. Children whose mothers used statements of feelings or appreciation shared, taught, and sympathized more. In addition, sympathetic behavior was related to mothers' use of physical affection, consequence-oriented, and other-oriented rationales. It appears in general that children who received explanations of their own positive behavior were more prosocial. These results support the idea (Walters and Grusec 1977) that explanatory statements from socializing agents provide the child with additional information concerning his or her behavior and promote the generalization of that behavior to other settings. Similar to results found when punishment techniques were assessed, mothers who chose not to respond to their children's prosocial behavior had less prosocial children. Teaching behavior was the one exception to this general finding; teaching in children increased as mothers' neutral responses increased. The reason for this discrepant relationship is not clear. But the pattern of results with the other prosocial indices suggests that mothers' lack of positive 
attention to their children's prosocial behavior may communicate less of the positive aspects of that behavior or the benefits of such behavior in the future. As a result, when these children are given opportunities to behave prosocially outside the home, they are less likely to display these behaviors.

The other measure of children's moral behavior in this study was resistance to temptation. Children were less likely to resist temptation when their mother used love withdrawal techniques in punishment situations. In addition, mothers who used techniques which incorporated elements of reasoning, i.e., statements of consequences or the parents' feelings, had children who touched the forbidden toy more often and for a longer period of time. These results are in agreement with Greenglass (1972), who found reasoning negatively related to resistance to cheating. When factors were examined, the number of deviations increased as the combination of love withdrawal, spank, withdrawal of privileges, and feelings increased. The relationships found between resistance to temptation and a variety of parenting techniques (love withdrawal, reasoning, spank, and withdrawal of privileges) provide inconsistent results and cali for further research.

When mothers' responses to prosocial situations were related to children's resistance to temptation, few relationships emerged, although children who received praise 
and affection for their prosocial behaviors were more likely to resist deviation for a longer time. It may be that a child who receives positive attention for his or her prosocial behavior is more willing to comply for a longer time with any request from an adult. The number of times children touched the forbidden toy was related to a variety of parenting techniques and no apparent pattern emerged. One of these results, however, is of special interest. Mothers who did not respond to their children's prosocial behavior were likely to have children who touched the forbidden toy a number of times. This finding is consistent with data discussed earlier which indicated that children were less likely to behave prosocially when their prosocial behavior or their misbehavior was met by neutral reactions from their mothers. In general, this pattern of results would seem to suggest that children's moral behaviors are enhanced when mothers choose to intervene, rather than igmore, their child's behavior.

With the exception noted above, it appears that the two indices of moral behavior, prosocial behavior and resistance to temptation, were differentially affected by parents' responses to both prosocial and punishment situations. In fact, when these indices were related to each other, only one significant relationship emerged, between helping and the duration of deviations. It seems certain that prosocial behavior and resistance to temptation are 
very different kinds of moral behavior, and relationships of parenting variables to one index should not be assumed to apply to the other index or to moral behavior in general.

The present study also called into serious question the usual delineation of parenting behavior into broad categories such as "inductive" or "power assertive." In the data presented here, those parenting behaviors which have traditionally constituted these categories had differential effects on children's moral behavior. Reasoning statements and explanations incorporated in this study (guilt, consequence-oriented, feelings, other-oriented) did not similarly relate to children's behavior. Likewise, mothers' responses which could together be called "power assertive" were not consistently related to the moral behavior of the children. In addition, when the punishment scales were subjected to a factor analysis, factors similar to power assertion or induction did not emerge. Instead, power techniques such as withdrawal of privileges and spank were related to love withdrawal. It seems that the delineations of power assertion or induction may be less accurate representations of parenting style than to consider mothers' particular behaviors themselves.

Examination of demographic variables and their relathionship to parenting style and children's moral behavior provided interesting results. As social position increased the use of remedy and consequence-oriented discipline 
increased, while verbally stopping the child decreased. Mothers of higher social position used reasoning or statements of direct consequences and were less likely to merely stop the behavior verbally (e.g., Get down!) This is in agreement with Hoffman and Saltzstein (1967), who found that parents of higher social class were more inductive. In prosocial situations, mothers of higher social class were more likely to praise prosocial behavior and offer alternatives when attempting to promote sharing. Children's prosocial behavior was also related to social class. Those from higher social positions were more sympathetic and more prosocial overall. These results are inconsistent with the majority of studies of older children which show that social class is unrelated to prosocial behavior (Krebs 1970; Mussen and Eisenberg-Berg 1977).

Unlike reports that boys receive more physical punishment (Maccoby and Jacklin 1974), this study found girls more likely to be spanked than boys. Girls also received more consequence-oriented discipline and were less likely to be punished for their misbehavior. Thus it appears that mothers' responses to girls range widely from physical punishment to nonintervention. In prosocial situations girls received more praise and physical affection. No sex differences emerged in children's prosocial behavior. With regard to resistance to temptation variables, girls had a longer latency to deviation while boys deviated longer and 
more often. This is in agreement with LaVoie (1973) who found girls more likely to resist temptation. No age differences were found in children's moral behaviors. When the relationship of parenting behaviors to children's age was examined, older children more often received a verbal stop, withdrawal of a privilege, or an alternative suggestion in disciplinary encounters. On the other hand, when the child behaved prosocially, younger children received more praise, physical affection, rewards, and otheroriented discipline.

With regard to birth order, first-borns were more likely to receive statements of rules from mothers while latter-borns received more power and love-oriented approaches. Unlike Krebs (1970), who suggested in his review of the literature that latter-born children were more altruistic, this study found that first-borns and those from smaller families were more helpful and prosocial in general. In summary, this study provided a number of interesting findings. First, mothers were more inconsistent in their responses to prosocial situations than to punishment situations. Second, there was some inconsistency between open-ended and closed-ended measures of parental behavior, especially in prosocial situations. Further research which makes use of naturalistic observation is needed to clarify the nature of mothers' inconsistency. Third, while an examination of the relationship of resistance to temptation to 
parenting behaviors provided conflicting results, prosocial behavior was positively related to the mothers' use of feeling statements and negatively related to neutral responses. These results provide some support for the effectiveness of reasoning in promoting prosocial behavior. An exception, helping, appeared to be increased by withdrawal of privileges, physical stop, or love-withdrawal techniques, and may be more related to mere obedience than to an active concern for others, hypothesized as necessary to share. Fourth, those techniques which have generally been grouped together as inductive or power assertive differentially predicted children's moral behavior, a result which questions the validity of these combinations of parenting techniques. Finally, the two indices of moral behavior, prosocial behavior and resistance to temptation, were unrelated to one another. Generalization beyond either specific behavior to moral behavior in general is thus questionable. 


\section{REFERENCES}




\section{REFERENCE NOTES}

1. Hollingshead, A. B. "The two-factor index of social position." Unpublished manuscript, Yale University, 1957. (Mimeo)

2. Grusec, J. and Kuczynski, L. Direction of Effect in Socialization: A Comparison of the Parent vs. the Child's Behavior as Determinants of Disciplinary Techniques. Unpublished manuscript, University of Toronto, 1978.

3. Zahn-Waxler, C. and Radke-Yarrow, M. Child Rearing and the Development of Children's Altruism. Paper presented at the meeting of the American Psychological Association, Toronto, Canada, August 1978.

\section{REFERENCES}

Aronfreed, J. The nature, variety, and social patterning of moral responses to transgression. Journal of $A b$ normal and Social Psychology, 1961, 63, 223-241.

Bryan, J. H., and Walbek, N. H. Preaching and practicing generosity: Children's actions and reactions. Child Development, $1970,41,329-353$.

Burton, R. V., Maccoby, E. E., and Allinsmith, W. Antecedents of resistance to temptation in 4 year old children. Child Development, 1961, 32, 689-710.

Cheyne, J.A. Some parameters of punishment affecting resistance to deviation and generalization of a prohibition. Child Development, 1971, 42, 1249-1261.

Cheyne, J. A., and Walters, R. H. Intensity of pumishment, timing of punishment and cognitive structure as determinants of response inhibition. Journal of Experimental Child Psychology, 1969, 7, 231-244.

Depalma, D. J. Effects of social class, moral orientation and severity of punishment of boy's moral responses to transgressions and generosity. Developmental Psychology, $1974,10,880-900$. 
Depalma, D. J., and Foley, J. Moral development: Current theory and research. Hillsdale, New Jersey: Lawrence ErIbaum Associates, 1975.

Dlugokinski, E., and Firestone, I. J. Congruence among four methods of measuring other-centeredness. Child Development, 1973, 44, 304-308.

Eisenberg-Berg, N., and Neal, C. Children's moral reasoning about their own spontaneous prosocial behavior. Developmental Psychology, 1979;, 15, 228-229.

Festinger, L., and Freedman, J. L. Dissonance reduction and moral values. In P. Worchel \& D. Bryne (Eds.), Personality change. New. York: Wiley, 1964, 220-243.

Greenglass, E. R. A cross-cultural study of the relationship between resistance to temptation and maternal communication. Genetic Psychology Monographs, 1972, 86, 119-139.

Grinder, R. E. Parental childrearing practices, conscience, and resistance to temptation in sixth grade children. Child Development, 1962, 33, 803-920.

Grusec, J. E., and Skubiski, S. L. Model nurturance, demand characteristics of the modeling experiment and altruism. Journal of Personality and Social Psychology, 1970, 14, 352-359.

Hetherington, E. M., and Parke, R. D. Child psychology: A contemporary viewpoint (2nd Ed.). New York: McGraw-Hil1, 1975 .

Hoffman, M. L. Parent discipline and child's consideration of others. Child Development, 1963, 34, 573-588.

Hoffman, M. L., and Saltzstein, H. Parent discipline and the child's moral development. Journal of Personality and Social Psychology, 1967, 5, 45-57.

Hoffman, M. L. Moral development. In P. H. Mussen (Ed.), Manual of child psychology. New York: Wiley, 1970 (a).

Hoffman, M. L. Conscience, personality, and socialization technique. Human Development, 1970, 13, 90-126 (b).

Hoffman, M. L. Altruistic behavior and the parent child relationship. Journal of Personality and Social Psychology, 1975, 31, 937-943. 
LaVoie, J. C. The Effects of an aversive stimulus, a rationale, and sex of child on punishment effectiveness and generalization. Child Development, 1973, 44, 505-510.

LaVoie, J. C. Cognitive determinants of resistance to deviation in seven, nine, and eleven-year-old children of low and high maturity of moral judgement. Developmental Psychology, 1973, 10, 393-401.

LaVoie, J. C. Type of punishment as a determinant of resistance to deviation. Developmental Psychology, 1974, $10,181-189$.

Maccoby, E. E., and Jacklin, C. N. The psychology of sex differences. Stanford: Stanford Univer sity Press, 1974.

Mussen, P., and Eisenberg-Berg, N. Roots of caring, sharing, and helping. San Francisco: W. H. Freeman, 1977 .

Olejnik, A. B., and McKinney, J. P. Parental value orientation and generosity in children. Developmental Psychology, $1973, \underline{8}, 311$.

Parke, R. D. Effectiveness of punishment as an interaction of intensity, timing, agent nurturance and cognitive structuring. Child Development, 1969, 40, 214-235.

Rice, M. E., and Grusec, J. E. Saying and doing: Effects on observer performance. Journal of Personality and Social Psychology, 1975, 32, 584-593.

Santrock, J. W. Father absence, perceived maternal behavior and moral development in boys. Child Development, $1975, \underline{46}, 753$.

Schaffer, R. Mothering. Cambridge, Mass.: Harvard University Press, 1977.

Sears, R. R., Maccoby, E. E., and Levin, H. Patterns of child rearing. Evanston, I11.: Row and Peterson, 1957.

Staub, E. The use of role playing and induction in children's learning of helping and sharing behavior. Child Development, 1971, 42, 805-815. 
Verna, G. The effects of four hour delay on punishment under two conditions of verbal instruction. Child Development, $1977,48,621-624$.

Walters, G., and Grusec, J. Punishment. San Francisco:

W. H. Freeman, 1977. 
APPENDICES 


\title{
APPENDIX A
}

\author{
SCORING SYSTEM
}

DEFINITIONS AND OBSERVATIONAL SCORING

SYSTEM: PROSOCIAL BEHAVIOR STUDIES

\section{SCORE CODE BEHAVIOR}

$4 \mathrm{H}$ Helping: Child assists in a task which is better or more quickly done by more than one person, e.g., finding a lost object (child must get up from seat and look for object for at least 5 seconds); locating any needed object; picking up objects which have dropped to the floor; moving objects from one place to another; clearing objects or materials from table.

If child looks for lost object for 5 seconds or more but does not get out of seat, score 3 .

If child looks for lost object for less than 5 seconds, score $\underline{2}$.

If child helps within one second and does everything by him/herself (e.g., picking up all sticks alone), score $\underline{5}$.

4 S Sharing: Child relinquishes an object which had been in the child's possession or use, or which was owned by the child (owernship must be previously established by telling the child, "This is yours").

If child shares only leftovers (e.g., playdough scraps not in shape of cookie), or very small portions of own materials, score 3 . If child shares all remaining materials, score $\underline{5}$. 
SCORE CODE BEHAVIOR

4 T Teaching: Child instructs another in a skill or activity. The instruction can be through physical demonstration or verbal explanation as long as the child gives another information which enables the individual to continue or complete an activity. Al1 3 components of teaching responses must be demonstrated or explained.

If child teaches only 2 components, score 3 . If child teaches only 1 component, score 2 .

If child demonstrates physically and verbalizes all 3 components of teaching response, score $\underline{5}$.

$4 \quad$ Sym Sympathy:

Child offers comfort or condolence, or expresses concern about another's condition. Verbalizations must include words such as sorry, hurt, better, alright, okay, etc. Verbalizations scored as sympathy include:

-"It's alright."

-"Sorry, I know you're hurt" or "I bet it hurts."

- "It's okay" or "That's okay" or "It will be okay."

-"I think it will stop hurting now."

-"It will feel better in awhile" or "It'Il get better."

-"I'm sorry."

-"I wish it didn't hurt."

- "Have to get a bandaid for you so it won 't hurt!"

-"Are you alright?"

-"Does it feel better?"

Physical demonstrations of comfort or sympathy include extending a hand or arm toward the injured person and patting, stroking, hugging, kissing in a positive manner. Physical demonstrations receive a score of 4 . If a child displays negative effect, and/or repeats the verbalization of need or equivalent (e.g. , "Ouch!") score 2. Hote: affect is 
scored only when there is no physical or verbal response.

If child remembers a similar

past incident or event which happended to self or others (e.g., "I got an owie and it bleeded"; "I hurted myself once"), score 2 .

If child's statement lacks sympathy or condolence or borders on criticism, or includes an account of own coping behavior in similar situations (e.g., "When I touched it, it didn't hurt me!"; "You didn't hit it very hard"; "What did you do that for?"; "That's what you get"), score as 1 .

If child verbalizes a sympathetic response (e.g., "I'm sorry") and displays another prosocial response (e.g., helping or sharing) at level 4 , score as 5 .

If child verbalizes a sympathetic response and physically demonstrates a response, e.g., kisses the hurt, score as 5 . If the child verbalizes an extensive sympathetic response (e.g. "I'm sorry you hurt yourself. It will get better soon"; "Want to put something on it? I believe it does really hurt. It will heal. I don't think it will be a bruise"), score as $\underline{5}$.

$3 \quad R_{3} \quad$ Remedy 3:

Any neutral or positive verbal response by the child which poses a solution to the problem implied by the verbalization of need. The following are examples of Remedy 3:

- (lost pen) "But we could go outside where you were. Could write with the brush."

- (no cup) "I'm going to bring one for you cause I didn't bring

- (no cup) "You could get a different one. Use that glass one." 
- (no cup) "You can plant in a garden. I planted in a garden with my dad."

- (no cup) "You can have that one (pointing to model)."

-(no flower sticker) "Take one off there (off model)."

- (no flower sticker) "Do you want a stem? Here's stem. Somebody must have pulled off the flower."

- (no snack) "Do you have some at home? Buy some. Are you going to buy some?"

- (no glitter) "Do you have some at home? Why don't you use some at home?"

- (bumped head) "Go out there and get a cold pack then."

- (bumped head) "Maybe we have some bandaids" or "Do you need a bandaid?"

$2 \quad \mathrm{R}_{3} \quad$ Remedy 2:

Any neutral or positive verbal response by the child which falls into one of the following categories:

a) Child tells adult to engage in

the behavior herself, e.g.

- (no cup) "Get one can't you? Aren't you allowed to get one yourself?"

- (things need to be moved to the table) "Alright--do that."

-(spilled sticks) "Pick 'em up."

-(spilled sticks) "Well, you'11 have to pick them up."

-(spilled sticks) "You pick them up because you spilled them."

- (lost box) "Go look for it" or "Look on the floor."

b) Child says that someone else (e.g., the other adult) engage in the behavior, e.g.

- (no flower sticker) "She's gonna go get some."

- (lost box) "Ask the other girl when she comes back."

-(no snack) "She'll give you
one." 
- (no snack) "We11, she can go get some more."

-(spilled cookie cutters) "She'11 do it."

c) Child "admonishes" adult by offering comments regularly made by socializing agents in similar situations, e.g.

-(spilled sticks) "You shouldn't have dropped them like that."

-(spilled sticks) "That's cause you shouldn't have opened it."

-(spilled sticks) "Don't drop them again."

- (stubbed toe) "You better watch where you're going."

- (stubbed toe) "What's there? You didn't see that."

- (don't know how to plant seeds) "You could if you wanted to."

- (don't know how to water seeds) "I wanna see if you can."

- (don't know how to water seeds) "Well, you have to try."

- (bumped head) "You'better be careful."

-(lost box) "Where'd you put it? Stand there till you remember."

-(spilled papers) "You better be careful."

d) Child makes an observation concerning the constraints within the situation, e.g.,

- (no cup) "I know--you missed all of it."

-(no glitter) "Where is it? This is for me."

-(no stars) "These are the only ones."

- (no snack) "There's only three-cause I like animal crackers."

- (no snack) "Only three for me."

- (don't know how to water seeds) "There's no more cups."

- (don't know how to do a flower sticker) "She just took the sticks away."

e) Child offers an explanation for the adult's state of need, e.g., 
SCORE CODE BEHAVIOR

- (no cup) "Where are the cups? Someone stole them?"

-(lost box) "Where'd you put it?"

-(lost pen) "Maybe it went to your home."

2 VP Verbal

Postponement :

Child promises to behave prosocially at a later time, but does not follow through.

-"I'II do it for you later."

-"Just a minute."

-"I'II find it after I'm done."

- "I'II show you when I get through."

$1 \quad \mathrm{~A}_{1} \quad \begin{aligned} & \text { Associa- } \\ & \text { tion: }\end{aligned}$

Child talks about content of need verbalization without apparent recognition of the need.

- (don't have any cookies) "One time when my mom and I went to the movie we bought this kind of cookies."

- (don't know how to cut a cookie) "I'm gonna make a ball."

-(don't know how to plant seeds)

"I have two cups of dirt now."

1 ACK Acknowl- Child verbally demonstrates awareedgement: ness of another's need, e.g., by repeating or paraphrasing need verbalization.

-(no cookies) "There's none for you."

-(no cookies) "You got no cookie."

- (no playdough) "You don't have any."

-"Oh."

-"Uh-huh."

- "It did?"

-"I do."

-"Uh, oh."

- (no seeds) "There's no seeds in there either."

1 D Diversion:

A verbal response by the child about an unrelated topic. 
SCORE CODE BEHAVIOR

1 NR No Child displays no physical or verResponse: bal response to verbalization of need.

0 Rf Refusal: Child verbally declines or physically declines by shaking head no.

-(no red paint) "I won't give you any of mine (covering own red paint with hand)."

- (no candy kisses) "You can't take mine. You can't take hers either."

- (no cookies to take home) "You can't take hers. Can't take mine either, 'cause you lost yours."

-(no flower sticker) "I can't share one of mine."

Additional Scoring Rules

(General)

1. Subject's responses which are delayed (occur after 7 seconds following need verbalization, model, or prompt) receive a score of 1 point less.

2. Subjects who respond prosocially but verbalize reluctance and/or reasons why s/he shouldn't (e.g., "Now I won't have very much"), score as 1 point less.

3. Subjects who report the inequity either before (e.g., "What about the other girl?") or after the need verbalization (e.g., "She doesn't have any playdough"; "She couldn't find her special box"), or who display a continued recognition of the need (e.g., "She bumped her head"; "Do you know where the special box is?") receive a score of I point more.

4. Subjects who respond prosocially before the need is verbalized receive a score of 1 point more. 
APPENDIX B

MATERNAL QUESTIONNAIRE AND RELATED FORMS

PARENTAL CONSENT AND PREINTERVIEW

INSTRUCTIONS

Dear Parents,

This interview is part of a study being conducted by Dr. Cathleen Smith and two graduate students, Jane Blackwell and Jennifer Jennings, from the Department of Psychology, Portland State University. This study will examine the relationship between prosocial behavior in children (helping, sharing, teaching, etc.), and parental childrearing practices.

The interview will describe typical parent child situations. We will ask you to imagine these situations as if you and your child were involved. For instance, suppose you can't find your keys, and on his own your child finds them and brings them to you. You would be asked to describe how you would react. You will then be handed a list of procedures which parents typically use in these situations and be asked how often you use them (Usually, Sometimes, Rarely, Never).

This interview: will be tape recorded for the accurate transciption of your responses and will take approximately one hour. Your contribution to this study is of extreme value. Little is known about the relationship between prosocial behavior and parental childrearing practices. Your descriptions of how you would react to various parent child situations will be useful information and you will be provided the chance to describe what techniques work best for you.

It is our policy to inform you that there may be no direct benefit from participation in this study but your involvement will aid in increasing the information known about how parents raise their children. Of course, your child's responses and your comments in the interview will be entirely confidential. If you have any further questions 
regarding this study following the interview, please feel free to call Dr. Cathleen Smith at 229-3923.

Thank you for your cooperation.

$$
\text { Sincerely, }
$$

S/Cathleen L. Smith

Cathleen L. Smith, Ph.D. Assistant Professor Department of Psychology Portland State University
S/Jane Blackwe11

Jane Blackwell

Graduate Assistant

S/Jennifer Jennings

Jennifer Jennings

Graduate Assistant

I, agree to participate in the above described interview concerning children's prosocial behavior and parental childrearing practices, as part of a study being conducted through Portland State University, Department of Psychology by Dr. Cathleen L. Smith, Jane Blackwell and Jennifer Jennings. 


\section{INFORMATION SHEET}

What is your age? $0-18$

$$
\begin{aligned}
& 19-24 \\
& 25-29 \\
& 30-39 \\
& 40-49 \\
& 50+
\end{aligned}
$$

What is your occupation?

What is the occupation of other adults in the home?

How many years of schooling have you had? (Circle highest

\begin{tabular}{|c|c|}
\hline $\begin{array}{l}\text { Grade School } \\
\text { High School } \\
\text { College } \\
\text { Professional }\end{array}$ & $\begin{array}{llllllll}1 & 2 & 3 & 4 & 5 & 6 & 7 & 8 \\
9 & 10 & 11 & 12 & & \\
13 & 14 & 15 & 16 & & \\
17 & 18 & 19 & 20 & 21 & 22 & 23+ \\
\end{array}$ \\
\hline
\end{tabular}
grade completed.)

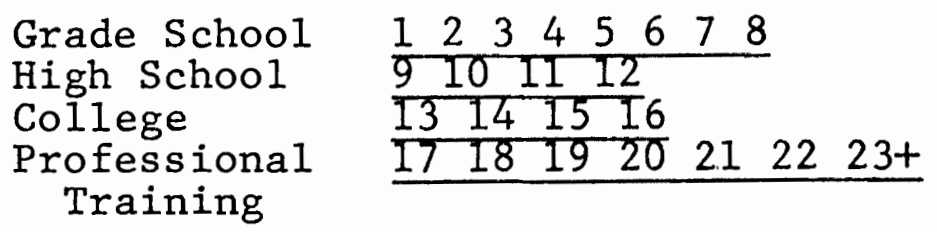

How many years of schooling have other adults in the home had? (Circle highest grade completed.)

Every child is individual and acquires different sorts of behaviors (such as helping, sharing or teaching) at differ-

\begin{tabular}{|c|c|c|c|}
\hline \multirow{2}{*}{\multicolumn{4}{|c|}{$\begin{array}{l}\text { Shares with others (you, } \\
\text { other adults, his/her } \\
\text { friends) }\end{array}$}} \\
\hline & & & \\
\hline $\begin{array}{l}\text { Helps others (you, other } \\
\text { adults, his/her friends) }\end{array}$ & & & \\
\hline $\begin{array}{l}\text { Sympathizes with others } \\
\text { (you, other adults, his / } \\
\text { her friends) }\end{array}$ & & & \\
\hline $\begin{array}{l}\text { Teaches others (you, other } \\
\text { adults, his/her friends) }\end{array}$ & & & \\
\hline
\end{tabular}
ent times. In comparing your child to other children of about the same age would you say your child:

(Somewhat (About the (Somewhat more than same as less than 
How many children presently live in your home?

What are their names and ages?

How many adults (including yourself) are presently living in the home?

What is your relationship with the child in our study? (for example: are you the mother, step-mother, grandmother etc.)

What is the relationship of the other adults in the home to the child in our study? (for example: friend, father, stepfather etc.)

What is the length of time that these other adults have been in the home? (for example: since the child's birth, before the birth of the child, 2 years, 6 months, etc.)

Are there other adults outside the home that your child regularly sees?

How often? 


\section{MATERNAL CHILDREARING PRACTICES}

\section{QUESTIONNAIRE (A)}

(1) Imagine a situation similar to this one. (child's name) is playing in the bedroom and you go in to check on him or her. You find busily coloring on the wall.

What do you usually do when something like that happens? Please describe exactly what words you use and what you usually do.

(Important note: Probe for as exact descriptions as possible, enough details to almost get a picture image of just what the parent said and did, also verbatim reports of exact words used or probably used.)

(Hand mother List 1) Now here is a list of things that some parents interviewed before do at times like this. Please check how often you do each one or something like it. (Take back list and make sure instructions have been followed and responses checked for each item.)

(2) Suppose you had just returned from shopping and were carrying the bags of groceries into the kitchen where (child's name) was playing at the table. Suddenly, the bottom of the grocery bag you are carrying tears and groceries fall to the floor. gets up from the table and begins to pick up some of the groceries. 
What do you usually do when something like that happens? Please describe exactly what you usually do and what words you use.

\section{(Parent Explanation)}

(Hand mother List 2) See above for following procedure.

(3) Suppose that (child's name) knew that he/she was not to disturb your personal belongings in your bedroom. One day you walk into your room and find going through your chest of drawers.

What do you usually do when something like that happens? Please describe exactly what you usually do and exactly what words you use.

(Parent Explanation)

(Hand mother List 3) See above for following procedure.

\section{MATERNAL CHILDREARING PRACTICES}

$$
\text { QUESTIONAIRE (B) }
$$

(4) Suppose (child's name) and one of his/her friends are playing in the backyard. You are inside working and hear a commotion outside. You go out and find them both hitting and yelling at each other. You ask what happened and the friend says, "I was just playing with one of his/her toys and he/she came over and grabbed it from me." says, "It's my toy and I want to play with it now." 
What do you usually do when something like this happens? Please describe exactly what you usually do and exactly what words you use.

(Important note: Probe for as exact descriptions as. possible, enough details to almost get a picture image of just what the parent did and said, also verbatim reports of exact words used or probably used.)

(Hand mother List 4) Now here is a list of things that some parents interviewed before do at times like this. Please check how often you do each one or something like it. (Take back list and make sure instructions have been followed and responses checked for each item.)

(5) Imagine a situation similar to this one. Suppose (child's name) was making a lot of noise in the other room. You go to see what is happening and find him/ her jumping up and down on the furniture.

What do you usually do when something like that happens? Please describe exactly what you usually do and exactly what words you use.

(Parent Explanation)

(Hand mother List 5) See above for following instructions.

(6) Suppose that (child's name) has just learned to do somersaults. When you go out to check on her/him and his/her friend, you find teaching his/her friend to do somersaults. 
What do you usually do when something like that happens? Please describe exactly what you usually do and exactly what words you use.

\section{(Parent Explanation)}

(Hand mother list 6) See above for following instructions.

\section{MATERNAL CHILDREARING PRACTICES \\ QUESTIONNAIRE (C)}

(7) Imagine a situation similar to this one. You hear a loud crash in the other room and go to see what is the matter. You find that (child's name) has thrown his/ her ball, hit the lamp and broken it.

What do you usually do when something like that happens? Please describe exactly what you usually do and what words you use.

(Important note: Probe for as exact descriptions as possible, enough details to almost get a picture image of just what the parent said and did, also verbatim reports of exact words used or probably used.) (Hand mother List 7) Now here is a list of things that some parents interviewed before do at times like this. Please check how often you do each one or something like it. (Take back list and make sure instructions have been followed and responses checked for each item.)

(8) Suppose you came into (child's name) room where he/she and his/her friend were playing. You observed 
sharing a cookie with his/her friend that you

had given him/her earlier.

What do you usually do when something like that happens? Please describe exactly what you usually do and exactly what words you use.

(Parent Explanation)

(Hand mother List 8) See above for following instructions.

(9) Suppose you and (child's name) have gone to the store to get some needed items. You tell him/her not to touch the objects on the shelves of the store. A few moments later you turn around and find holding an object from the shelf.

What do you usually do when something like that happens? Please describe exactly what you usually do and exactly what words you use.

(Parent Explanation)

(Hand mother List 9) See above for following instructions. 


\section{LIST 1}

\begin{tabular}{|c|c|c|c|c|}
\hline $\begin{array}{l}\text { Usu- } \\
\text { ally. }\end{array}$ & $\begin{array}{l}\text { Some- } \\
\text { times }\end{array}$ & Rarely & Never & \\
\hline Spank & & & & Hit or spank him. \\
\hline Guilt & & & & $\begin{array}{l}\text { Ask him why he behaves like that } \\
\text { when you do so much for him. }\end{array}$ \\
\hline Physic & cal s & top & & $\begin{array}{l}\text { Physically stop him from coloring } \\
\text { on the wall. }\end{array}$ \\
\hline Neutr: & al & & & Do nothing, don't say a word. \\
\hline Feelin & ngs & & s. & $\begin{array}{l}\text { Tell him not to color on the walls } \\
\text { because it makes me angry. }\end{array}$ \\
\hline Spank & & & & $\begin{array}{l}\text { Tell him I'll hit or spank him if } \\
\text { he doesn't behave. }\end{array}$ \\
\hline $\begin{array}{l}\text { Consed } \\
\text { ration }\end{array}$ & $\begin{array}{l}\text { quenc } \\
\text { nale }\end{array}$ & -orie & Led & $\begin{array}{l}\text { Tell him not to color on the walls } \\
\text { because he will have to clean it } \\
\text { up. }\end{array}$ \\
\hline Ignore & e & & & $\begin{array}{l}\text { Show him. I don't like what he did } \\
\text { by not paying attention to him for } \\
\text { awhile. }\end{array}$ \\
\hline $\begin{array}{l}\text { 'Consec } \\
\text { ratior }\end{array}$ & $\begin{array}{l}\text { quenc } \\
\text { nale }\end{array}$ & -orie & ted & $\begin{array}{l}\text { Tell him not to color on the wall } \\
\text { because he will get his crayons } \\
\text { taken away. }\end{array}$ \\
\hline Rules & & & & $\begin{array}{l}\text { Tell him it is the rule of the house } \\
\text { that he not color on the wall. }\end{array}$ \\
\hline Love & withd? & cawa1 & & Send him to his room/corner. \\
\hline Love & withdi & rawa 1 & & $\begin{array}{l}\text { Tell him I'm angry or give him an } \\
\text { angry look. }\end{array}$ \\
\hline Inte: & nal & tmit & & $\begin{array}{l}\text { Tell him not to color on the walls } \\
\text { because he is the kind of person } \\
\text { who takes care of his room. }\end{array}$ \\
\hline Love & withdr & cawal & & $\begin{array}{l}\text { Tell him I won't talk to him or } \\
\text { have anything to do with him if } \\
\text { that's the way he's going to act. }\end{array}$ \\
\hline $\begin{array}{l}\text { Withdr } \\
\text { privil }\end{array}$ & $\begin{array}{l}\text { rawal } \\
\text { leges }\end{array}$ & of & & $\begin{array}{l}\text { Not let him have something he likes } \\
\text { or do something he likes to do. }\end{array}$ \\
\hline Neutra & & & & Go back to what you were doing. \\
\hline
\end{tabular}

*Items removed from their respective scales due to low item total correlations. 


\begin{tabular}{|c|c|c|c|c|}
\hline $\begin{array}{l}\text { Usu- } \\
\text { ally }\end{array}$ & $\begin{array}{l}\text { Some- } \\
\text { times }\end{array}$ & Rarely & Never & \\
\hline Deleg & rate $t$ & anoth & & $\begin{array}{l}\text { Tell spouse or another adult and } \\
\text { let them handle it. }\end{array}$ \\
\hline Guilt & & & & $\begin{array}{l}\text { Tell him when he behaves that way } \\
\text { he doesn't care about you. }\end{array}$ \\
\hline
\end{tabular}

\section{LIST 2}

\begin{tabular}{|c|c|c|c|c|}
\hline $\begin{array}{l}\text { Usu- } \\
\text { ally }\end{array}$ & $\begin{array}{l}\text { Some- } \\
\text { times }\end{array}$ & Rarely & Never & \\
\hline Rules & & & & $\begin{array}{l}\text { Tell him he picked up the groceries } \\
\text { because it is the rule of the house }\end{array}$ \\
\hline Feeli & ngs & & & $\begin{array}{l}\text { Tel1 him because he picked up the } \\
\text { groceries it makes me happy. }\end{array}$ \\
\hline Rewar & & & & $\begin{array}{l}\text { Give him a reward or extra privi- } \\
\text { leges (stay up late). }\end{array}$ \\
\hline $\begin{array}{l}\text { Conse } \\
\text { ratio }\end{array}$ & $\begin{array}{l}\text { quence } \\
\text { nale }\end{array}$ & -orie & ced & $\begin{array}{l}\text { Tell him because he helped pick up } \\
\text { the groceries, nothing will have } \\
\text { a chance to spill. }\end{array}$ \\
\hline Affed & tion & & & $\begin{array}{l}\text { Be especially affectionate, spend } \\
\text { more time with him. }\end{array}$ \\
\hline Inter & & Etribut & & $\begin{array}{l}\text { Tell him he picked up the groceries } \\
\text { because he is the kind of person } \\
\text { who helps others. }\end{array}$ \\
\hline Physi & cal af & Efection & & Give him a hug. \\
\hline Affec & tion & & & Tell him it makes me love him more. \\
\hline Dele & ate & & & $\begin{array}{l}\text { Tell spouse or another adult and } \\
\text { let them handle it. }\end{array}$ \\
\hline Guilt & & & & $\begin{array}{l}\text { Tel1 him that now I know he cares } \\
\text { about me. }\end{array}$ \\
\hline Neutr & & & & Go back to what you were doing. \\
\hline Affec & tion & & & $\begin{array}{l}\text { Tel1 him when he acts that way it } \\
\text { makes me want to spend more time } \\
\text { with him. }\end{array}$ \\
\hline
\end{tabular}




\begin{tabular}{|c|c|c|c|c|}
\hline $\begin{array}{l}\text { Usu- } \\
\text { ally }\end{array}$ & $\begin{array}{l}\text { Some- } \\
\text { times }\end{array}$ & Rarely & Never & \\
\hline \multicolumn{2}{|c|}{ *Neutral } & & & Do nothing, don't say a word. \\
\hline \multicolumn{3}{|c|}{$\begin{array}{l}\text { Other-oriented } \\
\text { rationale }\end{array}$} & & $\begin{array}{l}\text { Tel1 him because he picked up the } \\
\text { groceries you can get them put } \\
\text { away sooner. }\end{array}$ \\
\hline Guilt & & & & $\begin{array}{l}\text { Tell him he picked up the grocerie } \\
\text { because you do so much for him. }\end{array}$ \\
\hline Rewar & & & & $\begin{array}{l}\text { Tell him he can have something he } \\
\text { likes or do something he likes to } \\
\text { do. }\end{array}$ \\
\hline
\end{tabular}

LIST 3

\begin{tabular}{|c|c|c|c|c|}
\hline $\begin{array}{l}\text { Usu- } \\
\text { ally }\end{array}$ & $\begin{array}{l}\text { Some- } \\
\text { times }\end{array}$ & Rarely & Never & \\
\hline $\begin{array}{l}\text { Withd } \\
\text { privi }\end{array}$ & irawal & of & & $\begin{array}{l}\text { Not let him have something he likes } \\
\text { or do something he likes to do. }\end{array}$ \\
\hline Physi & cal si & top & & $\begin{array}{l}\text { Physically stop him from what he } \\
\text { is doing (e.g., take his hands out } \\
\text { of the drawer). }\end{array}$ \\
\hline Deleg & 5ate tc & 0 anoth & & $\begin{array}{l}\text { Tell spouse or another adult and } \\
\text { let them handle it. }\end{array}$ \\
\hline Neutr & & & & Go back to what you were doing. \\
\hline Rules & & & & $\begin{array}{l}\text { Tell him it is the rule of the } \\
\text { house that he not get into your } \\
\text { personal belongings. }\end{array}$ \\
\hline Spank & & & & Hit or spank him. \\
\hline Guilt & & & & $\begin{array}{l}\text { Tell him when he behaves that way } \\
\text { he doesn't care about me. }\end{array}$ \\
\hline Spank & & & & $\begin{array}{l}\text { Tell him I' } 11 \text { hit or spank him if } \\
\text { he doesn't behave. }\end{array}$ \\
\hline \multicolumn{3}{|c|}{ Love, withdrawal } & & Send him to his room/corner. \\
\hline Guilt & & & & $\begin{array}{l}\text { Ask him why he behaves that way } \\
\text { when you do so much for him. }\end{array}$ \\
\hline
\end{tabular}

*Item was removed from neutral scale due to a low item total correlation. 


\begin{tabular}{|c|c|c|c|c|}
\hline $\begin{array}{l}\text { Usu- } \\
\text { ally }\end{array}$ & $\begin{array}{l}\text { Some- } \\
\text { times }\end{array}$ & Rarely & Never & \\
\hline \multicolumn{4}{|c|}{$\begin{array}{l}\text { Consequence-oriented } \\
\text { rationale }\end{array}$} & $\begin{array}{l}\text { Tell him not to get into my things } \\
\text { because he won't be able to come } \\
\text { in the room. }\end{array}$ \\
\hline \multicolumn{3}{|c|}{ Love withdrawal } & & $\begin{array}{l}\text { Tell him I won't talk to him or } \\
\text { have anything to do with him if } \\
\text { that's the way he's going to act. }\end{array}$ \\
\hline \multicolumn{2}{|c|}{ Feelings } & & & $\begin{array}{l}\text { Tell him not to get into my things } \\
\text { because it makes me angry. }\end{array}$ \\
\hline \multicolumn{2}{|c|}{ Neutral } & & & Do nothing, don't say a word. \\
\hline \multicolumn{2}{|c|}{ Ignore } & & & $\begin{array}{l}\text { Show him I don't like what he did } \\
\text { by not paying attention to him for } \\
\text { awhile }\end{array}$ \\
\hline Inter & al & ribut & ion & $\begin{array}{l}\text { Tell him not to get into my per- } \\
\text { sonal belongings because he is the } \\
\text { kind of person who respects other's } \\
\text { privacy. }\end{array}$ \\
\hline Love & withd & cawal & & $\begin{array}{l}\text { Tell him I'm angry or give him an } \\
\text { angry look. }\end{array}$ \\
\hline \multicolumn{2}{|c|}{$\begin{array}{l}\quad 1 \\
\text { Consequence } \\
\text { rationale }\end{array}$} & & & $\begin{array}{l}\text { Tel1 him not to play with your } \\
\text { things because something might } \\
\text { get lost. }\end{array}$ \\
\hline
\end{tabular}

LIST 4

\begin{tabular}{|c|c|c|c|}
\hline \begin{tabular}{l|l|} 
Usu- & Some- \\
ally & times
\end{tabular} & Rarely & Never & \\
\hline Affection & & & $\begin{array}{l}\text { Be especially affectionate, spend } \\
\text { more time with him. }\end{array}$ \\
\hline $\begin{array}{l}\text { Other-orien } \\
\text { rationale }\end{array}$ & ited & & $\begin{array}{l}\text { Tell him to share his toy because } \\
\text { then his friend will have a toy } \\
\text { to play with too. }\end{array}$ \\
\hline Guilt & & & $\begin{array}{l}\text { Tell him to share his toy because } \\
\text { I do so much for him. }\end{array}$ \\
\hline Reward & & & $\begin{array}{l}\text { Give him a reward or extra privi- } \\
\text { leges (stay up late). }\end{array}$ \\
\hline $\begin{array}{l}\text { Consequenc } \\
\text { rationale }\end{array}$ & & & $\begin{array}{l}\text { Tell him to share his toy because } \\
\text { then he and his friend can have } \\
\text { fun together. }\end{array}$ \\
\hline
\end{tabular}




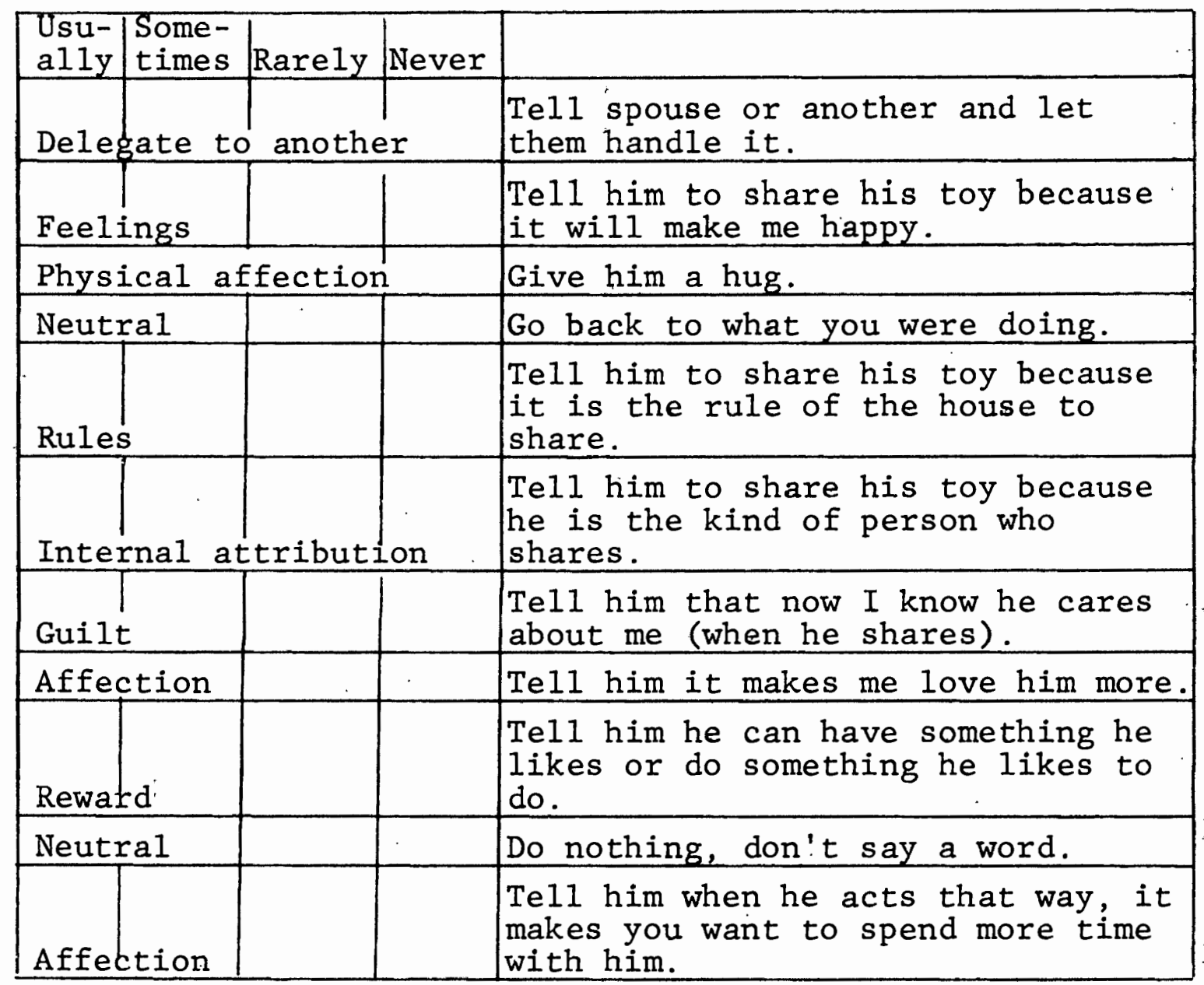

\section{LIST 5}

\begin{tabular}{|c|c|c|c|c|}
\hline $\begin{array}{l}\text { Usu- } \\
\text { ally }\end{array}$ & $\begin{array}{l}\text { Some- } \\
\text { times }\end{array}$ & Rarely & Never & \\
\hline Inter & enal a & teribut & ion & $\begin{array}{l}\text { Tell him not to jump on the furni- } \\
\text { ture because he is the kind of } \\
\text { person who takes care of furniture. }\end{array}$ \\
\hline Guilt & & & & $\begin{array}{l}\text { Ask him why he behaves that way } \\
\text { when I do so much for him. }\end{array}$ \\
\hline Lovel & withd & rawal & & $\begin{array}{l}\text { Tell him I'm angry or give him an } \\
\text { angry look. }\end{array}$ \\
\hline Spank & & & & Hit or spank him. \\
\hline
\end{tabular}




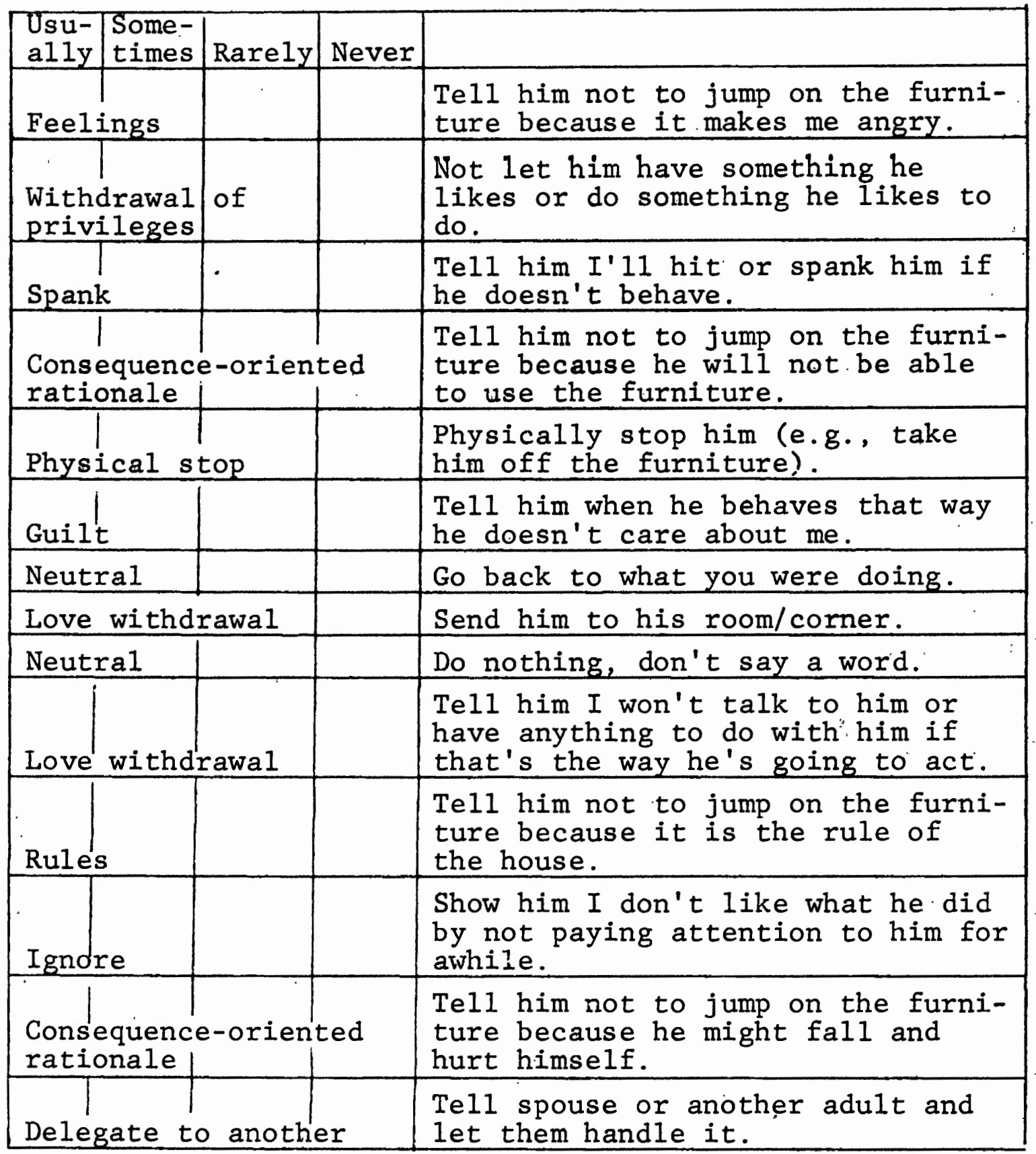


LIST 6

\begin{tabular}{|c|c|c|c|}
\hline \begin{tabular}{|l|l|} 
Usu- & Some- \\
al1y & times \\
\end{tabular} & Rarely & Never & \\
\hline Rules & & & $\begin{array}{l}\text { Tel1 him he taught his friend be- } \\
\text { cause it is the rule of the house } \\
\text { to teach. }\end{array}$ \\
\hline Neutral & & & Go back to what you were doing. \\
\hline Affection. & & & $\begin{array}{l}\text { Te11 him when he acts that way it } \\
\text { makes me want to spend more time } \\
\text { with him. }\end{array}$ \\
\hline \multicolumn{3}{|c|}{ Physica1 affection } & Give him a hug. \\
\hline Guilt & & & $\begin{array}{l}\text { Tel1 him that now I know he cares } \\
\text { about me. }\end{array}$ \\
\hline Delegate to & anoth & & $\begin{array}{l}\text { Tell spouse or another adult and } \\
\text { let them handle } i t .\end{array}$ \\
\hline Feelings & & & $\begin{array}{l}\text { Te11 him because he taught his } \\
\text { friend it makes me happy. }\end{array}$ \\
\hline $\begin{array}{c}1 \\
\text { Reward }\end{array}$ & & & $\begin{array}{l}\text { Give him a reward or extra privi- } \\
\text { leges (stay up late). }\end{array}$ \\
\hline Guilt : & & & $\begin{array}{l}\text { Tell him he taught his friend be- } \\
\text { cause I do so much for him. }\end{array}$ \\
\hline Affection & & & Tell him it makes me love him more \\
\hline $\begin{array}{l}\text { Consequenc } \\
\text { rationale }\end{array}$ & & ted & $\begin{array}{l}\text { Tel1 him because he taught his } \\
\text { friend now they can play together } \\
\text { better. }\end{array}$ \\
\hline Reward & & & $\begin{array}{l}\text { Tell him he can have something he } \\
\text { likes or do something he likes to } \\
\text { do. }\end{array}$ \\
\hline Affection & & & $\begin{array}{l}\text { Be especially affectionate, spend } \\
\text { more time with him. }\end{array}$ \\
\hline $\begin{array}{l}\text { Other-orien } \\
\text { rationale }\end{array}$ & hted & & $\begin{array}{l}\text { Tell him because he taught his } \\
\text { friend his friend won't feel left } \\
\text { out. }\end{array}$ \\
\hline Internal & & & $\begin{array}{l}\text { Tel1 him he taught his friend be- } \\
\text { cause he is the kind of person who } \\
\text { teaches others. }\end{array}$ \\
\hline Neutral & & & Do nothing, don't say a word. \\
\hline
\end{tabular}


LIST 7

\begin{tabular}{|c|c|c|c|c|}
\hline $\begin{array}{l}\text { Usu- } \\
\text { ally }\end{array}$ & $\begin{array}{l}\text { Some- } \\
\text { times }\end{array}$ & Rarely & Never & \\
\hline Inter & & & & $\begin{array}{l}\text { Tell him not to throw the ball in } \\
\text { his room because he is the kind } \\
\text { of person who takes care of his } \\
\text { room. }\end{array}$ \\
\hline \multicolumn{4}{|c|}{$\begin{array}{l}\text { Internal attribution } \\
\text { Consequence-oriented } \\
\text { rationale }\end{array}$} & $\begin{array}{l}\text { Tell him not to throw the ball } \\
\text { because he might hurt himself. }\end{array}$ \\
\hline Guilt & & & & $\begin{array}{l}\text { Ask him why he behaves that way } \\
\text { when I do so much for him. }\end{array}$ \\
\hline \multicolumn{2}{|c|}{ Guilt } & & & Go back to what you were doing. \\
\hline \multicolumn{2}{|c|}{ Delegate } & anothe & & $\begin{array}{l}\text { Tell spouse or another adult and } \\
\text { let them handle it. }\end{array}$ \\
\hline \multicolumn{2}{|c|}{ Love withdr } & Eawal & & $\begin{array}{l}\text { Tell him I'm angry or give him an } \\
\text { angry look. }\end{array}$ \\
\hline \multicolumn{3}{|c|}{$\left.\right|_{\text {Physical stop }}$} & & $\begin{array}{l}\text { Physically stop him (e.g., take } \\
\text { away ball). }\end{array}$ \\
\hline \multicolumn{2}{|c|}{ Spank } & & & Hit or spank him. \\
\hline \multicolumn{2}{|c|}{ Neutral } & & & Do nothing, don't say a word. \\
\hline \multicolumn{2}{|c|}{ Ignore } & & & $\begin{array}{l}\text { Show him I don't like what he did } \\
\text { by not paying attention to him for } \\
\text { awhile. }\end{array}$ \\
\hline \multicolumn{2}{|c|}{$\begin{array}{l}\text { Withdrawal } \\
\text { privileges }\end{array}$} & of & & $\begin{array}{l}\text { Not let him have something he likes } \\
\text { or do something he likes to do. }\end{array}$ \\
\hline \multicolumn{2}{|c|}{$\begin{array}{c}\text { I } \\
\text { Feelings } \\
\end{array}$} & & & $\begin{array}{l}\text { Tell him not to throw the ball } \\
\text { because it makes me angry. }\end{array}$ \\
\hline \multicolumn{2}{|l|}{ Guilt } & & & $\begin{array}{l}\text { Tell him when he behaves that way } \\
\text { he doesn't care about me. }\end{array}$ \\
\hline \multicolumn{3}{|c|}{ Love withdrawal } & & Send him to his room/corner. \\
\hline $\begin{array}{l}\text { Conse } \\
\text { ratior }\end{array}$ & $\begin{array}{l}\text { quenc } \\
\text { nale }\end{array}$ & -orient & ed & $\begin{array}{l}\text { Tell him because he threw the ball } \\
\text { now he doesn't have a lamp for his } \\
\text { room. }\end{array}$ \\
\hline Love & withdr & Eawal & & $\begin{array}{l}\text { Tell him I won't talk to him or } \\
\text { have anything to do with him if } \\
\text { that's the way he's going to act. }\end{array}$ \\
\hline Rules & & & & $\begin{array}{l}\text { Tell him not to throw the ball be- } \\
\text { cause it is the rule of the house. }\end{array}$ \\
\hline
\end{tabular}




\begin{tabular}{|l|l|l|l|l|}
\hline $\begin{array}{l}\text { Usu- } \\
\text { ally }\end{array}$ & $\begin{array}{l}\text { Some- } \\
\text { times }\end{array}$ & Rarely & Never & \\
\hline Spank & & & $\begin{array}{l}\text { Tell him I'll hit or spank him if } \\
\text { he doesn't behave. }\end{array}$ \\
\hline
\end{tabular}

LIST 8

\begin{tabular}{|c|c|c|c|}
\hline \begin{tabular}{l|l|} 
Usu- & Some- \\
ally & times \\
\end{tabular} & Rarely & Never & \\
\hline Guilt & & & $\begin{array}{l}\text { Tell him that now I know he cares } \\
\text { about me (when he shares). }\end{array}$ \\
\hline Feelings & & & $\begin{array}{l}\text { Tell him because he shared his } \\
\text { cookie it makes me happy. }\end{array}$ \\
\hline Reward & & & $\begin{array}{l}\text { Give him a reward or extra privi- } \\
\text { leges (stay up late). }\end{array}$ \\
\hline Affection & & & $\begin{array}{l}\text { Tell him when he acts that way it } \\
\text { makes me want to spend more time } \\
\text { with him. }\end{array}$ \\
\hline Guilt & & & $\begin{array}{l}\text { Tell him he shared his cookie be- } \\
\text { cause I do so much for him. }\end{array}$ \\
\hline Neutral & & & Go back to what you were doing. \\
\hline Internal at & & ion & $\begin{array}{l}\text { Tell him he shared his cookie be- } \\
\text { cause he is the kind of person who } \\
\text { shares. }\end{array}$ \\
\hline Affection & & & $\begin{array}{l}\text { Tel1 him when he shares it makes } \\
\text { you love him more. }\end{array}$ \\
\hline Physical af & Efection & & Give him a hug. \\
\hline $\begin{array}{l}\text { Other-orien } \\
\text { rationale }\end{array}$ & 2 ted & & $\begin{array}{l}\text { Tell him because he shared his } \\
\text { snack now his friend has a snack } \\
\text { too. }\end{array}$ \\
\hline $\begin{array}{l}\text { Consequence } \\
\text { rationale }\end{array}$ & -orien & ted & $\begin{array}{l}\text { Tell him because he shared his } \\
\text { cookie they can have a snack to- } \\
\text { gether. }\end{array}$ \\
\hline Neutral & & & Do nothing, don't say a word. \\
\hline Reward & & & $\begin{array}{l}\text { Tell him he can have something he } \\
\text { likes or do something he likes to } \\
\text { do. }\end{array}$ \\
\hline
\end{tabular}




\begin{tabular}{|c|c|c|c|c|}
\hline $\begin{array}{l}\text { Usu- } \\
\text { ally }\end{array}$ & $\begin{array}{l}\text { Some- } \\
\text { times }\end{array}$ & Rarely & Never & \\
\hline Rules & & & & $\begin{array}{l}\text { Tell him he shared his cookie be- } \\
\text { cause it is the rule of the house } \\
\text { to share. }\end{array}$ \\
\hline Dele: & ate & anothe & & $\begin{array}{l}\text { Tell spouse or another adult and } \\
\text { let them handle it. }\end{array}$ \\
\hline Affec & tion & & & $\begin{array}{l}\text { Be especially affectionate, spend } \\
\text { more time with him. }\end{array}$ \\
\hline
\end{tabular}

\section{LIST 9}

\begin{tabular}{|c|c|c|c|c|}
\hline $\begin{array}{l}\text { Usu- } \\
\text { ally }\end{array}$ & $\begin{array}{l}\text { Some- } \\
\text { times }\end{array}$ & Rarely & Never & \\
\hline Love & withd & cawal & & $\begin{array}{l}\text { Tell him I'm angry or give him an } \\
\text { angry look. }\end{array}$ \\
\hline Neutr & & & & Do nothing, don't say a word. \\
\hline $\begin{array}{l}\text { Withd } \\
\text { privi }\end{array}$ & $\begin{array}{l}\text { Irawal } \\
\text { leges }\end{array}$ & of & & $\begin{array}{l}\text { Not let him have something he } \\
\text { likes or do something he likes to } \\
\text { do. }\end{array}$ \\
\hline Deleg & rate t & anoth & & $\begin{array}{l}\text { Tell spouse or another adult and } \\
\text { let them handle it. }\end{array}$ \\
\hline Guilt & & & & $\begin{array}{l}\text { Tell him when he behaves that way } \\
\text { he doesn't care about me. }\end{array}$ \\
\hline Inter & nal & ttribut & ion & $\begin{array}{l}\text { Tell him not to touch the things } \\
\text { on the shelves because he is the } \\
\text { kind of person who respects the } \\
\text { store's property. }\end{array}$ \\
\hline Neutr & & & & Go back to what you were doing. \\
\hline Spank & & & & $\begin{array}{l}\text { Tell him I' } 11 \text { hit or spank him if } \\
\text { he doesn't behave. }\end{array}$ \\
\hline Affec & tion & & & $\begin{array}{l}\text { Tell him I won't talk to him or } \\
\text { have anything to do with him if } \\
\text { that's the way.he's going to act. }\end{array}$ \\
\hline \multicolumn{2}{|c|}{ Feelings } & & & $\begin{array}{l}\text { Tell him not to touch the things } \\
\text { on the shelves because it makes } \\
\text { me angry. }\end{array}$ \\
\hline \multicolumn{2}{|c|}{ Spank } & & & Hit or spank him. \\
\hline
\end{tabular}




\begin{tabular}{|c|c|c|c|c|}
\hline $\begin{array}{l}\text { Usu- } \\
\text { ally }\end{array}$ & $\begin{array}{l}\text { Some- } \\
\text { times }\end{array}$ & Rarely & Never & \\
\hline Rules & & & & $\begin{array}{l}\text { Tell him not to touch the things on } \\
\text { the shelves because it is the rule. }\end{array}$ \\
\hline Guilt & & & & $\begin{array}{l}\text { Ask him why he behaves that way } \\
\text { when I do so much for him. }\end{array}$ \\
\hline Ignor & & & & $\begin{array}{l}\text { Show him I don't like what he did } \\
\text { by not paying attention to him for } \\
\text { awhile. }\end{array}$ \\
\hline Physi & ical st & & & $\begin{array}{l}\text { Physically stop him (e.g., put } \\
\text { item back on shelf). }\end{array}$ \\
\hline $\begin{array}{l}\text { Conse } \\
\text { ratio }\end{array}$ & $\begin{array}{l}\text { equence } \\
\text { onale }\end{array}$ & -orient & ed & $\begin{array}{l}\text { Tell him not to touch the things } \\
\text { on the shelves because something } \\
\text { might fall or hurt him. }\end{array}$ \\
\hline Love, & withdr & cawal & & Send him to a corner/out of store. \\
\hline $\begin{array}{l}\text { Cons } \\
\text { rati }\end{array}$ & $\begin{array}{l}\text { equenc } \\
\text { onale }\end{array}$ & -orien & & $\begin{array}{l}\text { Tell him not to touch the things } \\
\text { on the shelves because something } \\
\text { might break. }\end{array}$ \\
\hline
\end{tabular}

